\title{
Socialising Office

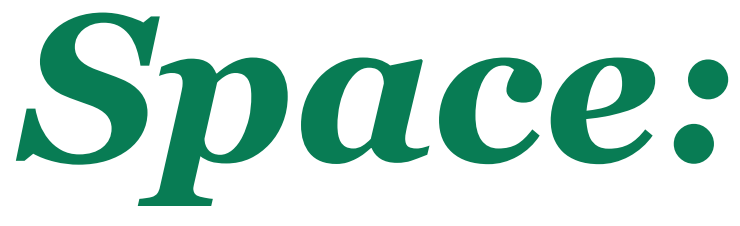

Flexibility through a layering of multiple programs in traditional office buildings.

Bradley Wyatt 


\title{
Socialising Office Space:
}

\author{
Flexibility through a layering of \\ multiple programs in traditional \\ office buildings.
}

A 120 point thesis submitted to Victoria University of Wellington partial fulfilment of the requirements for the degree of Master of Interior Architecture (Professional)

Victoria University 


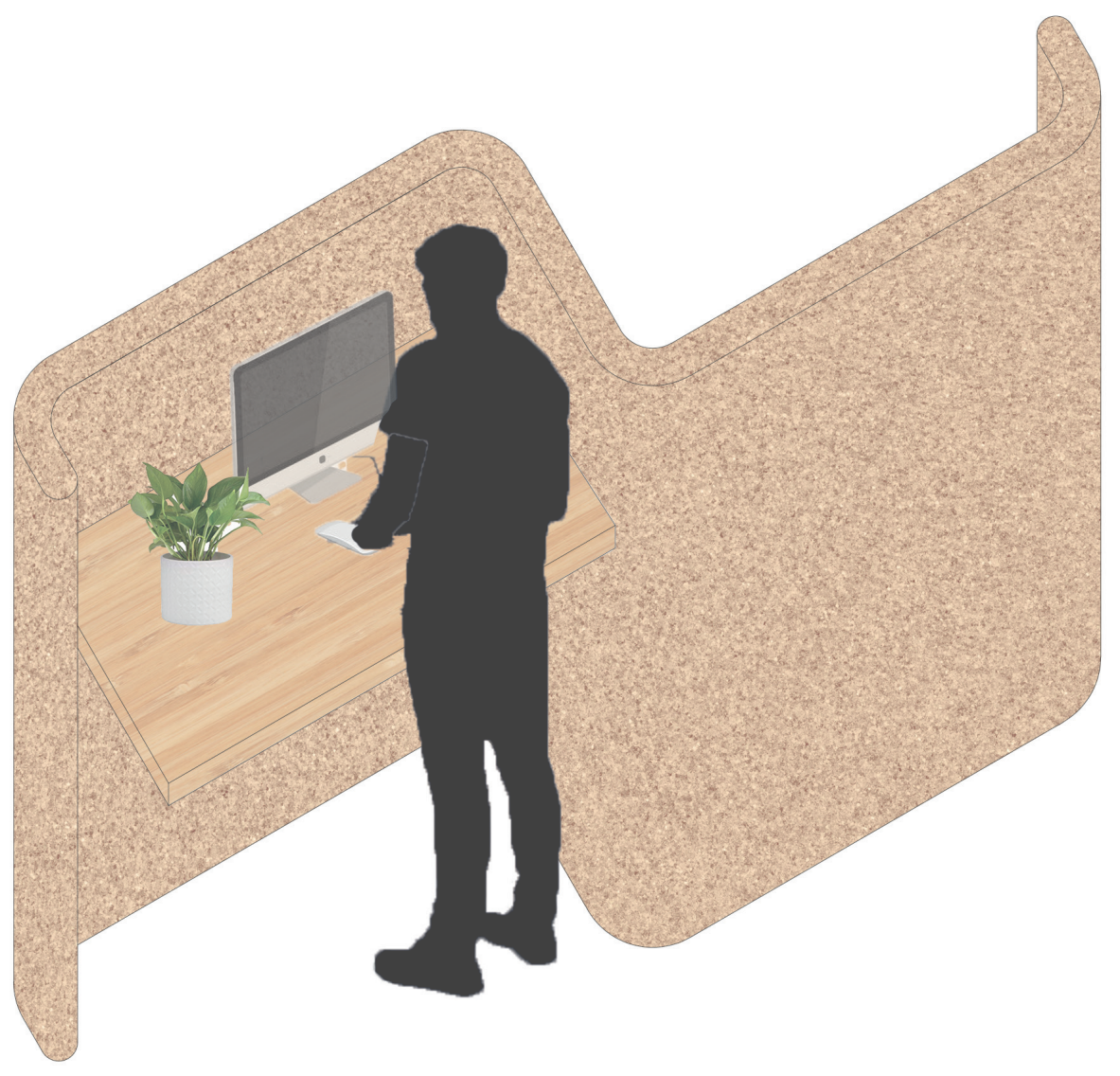




\section{Abstract}

This design-research project explores extending the flexibility of a typical 1960 s open-plan office building. Through the use of cross-programming, the building now works along a 24hour timespan. Housing a coworking office, community space and a night shelter, the building models a more efficient use of office space within our central cities. A focus on the individual allows a meaningful connection to space and to others through parallel design interventions that operate as desks and as sleeping pods. 
I would like to thank my supervisor Joanna Merwood-Salisbury, my partner, family, and friends. 


\section{Contents}


Introduction

$006-007$

Methodology

008 - 011

$\begin{array}{lr}\text { A History of the office } & 014-019 \\ \text { Literature review } & 020-025 \\ \text { Precedents analysis } & 026-031\end{array}$

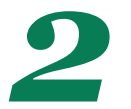
Series of tests
Exploration of the desk
What are proxemics?
Proxemic study
- Airplane proxemic
- Economy desk
- Premium economy desk
- Business desk

$034-035$

$036-037$

038 - 039

040 - 050

Critical reflection

$051-052$

Model study

$054-061$

Conceptual model study 1

$062-069$

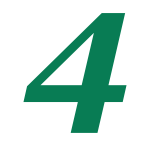

The Site

$072-075$

Conceptual model study 2

$076-085$

Conceptual model study 3

$086-095$

Critical reflection

$096-097$

Conceptual Design

$100-109$

Building Make up

$110-111$

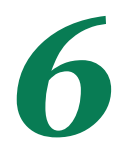

Public space

$114-119$

Sleeping space

$120-127$

Working space

128 - 139

Building section

$140-141$

Critical reflection

$142-143$

Conclusion

$146-147$

Bibliography

$148-150$

Table of Figures

$151-153$ 


\section{Introduction}

\author{
Socialising space
}

In the study of workspace, how will 'where' we work affect 'how' we work? Is an important concept; the rigid nature of the traditional open-plan office with rows of desks creates a harsh environment to work in. Where we work will always affect how we work thus the spaces we work in should be flexible and adaptable. For people who work in an office eight to nine hours a day the way it operates is significant. If a space is efficient and intelligent it is barely noticeable, however, if a space is challenging or disruptive it is almost impossible to focus.

What does a space that operates effectively look like? The idea of a flexible working environment aims to optimize both efficiency and worker satisfaction. What does flexibility look like in an office space? Is it the flexibility to work from home when needed? Is it the flexibility of having visual or audible privacy, or a variety of kinds of workspace? Can people be flexible, adaptable to different working and office environments?
At its most expansive, flexibility allows for the possibility of cross-programming. The idea of cross-programming pushes the concept of flexibility, posing the question; can more than one program work within a single space? If the theory of flexibility is applied to open-plan office space, how may a cross-programmable space allow it to function in new and unexpected ways? Lastly, how can personalisation meld with the concepts of flexibility and crossprogramming and allow those who work and or inhabit such a space a connection to the place? This thesis argues that flexibility can be extended through a layering of multiple programmes within traditional open-plan office buildings, opening them up for more effective use in our cities.

Through an exploration of the history of modern office design, a literature review, case study analysis, and a series of research through design tests, this research study proposes the implementation of flexibility at multiple scales, from furniture to programme. Along with personalisation, flexibility will have an overwhelmingly positive effect on the office worker. The use of cross-programming will open space for more than just typical office work, allowing an open community space, a night shelter, and a coworking space to radically alter the performance of the building to accommodate a 24-hour timeline. 


\section{Question:}

How can we begin to design truly flexible spaces that continue to operate along a 24-hour timespan through design for flexibility and crossprogramming? How can this understanding of flexibility begin to anticipate different ways of working, allowing meaningful personalisation? 


\section{Methodology}

Phase one

An architectural approach was undertaken to explore the history of the individual in an office environment. This led to an exploration of key terms such as people-centric workplace and individuality or personalisation in an office environment. These terms were used to explore the literature. The literature was broken into sections pertaining to architectural research and anthropological/ psychological research. Case study analysis overlapped with the exploration of literature to explore the effectiveness of current projects and to gain an understanding of where these offices lack focusing on the individual in these spaces. The study of proxemics was a key exploration to understand people's perception of the space around them. This included exploring the extremes of proxemics specifically within an aircraft setting where intimate and personal space severely overlap.

\section{Phase two}

Phase two explored 'research through design'. A series of three modelling tests will explore the ideas of flexibility and anticipatory work environments. The tests are in response to a theory heavy phase one. Each test will blend physical modelling with digital elements to explore areas of interest. Images were created and analysed for points of interest and issues. The introduction of a specific site helped to ground the experiments into more physical constraints. A critical reflection will conclude phase two through an analysis of how successful the tests were and how to begin to implement them physically into the chosen site.

Phase three

Phase three explored the idea of flexibility through a dual program operating within the building. This will be explored through the exploration of zoning the building into segments of public and private. The creation of flow throughout the building will relate to the differing furniture typologies through a unified design aesthetic. The developed design will see cohesive spaces that are critiqued on their effectiveness of flexibility and anticipatory elements. 


\section{Question:}

How can we begin to design truly flexible spaces that continue to operate along a 24-hour timespan through design for flexibility and cross-programming? How can this understanding of flexibility begin to anticipate different ways of working, allowing meaningful personalisation?

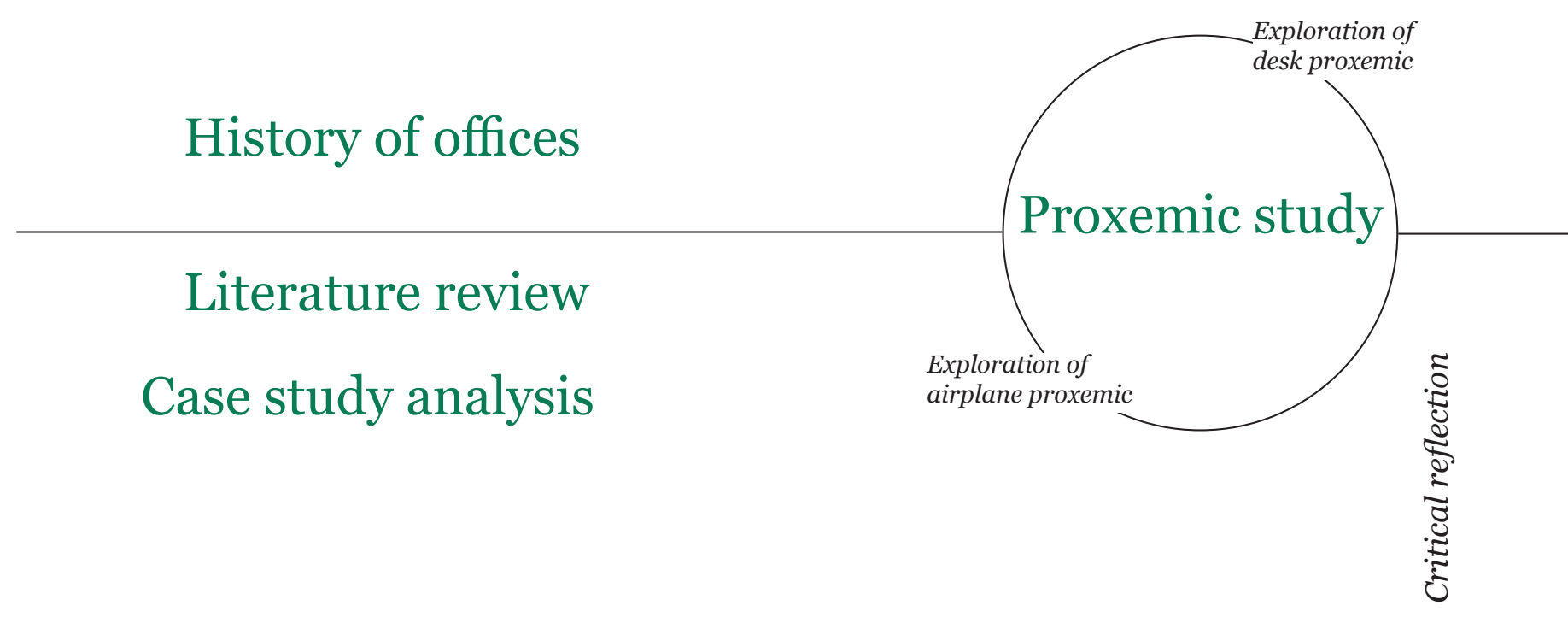




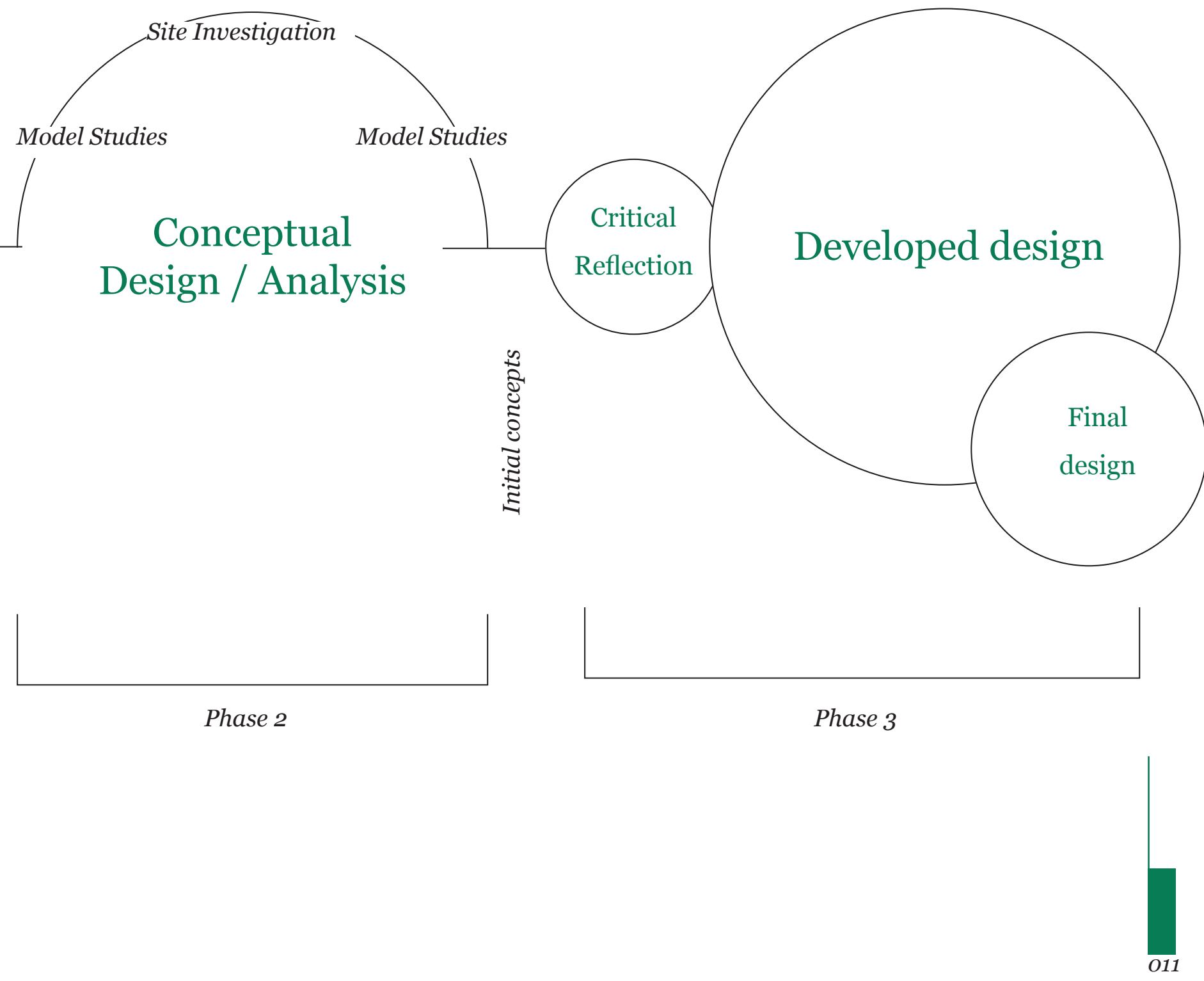




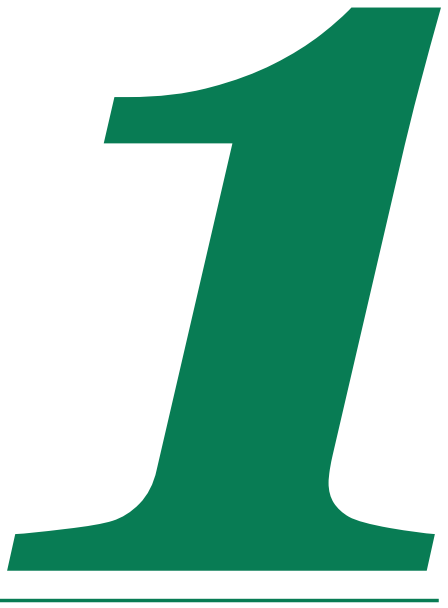




\section{A history of the office}

A brief overview of the development of offices from the 1950's in corporate America and the rise of problematic shareholder office typologies.

\section{Literature review}

A review of literature exploring the break down of the shareholder and cubicle office structure specifically exploring flexibility and the effects personalisation can have on the people working in workspace.

\section{Precedent analysis}

An exploration of three different workspace interior focused office environments and the way the exhibit privacy and flexibility. 


\section{A brief history of the office}

The historical office has traditionally been one built on hierarchies held within each organisation. The size or in most cases whether or not you have an office is very much based upon your position within the company. This idea of the 'Taylorist' office came out of the very first designs for office layouts in the very early 1900s (Saval, 2014). This research will begin to explore the history of the office from 1950s America till the present.

\section{0's US Corporate}

The international modern movement had well and truly arrived in the 1950s in the form of corporate America, bringing with it a uniquely capitalist office style (Caruso St John, 2017 p. 18). The rise of the open-plan office began in these illustrious modern interiors. The buildings were at the forefront of new technologies such as air conditioning and fluorescent lighting. These new modern buildings were completely free of structural walls and just had columns and central units which hid stairs, elevators and services. The structure was completely wrapped in curtains of glass, standing very sleek and modern.

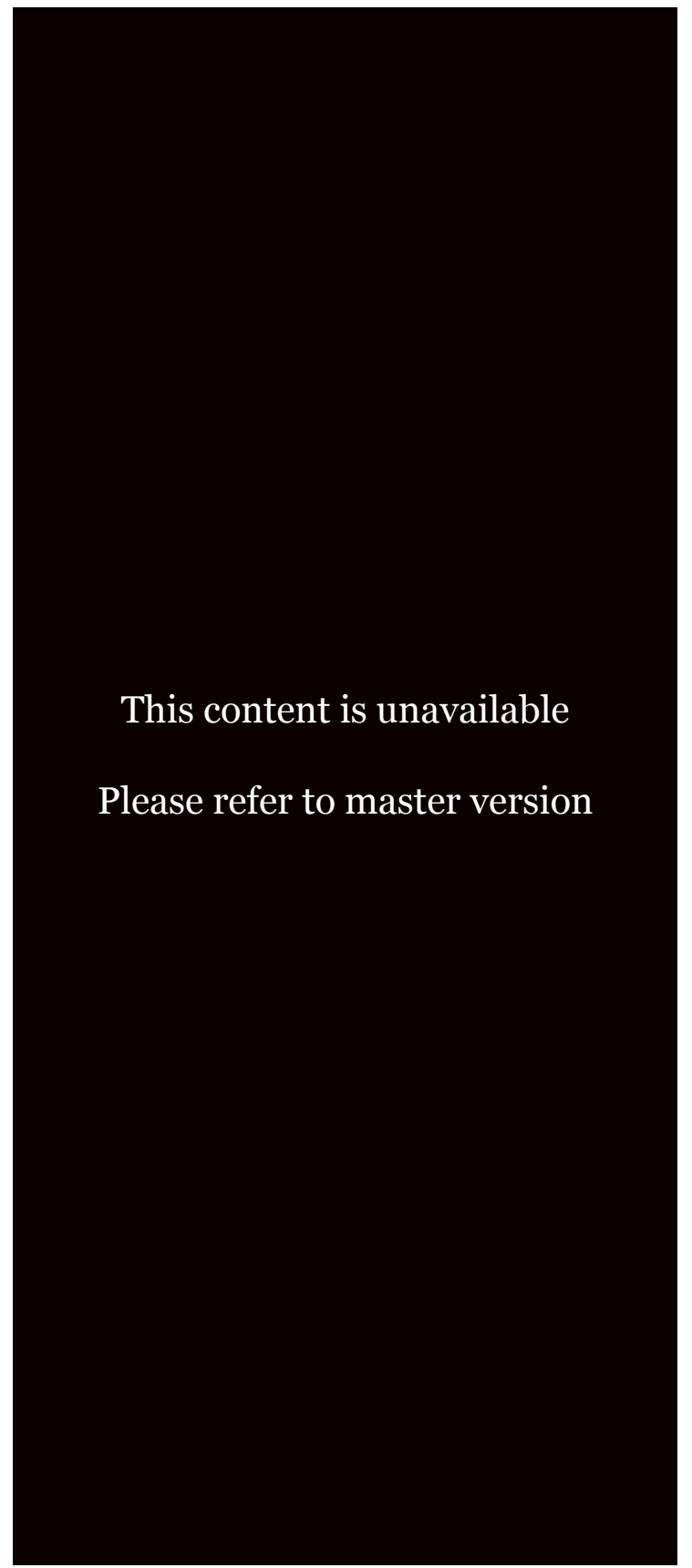

Figure 1.1

Skidmore Owings and Merrill.

Chase Manhattan Bank.

New York, 1961. 


\section{Quickborner Landscape}

In post-war Germany

'Bürolandschaft' was created through the Quickborner team of management consultants (Caruso St John, 2017, p. 20). This system challenged the rigid orthogonal layout of the modernist openplan office. Saval explains the arrangement of desks as "utterly chaotic, totally unplanned-a mess, like a forest of refrigerator magnets" (2014, p. 202). However goes on to express the details of planning go far beyond any symmetrical office (Saval, 2014, p. 202).

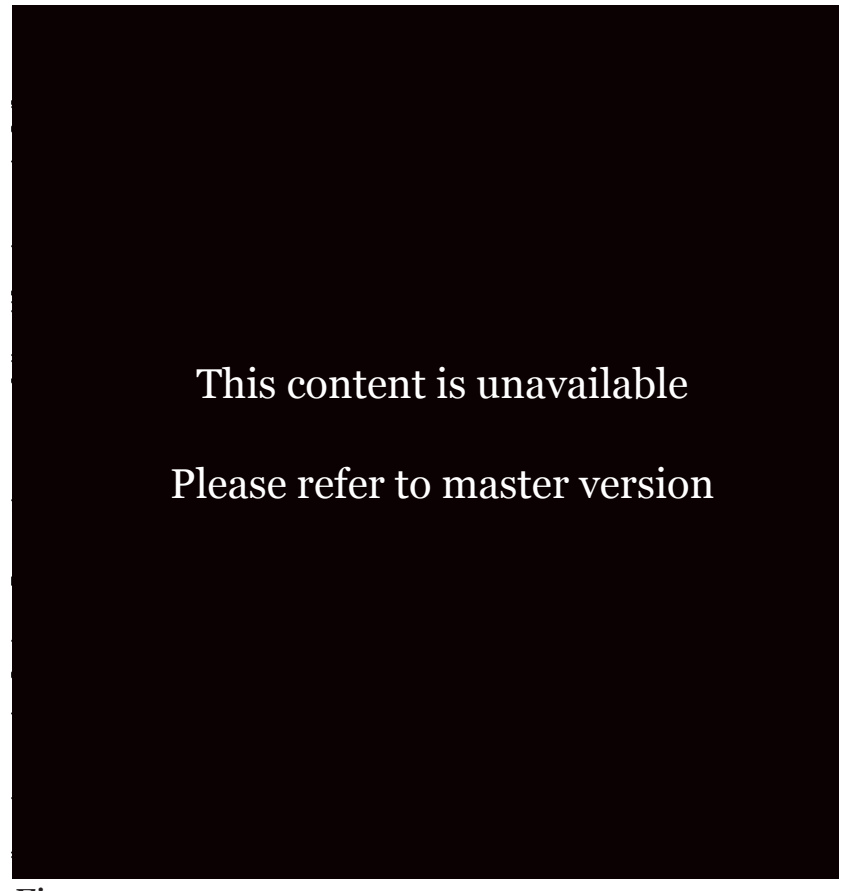

Figure 1.2 Walter Henn. Osram Offices. Munich, 1963 


\section{Structuralist Office}

After the critique of modernist functionalism, the 'Structuralist' office became the model to strive towards in the 1970s. This style of office was modelled on villages where groups of 8-10 people inhabited a small open plan space. They were encouraged to personalise and decorate the space to make it theirs (Caruso St John, 2017, p. 22). This style of office was successful at focusing on the individual and their needs rather than the company identity.

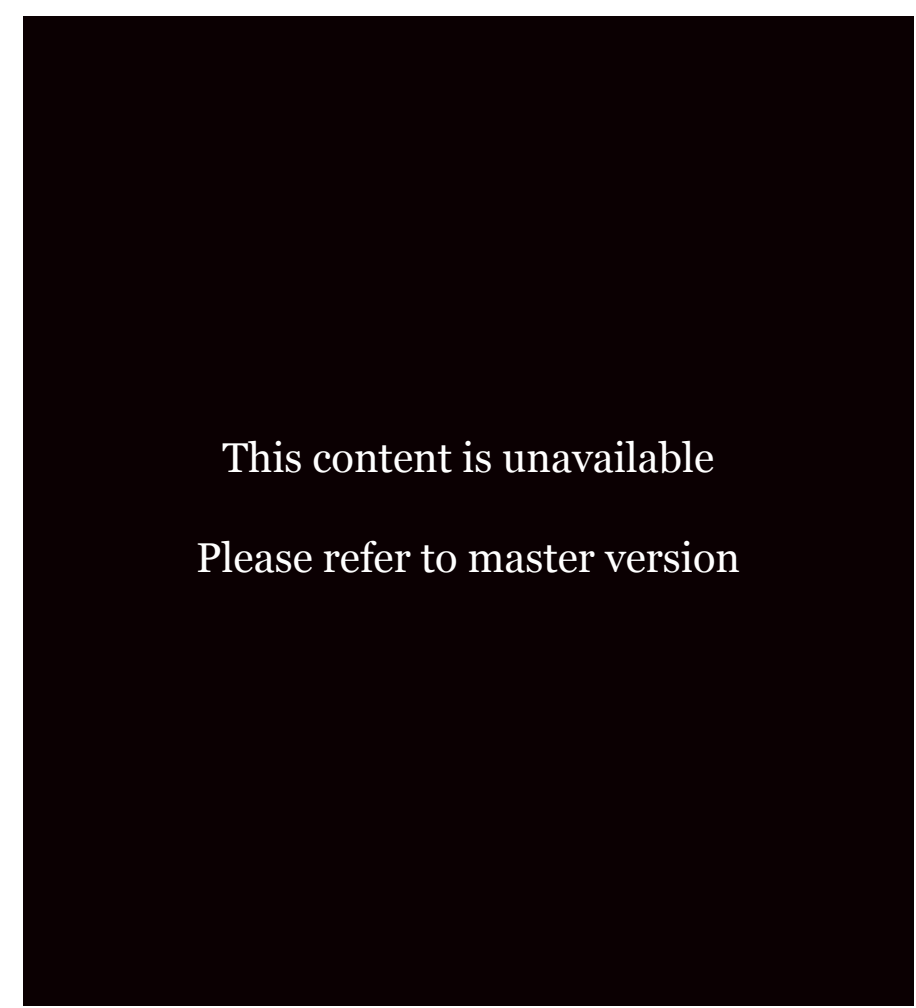

Figure 1.3

Herman Hertzberger.

Centraal Beheer.

Apeldoorn, 1970-73. 


\section{Euro}

\section{Stakeholder Office}

The Euro stakeholder office ideal came about in the ' 8 os and was driven by the increased involvement of the employee in corporate decision making. The Euro office dominated mainland Europe as individual offices lining an internal street, this allowed access to openable windows, natural light and better wellbeing. The idea of personal control was important and allowed the worker to control the environmental factors around them such as light, temperature and draughts. This office style was enabled by a large number of companies actually owning the buildings they occupied (Caruso St John, 2017, p. 24).

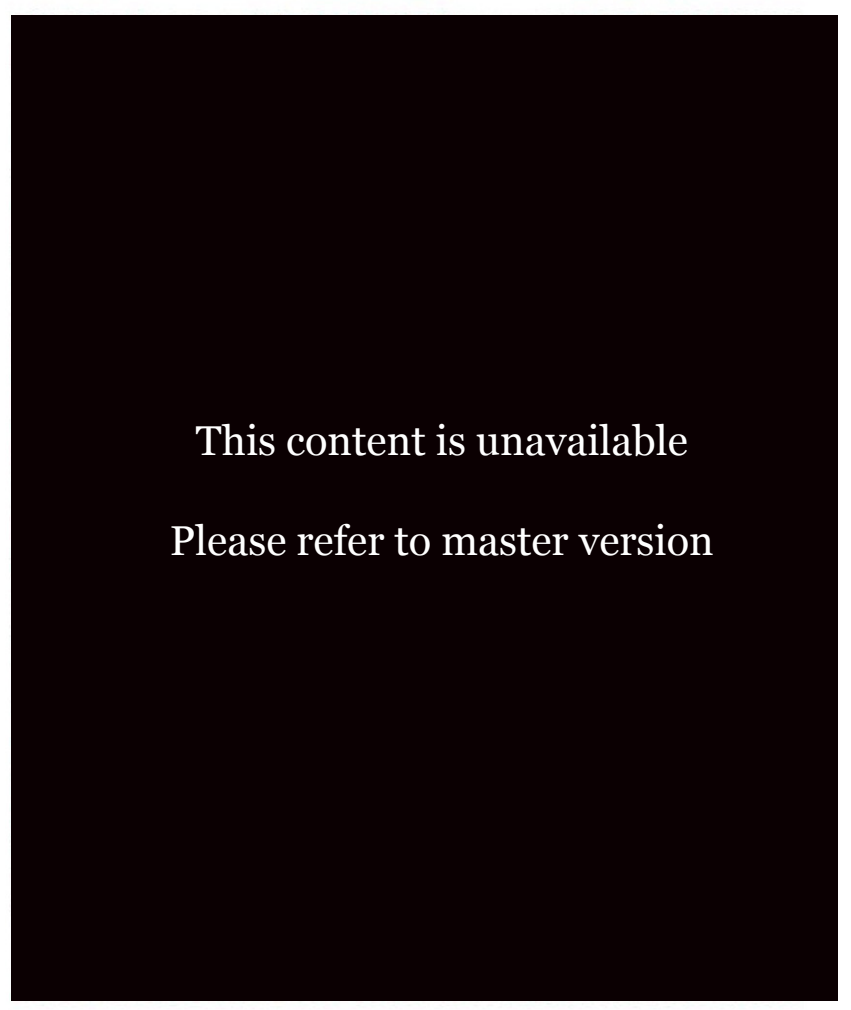




\section{US/UK Shareholder Office}

The Shareholder office of the United States and the United Kingdom was built on a very different dynamic than the Euro office and reverted to the space-saving open plan ideas of the modernist office. The office layout was built upon company hierarchies where senior workers and managers had private closeable offices that lined the walls of windows, allowing only themselves natural light and a view. The other staff sat in 'pens' in the middle of the building. It was this style of office development that brought on sick building syndrome due to the internal and artificial environment that people were subjected to (Caruso St John, 2017, p. 26). The shareholder buildings were often large skyrise developments in which floors were leased.

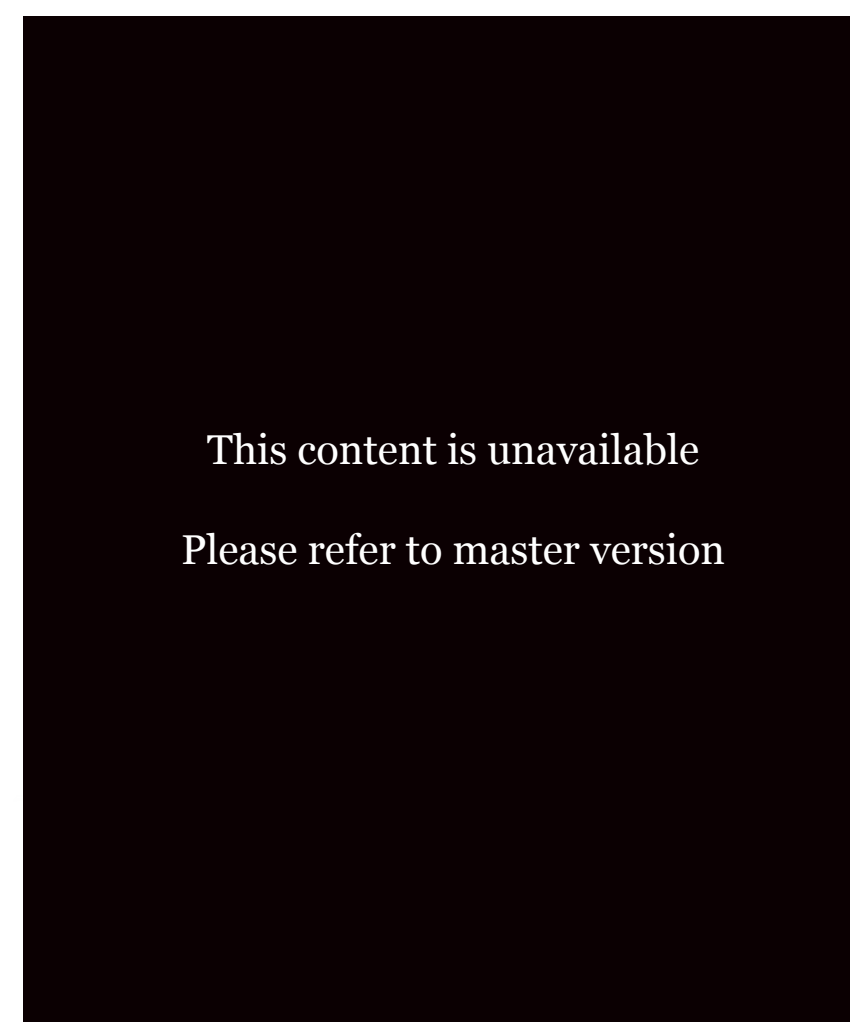

Figure 1.5

Foster and Partners.

Citibank headquarters.

London, 1996-2000 


\section{Virtual Office}

The virtual office of the late '9os was enabled through the use of laptops and mobile phones, allowing one to work more freely (or more often). The fluidity of the workspace meant people could work between the office, home and the third space meaning a cafe or a library. The actual offices were designed as hot desks, or non-territorial environments which take away the assigned desk, with the thought that people may only commute to the office a few times a week (Caruso St John, 2017, p. 28). This began to make it difficult for office workers to connect with their space and therefore the work they were doing. The virtual office was less about flexibility and fluidity than it was about cost savings meaning it left the workers with a sense of disconnectedness.

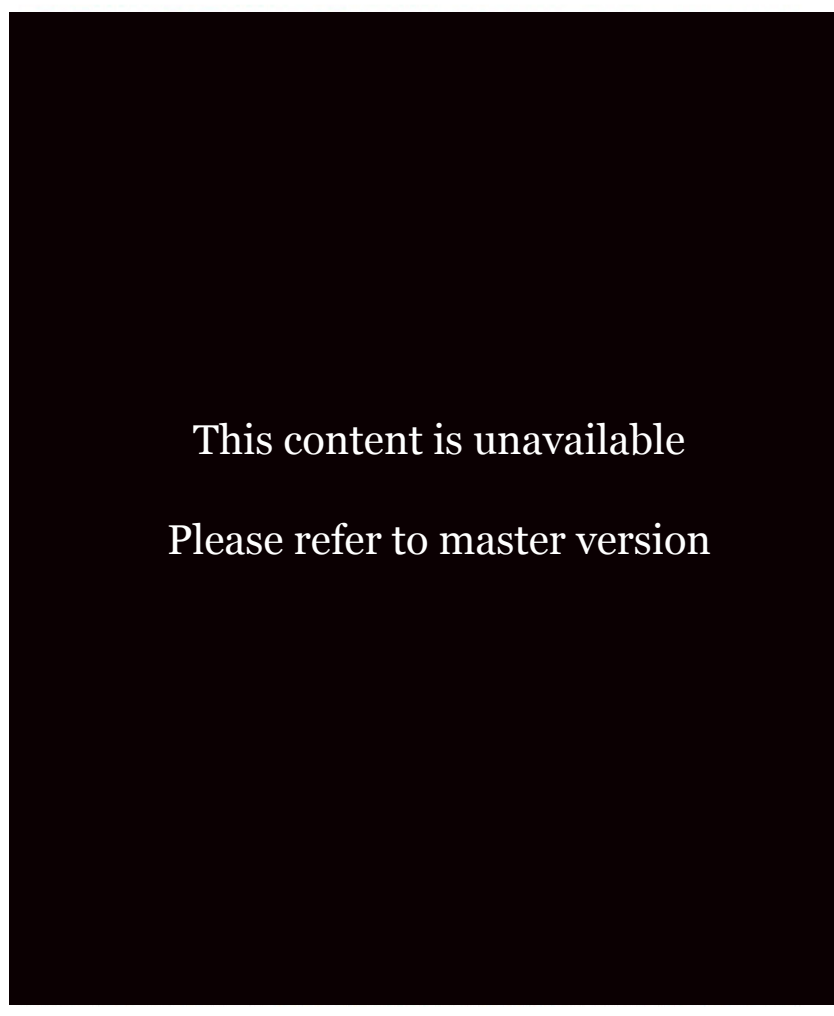

Figure 1.6 DEGW (fit-out) British Telecom offices. Stockley Park, 1996 


\section{Literature Review}

\section{A review of flexibility in the office worksphere}

The rise of non-specific office developments across the financial and tech centres of the globe led to a large amount of unused and vacant offices, thousands of square metres of space empty in the middle of cities (Saval, 2014, p. 304). The argument can also be made for how wasteful offices can be. Even when filled, they are empty half the day even when the lights are still on "illuminating pens of vacant desks throughout the night"(Saval, 2014, p. 304). The neo-liberal outlook of cost-saving on space and work creates a problematic dynamic of easily absorbed loss at the price of keeping a specific facade (Sticklells, 2013, p 196). Companies begin to create calculative accountability in which people are given the privilege of responsible choice, within an economic calculus of value (Sticklells, 2013, p. 197). This value is perceived, an example of this is from fashion label Burberry burning stock to ensure things are not given away or sold to keep the high price and level of exclusivity (Lieber, 2018).
This leads to the question is flexibility the implementation of a companywide subscription for a coworking space? The ability to outsource physical office space and therefore the physical objects in said space becomes desirable for businesses (Mozas, 2017, p. 42). Although having large benefits for companies to outsource offices for staff this has the potential to work well and to encourage a more open collaboration with people in similar and different fields. This serendipitous relationship with working will have benefits for the worker. The idea of coworking environments was heavily influenced by the rise of the freelancing digital nomad (Mozas, 2017, p. 44). Nikil Saval (2014, p. 308) explores the initial larger scale co-working space in the U.S. where companies joined together to create a space of collaboration and conversation to improve their working ways.

Of specific importance to the flexibility of office space is the introduction of modules that can work flexibly within interior shared space, beginning to allow the occupants a sense of place and privacy in office environments. Regardless of how advantageous the partitioning is, the space has the ability to expose people to a provocative mix of seeing and being seen. Using a series of fabric or malleable partition systems allows the space to be free and open plan (Eggler, 2009, p. 80). While the fabric partitions allow spaces to be made within, this in no way affects what the space can be from changing hourly, daily, weekly, monthly and so on. 
The system is used functionally and very effectively in many modernist masterpieces such as the Women's Exhibition by Lily Reich and Mies Van der Rohe. Eggler explains how the partitioning system in some Reich and Mies' projects are designed to begin to enclose people into a smaller, therefore 'safer' space $(2009$, p. 84). This is a way in which people begin to make themselves feel protected in certain situations. This use of partition allows an interior, within an interior, in turn, consenting an agreement of interior shared space. The idea of the moveable curtains was described as utilitarian in design which adds to their functionalism. The ability to be pulled backwards and forwards; opened and closed is useful and helpful (Eggler, 2009, p. 68). The ability to allow an openness or to allow privacy depending on the tasks or environment for work is inherently the ability to be flexible and also anticipate the work.

It is suggested that the new typologies of work and workspaces have created a "hybrid troop of nomadic urbanites"(Idenburg, 2012, p. 117) due to "home becoming less home and the office as a type has vanished". Idenburg (2012, p. 117) argues hierarchy was easily attainable within the old model of closed offices and cubicle offices, however, the social exploration between workers is far more intricate due to the closer proximity and perceived loss of status. Saval explores this break down of the office hierarchy through the 90's tech revolution and the erratic changing of the office typology (Saval, 2014, p. 277).
It was at this point the idea of the modern open plan office was heavily critiqued for the flaws of not only the spatial makeup but also the company makeup.

Anticipating how people use an office day-to-day is hard but what about building an anticipatory work environment? Anticipatory means happening, performed or felt in anticipation of something, in the sense of the workplace it alludes to spaces that can anticipate the type of work and therefore the type of workspace for different tasks and morph into a space that will work comfortably. 'Workspheres' explores the design of anticipatory work environments, Idenburg states that "work is anywhere but in the traditional office" (2012, p. 117), this is in reflection to the ways we can work due to advancements not limited to technology but also to the types of work. It is due to this change in work that the static office workspace has been lost, a virtual world allows us to hold meetings and organise schedules which begin to further remove yourself from the physical and static space (Idenburg, 2012, p. 117). Idenburg explains how through the exploration of each organization looking toward a new office, architecture is there to help and understand the complex spatial relationships that manifest. The new typologies look to allow the space to adapt expertly for different use specifically without the need to continuously move furniture around. It is within this that anticipatory design excels (2012, p. 117). Anticipatory space is complex and forever changing through flexibility and an understanding of the work types. 
The ideas of flexibility meld inextricably well with the ideas of cross-programing. Rather than a building meeting a specific function or 'program' crossprogram architecture begins to layer differing functions upon one another regardless of how they are related. Tschumi explains cross programming through an anecdote:

You see a photograph of a large interior in a magazine. It looks like an image of an unfinished or former church that has been turned into a gymnasium. The space is full of people. You realize that they are voting. You like the idea-three programs that have nothing to do with each other, but seem to work well together. You say to yourself: there is no architecture without a program, no space without the movement of human beings intersecting it. (Tschumi, 2012, p. 182)

Cross-programming allows differing functions to co-exist within a space; this co-mingling of functions begins to morph and change over the course of a building's life. The result of cross-programming is "greater than the sum of its parts" (Tschumi, 2012, p. 185). Tschumi makes the point that multiple programs inhabiting a space are more valuable than if they were separate because this allows groups of people to interact who may normally not interact. This inherent flexibility of cross-programming only exists because of the movement of people. As an example, Tschumi cites a church in New York. The building was a church, a nightclub, a storage barn, a pizzeria, a Salvation Army outpost and a shopping mall (2012, p. 191). Spaces can have specific functions and programmes, however, those programmes are only ever activated when space is occupied by people seeking that specific program. The idea of flexibility explores the way a cross-programmed building might continue to function at different times and the ways in which different programmes might productively interact with each other.

\section{A review of personalisation in the workspace}

Flexibility and the individual in office space should be explored through more than an architectural lense, dealing also with the psychological notions of people. Most important is people's perception of identity within an office space. This can manifest in many ways but most notably the way they begin to personalize a space. It is widely understood and agreed upon that employee satisfaction goes down when the ability to have autonomy over their own space is taken away (Elsbach, 2003, p. 626). so why has the nonterritorial space or hot-desking become the norm? Personalisation has both implicit and explicit ways of presenting itself outwardly to employees and colleagues.

Employees explicitly represent themselves in space through visual cues such as personal items, furniture or the arrangement of items on a desk. Elsbach (2004, p. 625) used qualitative methods to explore the effects non-territorial office environments had on employees and the perceived threat to their identity (Elsbach, 2004, p. 625). 
This investigation used a workplace case study that analysed the employee's perception of a workspace in a newly non-territorial officescape. This study examined how the employees attempted to exert themselves in the newly homogenised workspace. It was found that the employees had a high reliance on markers to express their personal identity to the rest of the workplace (Elsbach, 2004, p. 624). Findings from another study indicate personalization to be a relevant factor for consideration when implementing a nonterritorial or hot-desking office design.

\section{When objects are prohibited to personalize your work environment, people seek several additional ways to make the environment familiar and comfortable for them and to mark their identity in the organization (Brunia, Hartjes- Gosselink, 2009, p. 169).}

When areas of autonomy are taken away people begin to explore other ways to exert themselves and their personal taste and style. Through different studies, it is clear how important the role of personal items such as furniture, photos and personal items have on the perceived happiness and comfort level of employees. The study by Elsbach gives valuable and interesting insight into the role personal objects have in making someone feel connected to a space. Their study went into more depth exploring the office landscape, or the more objective means of individual office identity and how the employees fit into this.
The practical implication is that balanced decisions and rules between organizational policy and human needs help the acceptance of personal workplace being lost in non-territorial offices (Brunia, Hartjes-Gosselink, 2009).

The personalisation of space is not always explicitly expressed via personal items such as through the photo frame of the family on a desk but rather more implicitly. This indirect personalisation is more complex as it reflects an employees connection to a workplace (Van Der Vordt. 2004, p. 145). Research explores the effects non-territorial offices have on employees and the lack of a personalized experience they can have. Vordt explains personalisation also occurs mentally via becoming familiar with an environment as to feel safe and secure in that environment. Further, it also occurs with social contacts which imply that community is a way in which people personalise their environments.
The lack of a personal territory and personalization opportunities can be partially offset by applying these principles to an organizational unit as a whole: that is, by giving a department its own identity by means of a colour and personal or collective attributes, thereby creating the feeling of a 'group territory' (Vordt, 2004, p. 146).

Through implicit personalisation such as having a different colour or identity for floors or teams of a company begins to allow them to connect with an overall space rather than just an individual space. 
Other issues identified are things such as the inability to control climate and lighting settings had a negative impact. This is an age-old debate in the office environment of the thermostat. Buildings will typically take away personal heaters as it adversely affects with the central heating of the building. Workplace comfort, ergonomics, paired with the loss of places to store things also had negative impacts on people's view of nonterritorial offices.

The design for workplace considerations must be made and thought of to ensure the space will benefit those working within it. Mildred and Edward Hall (1975, p. 34) argue that the main three points should be thought of and examined in detail individually and also together. These points are;

1. The structure itself, its program, design, workmanship, materials, detailing, etc.

2. The people as physiological and psychological organisms who perform the functions the structure was designed for. 3. The organisation that is also housed by the building but which exists in a larger context. The organisation and its structure become the context of a statement that can only be "read" in terms of its setting (Hall, 1975, p. 34)

Within the study of buildings, Mildred and Edward Hall explain that it is important to examine in detail three separate but connected points. It is very important that point two and three do not get bundled together as is normally the case, personal identity gets mixed in and lost with the corporate identity.

The ideas of personalisation and flexibility in the non-territorial office environment are incredibly complex and unique. The wasteful office environments that are currently flooding the market need to be changed, is the flexibility the answer? Flexibility creates a typology of space that can begin to anticipate the ways of working. Flexibility is inherently a form of personalisation for a space, the idea of partition walls and curtains could begin to be used as a way to allow a sense of identity to a group or team of people as argued by Van Der Voordt.

\section{Case Study Analysis}

The precedents were chosen to explore a range of modern office space development, critiquing how successful the projects have been at integrating levels of flexibility, cross-programing, and personalisation. Each project explored these ideas in differing levels of importance and success, to then begin to anticipate the styles of working needed. 


\section{Hybrid Office Edward Ogosta Architecture,}

\author{
Los Angeles, CA, USA \\ 2012
}

The Hybrid office is a unique project designed for a creative media agency located in Los Angeles, California. The overall space was designed for 30 people with a building footprint of 60oosqft or $557 \mathrm{~m} 2$ this accounts for a generous $18 \mathrm{~m} 2$ a person.

The Hybrid office creates a unique interior world through a number of hybrid typologies, blending the surrounding terrain inside to foster creativity and to embody the spirit of the company. This blending of ideas is manifested through two parent traits such as bookshelves joined with an arena resulting in a multi-functional book arena. This area can be used individually for reading or working but also for team meetings and events where everyone can sit around comfortably. A further example of these hybrid typologies is the coming together of a tree like structure and a chair to create a more intimate and private way to sit and read, allowing the individual to retreat further into a private space away from the busy office to focus on some work or to rest for a moment. The hybrid typologies are an important part of creating a joint office identity for the people using the space.
This blend of office terrain allows people to move around the office throughout the day to make themselves most comfortable for each task they are performing. One may start at a desk to reply to emails and then move themselves to a treechair to read documents and then finish off at the communal table. This flexibility in the office allows each employee to personalise how they work each day. The way this office works is to bring the outside in to stimulate but also make the employees who occupy the space more comfortable.

The white colour pallet is very intense and clean and is only abandoned inside of spaces such as the inverse of the mountain desks or the kick panels of the book arena. This harsh stark white is contrasting with the feel of the space trying to mimic the outdoors. For a greater sense of comfort and naturality more natural materials and coverings should have been used to allow more texture and feeling into the space. The use of hybrid typologies of furniture begins to create a series of families that can begin to change for different functions such as sitting, standing, lying down. These families can then begin to manipulate materials depending on their required use.

The flexibility of the space is a very strong and unique aspect of the project allowing people the comfort and ability to break the mould of the traditional working office and work structure through the spatial relationship they can have within an office environment. 
Top Left:

Figure 1.8

Ground and mezzanine plan view of the Hybrid

Office showing the unique office landscape and typologies for working.

\section{Top Right:}

Figure 1.9

A view of the 'book arena' within the Hybrid Office, an area that has arena like seating combined with bookcases.

\section{Bottom Centre:}

This content is unavailable

Figure 1.10

A view of some desks within the Hybrid Office,

showing the use of encasement for privacy.

Please refer to master version

This content is unavailable

Please refer to master version

This content is unavailable

Please refer to master version 


\section{Paramount - The office Space -Woods Bagot}

Sydney, NSW, Australia 2015

Located in the Paramount Building in Surry Hills, Sydney, Paramount by Office Space is a sophisticated and discreet co-working space. The adaptive re-use project sits above a Sydney cafe. The space has 22 dedicated suites for 1-3 people.

The suites are elegant pods angled throughout the space at approximately 30 degrees. Space allows for meaningful visual and auditory privacy within, however still has a connection to the outside space through large connecting glass doors allowing a restrained amount of the outside in. The lighting in the suites is thoughtful, allowing a warm glow from above which catches the off white ceilings of the pods, (the only spot of pure white in the space) to create a more ambient light in the space and a strip of diffused LED lighting on to the large bench desks in a way to avoid shadows.
The lack of direct lighting in the space adds to and enhances the warmth of timber. The material pallet of Paramount not only honours the building's heritage it goes beyond being modern or retro. The space is timeless from the blending of solid timber and marble or the large panes of curved glass. Space honours the art deco period while being completely timeless. The use of timber and brass add a sense of deep warmth to the space adding deep golden tones to the space, making it feel more elegant. The use of negative detailing between the connection of the walls to the suspended ceiling enhances the feeling of adaptive re-use while also paying homage to the original art deco building.

The private pods are all connected to a more central space rather more like a living room than an office break room. These intersect the private meeting rooms which begin to feel like more formal living rooms. The interconnected space feels formal while at the same time the spatial configuration creates a sense of homely informaility.

It is the blend of intimacy that creates a successful space of privacy and homelyness. The spaces are comforting and private allowing the user to have full focus on their work, the space is completely designed to feel like it is there and not there at the same time which is a real homage to good design and what good design can do for the workplace. 
Top Left:

Figure 1.12

Inside one of the office spaces showing built in storage and intelligent lighting combined with right timber, the space can be shut off from the corridor with the use of a door.

\section{Middle right:}

Figure 1.13

A plan showing the layout of the Paramount offices.

\section{Bottom Centre:}

Figure 1.14

A view showing one of the meeting pods with curved glass that mimic the use of curves of the office spaces. The view down the hallway shows the use

This content is unavailable timber, glass and marble throughout the space.

\section{Please refer to master version}

This content is unavailable

Please refer to master version

This content is unavailable

Please refer to master version 


\section{Stepping Stones \\ -Morris+Company}

\author{
London, England
}

2019

Centred in an old Tube Station in the middle of London this project explores layering the social issues of youth homelessness over a coworking office. The project is exciting and engaging building. Housed in a three-story building that was unused. The project was the winner of a competition that attempted to tackle youth homelessness in London city (Walsh, 2019). The project looks at integrating one of the most disadvantaged and vulnerable groups in our society into a safe base to allow them a stepping stone to a more secure future. The project looks to integrate these young people with an exciting and engaged group of startups (young business owners) and creatives through a co-working, co-living environment (Walsh, 2019).

The relationship to space within the project is interesting. The ground floor is large and for the most part open; few walls divide up the space allowing viewpoints throughout the space for some moments of privacy; the downstairs space is very public and houses a charity shop, coworking offices, tables, bike storage facilities, check-in counters for homeless youth, a secret outdoor courtyard and a laundry area.
This large area downstairs allows the youth to make the space their own through creative outlets such as art. The space is also open to utilize the facilities such as washing and drying machines and television rooms. The ground floor is connected through the building by a large open central staircase.

The accommodation has been thoughtfully designed for differing lengths of occupation; short term, midterm and long term accommodation options. Each of the options is designed and built in a modular way that is easy to assemble.

The short term option is the smallest: it has a bed with built-in storage and a small area for study, the unit is $7 \mathrm{~m} 2$. The bed area is elevated with cupboards and areas to store things, the steps up to the bed also include areas to store things. The bed can become a more private space with the pulling of a curtain almost making the bed into a fort space. The mid stay space has very much the same bed and study space set up however is slightly more private. It has a breakout space away from the bed you can relax on a sofa in privacy still allowing the bed area to be closed behind a curtain for a feeling of security. The long-stay space allows the residents a more personal and autonomous experience in living with their own bathroom and kitchenettes and also providing a studio space. The space allows for comfort privacy and security for this vulnerable group of people, allowing them to have a space of their own for however long they stay for. The space also allows autonomy of self, with bathrooms and kitchenettes in some of the rooms. 
The Coworking space occupies a large portion of the ground floor, with spaces for group work and individual work. Although not the most flexible of spaces the space has a strong connection to the social functions of the rest of the building which allows a connection to occur between the workers and the homeless youth.

This content is unavailable

The project is successful in integrating a vulnerable group into a safe a secure space. Most successfully though is the efficient use of space. The duality of the project allows a layering of two different groups of people to occupy a space in harmony, having people occupying the space over a 24 hour time scale is a unique point that begins to intelligently use space in our cities. The connection the groups share begins to allow a more comfortable space for conversation and collaboration to flourish.

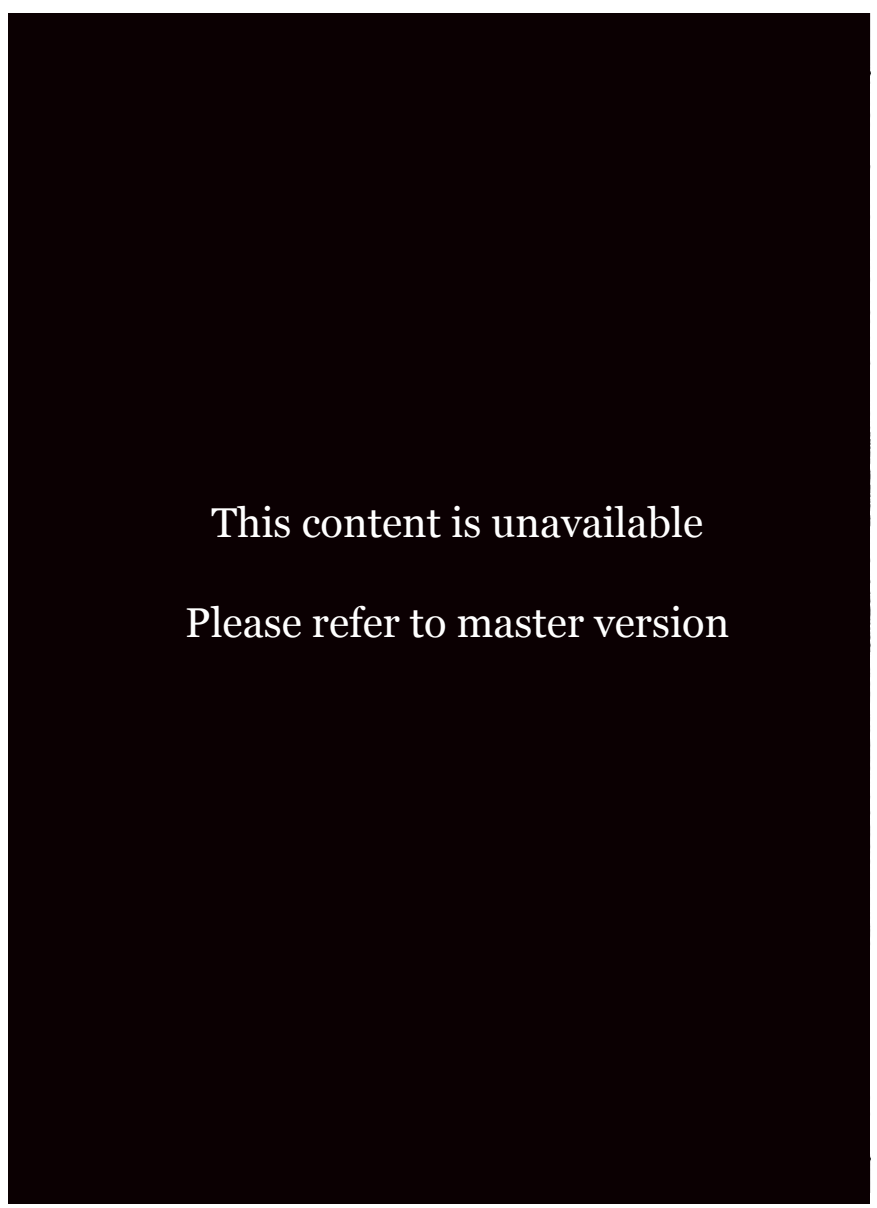

Top Left:

Figure. 1.15

A plan view showing the first floor which has a mix of short term and long term accommodation.

\section{Bottom Left:}

Figure. 1.16

A plan view showing the first floor which has co-working desks and a garden space, along with facilities for both the office workers and the rough sleepers. This floor is a space where conversation between the two groups can happen.

\section{Bottom Right:}

Figure. 1.17

A render view showing the main entrance to the space along with the large central staircase that moves up through the project.

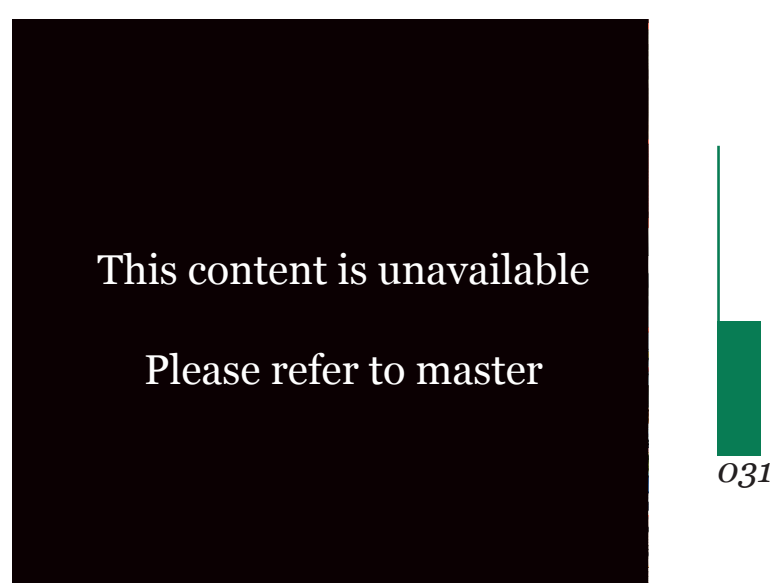




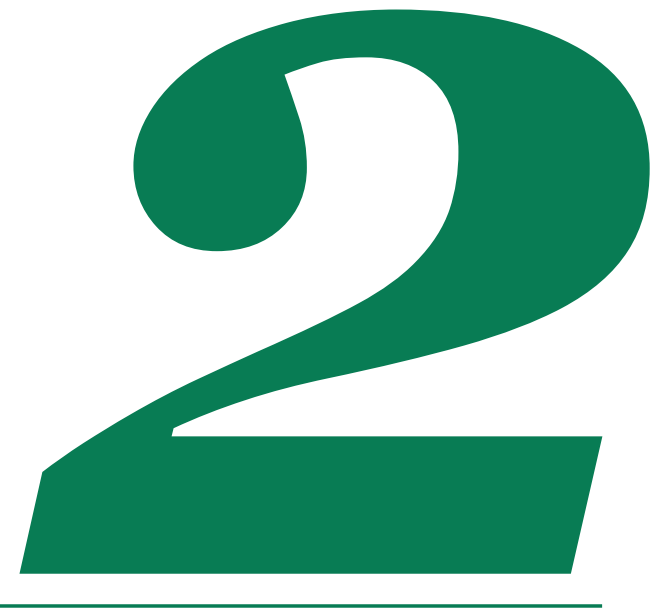




\section{A series of tests}

An exploration of 3 different tests at a visual, physical and environmental scale.

\section{An exploration of the desk} An analysis into the way people spread out and personalise their desk space in a shared office.

\section{What are proxemics?}

A brief introduction into the study of proxemics.

\section{Proxemic study}

A exploration of proxemic in relation to aircraft seating. A test of three different desks and arrangements and analysis.

\section{Critical reflection}




\section{A series of tests}

\section{-Visual \\ -Physical \\ -Environmental}

These three tests explored different factors that could begin to allow the individual begin to allow the individual in a space autonomy and personalisation. The test were explored around a non-specific workstation in a typical open plan office. The visual test explored the visual cues and markers such as lines to differentiate between workstations. A physical test explored physical barriers and the placements of these around the individual in a workspace. These barriers were at differing heights and distances to understand the effects they had on the person in a space to ensure focus. An environmental test explored environmental factors such as the use of directional light and the control of air conditioning. From these tests the idea of a plane seat was the only example of a space that has the ability to control all 3 factors, this is explored further later. 


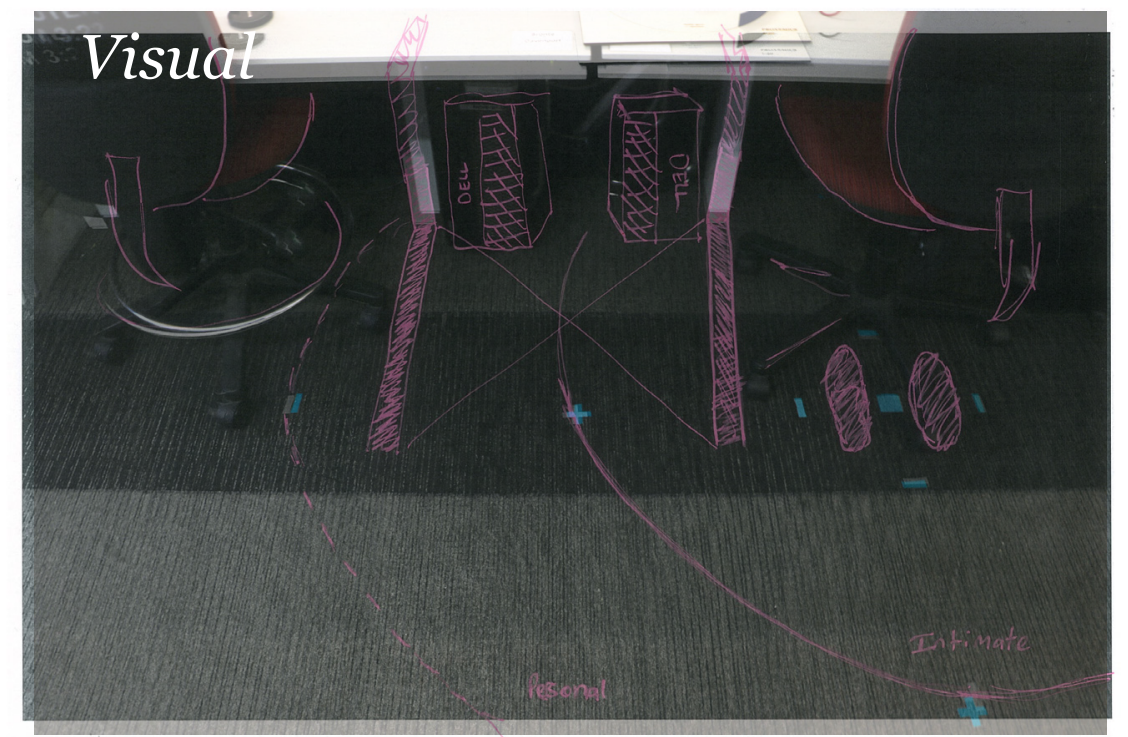

Physical
Figure. 2.1.

A test exploring the visual aspects of understanding individual space in the work environment.
Figure. 2.2

A test exploring the physical aspects of understanding the individual space in the work environment, specifically physical partitioning.
This content is unavailable

Please refer to master version
Figure. 2.3

A test exploring the environmental aspects of understanding the individual in the work environment, specifically around lighting and air conditioning. 


\section{An exploration of the desk}

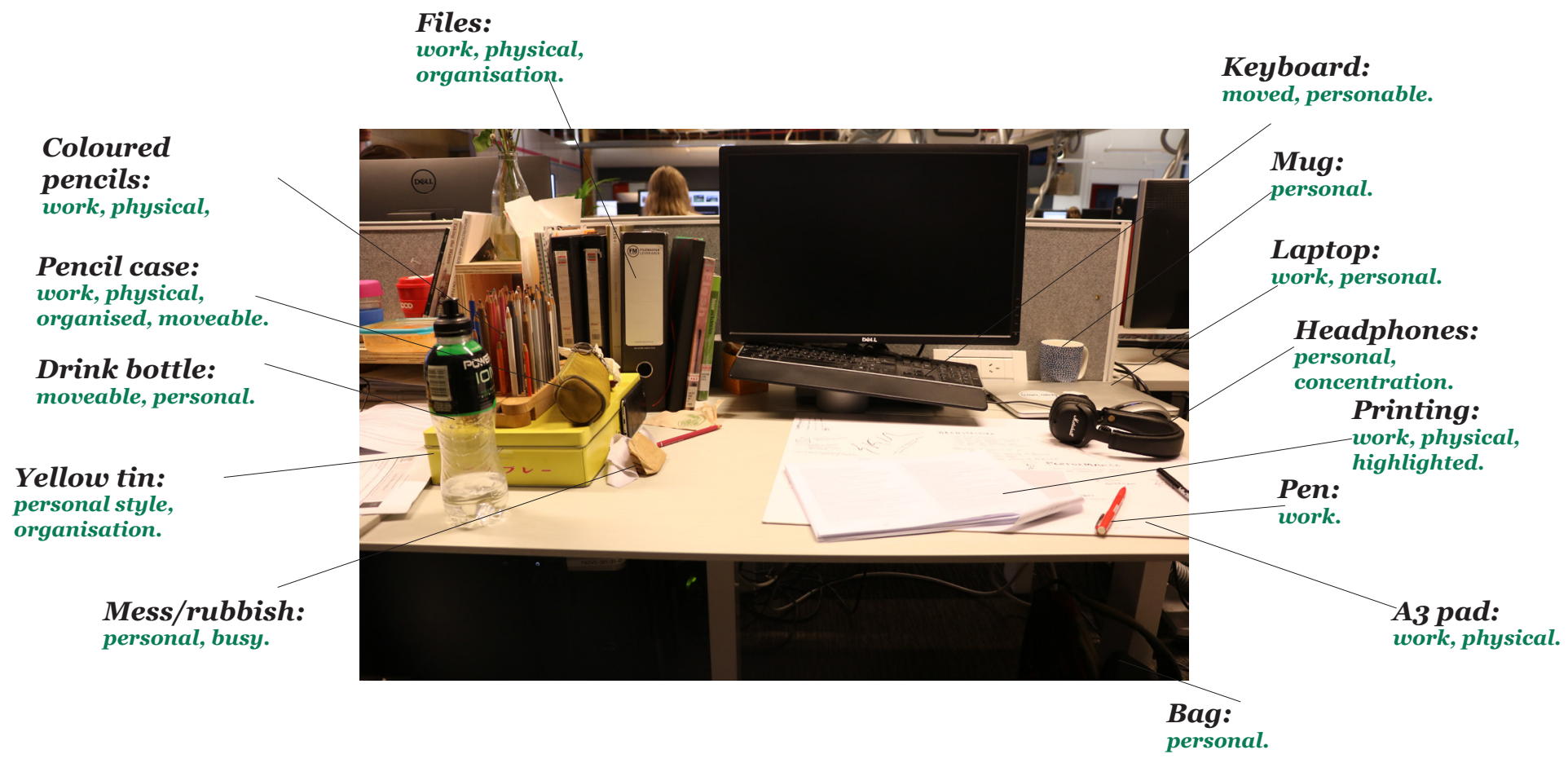

Figure. 2.4

A persons' desk showing the way they personalize and organise their own space. This begins to explain to the people around them how they may work. This particular example shows an organised chaos and also the lack of room for the type of work the person is undertaking. 


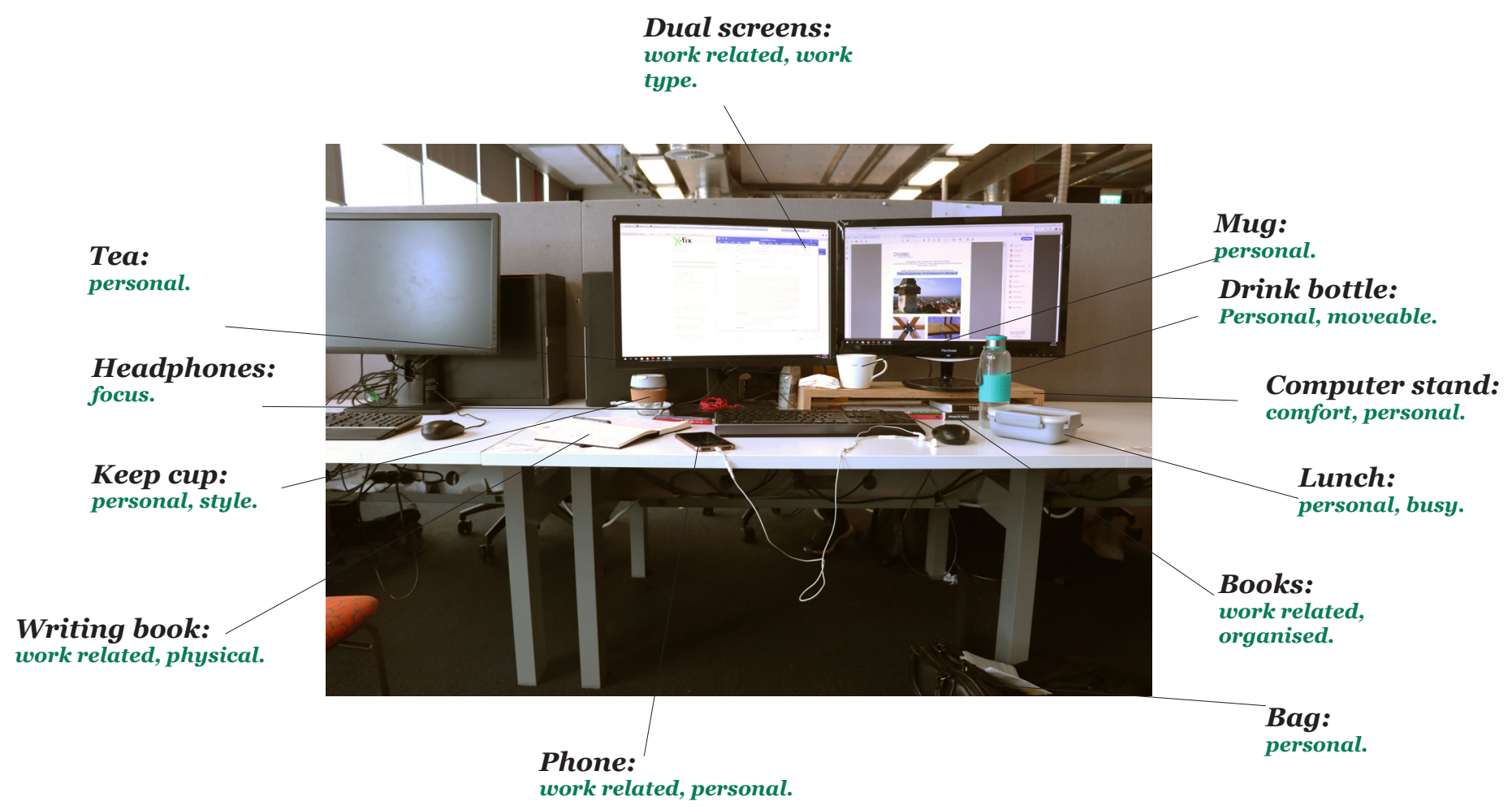

Figure. 2.5

A persons' desk showing the way they personalize and organise their own space. This begins to explain to the people around them how they may work. This particular example shows an organised almost minimal desk, hunting the way they work in mainly on the computer. 


\title{
Proxemic bubble
}

\author{
-Intimate \\ -Personal \\ -Social
}

Proxemics is simply put "the branch of knowledge that deals with the amount of space that people feel it necessary to set between themselves and others" (Oxford Dictionary). The term proxemics was coined by Edward Hall (Hall, 1969) in the 1960's. This test explored peoples' perception of the space around them and broke that space down into different perceptual zones. Hall broke down the idea of proxemics into a person's intimate space (450mm from one's own body), their personal space (1200mm), social space (360omm), and public space $(7600 \mathrm{~mm})$. As understood in figure 2.6 proxemics centre the individual in the middle and move out in rings. These rings may change shape and morph depending on the shape and layout of a room. 


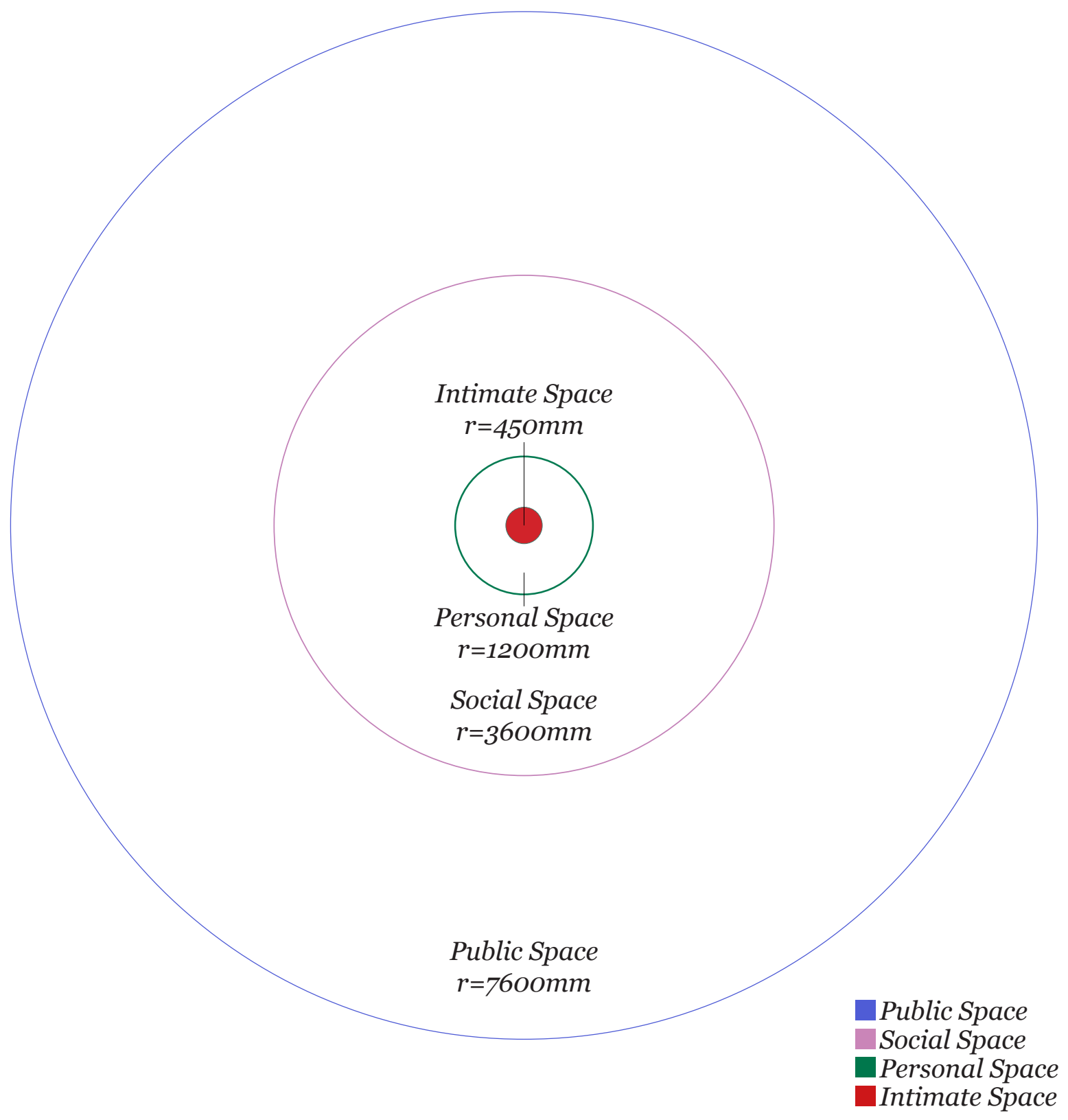

Figure. 2.6

A diagram of the proxemic bubble created by Edward T Hall, showing the distances between intimate, personal, social and public space as perceived by people. 


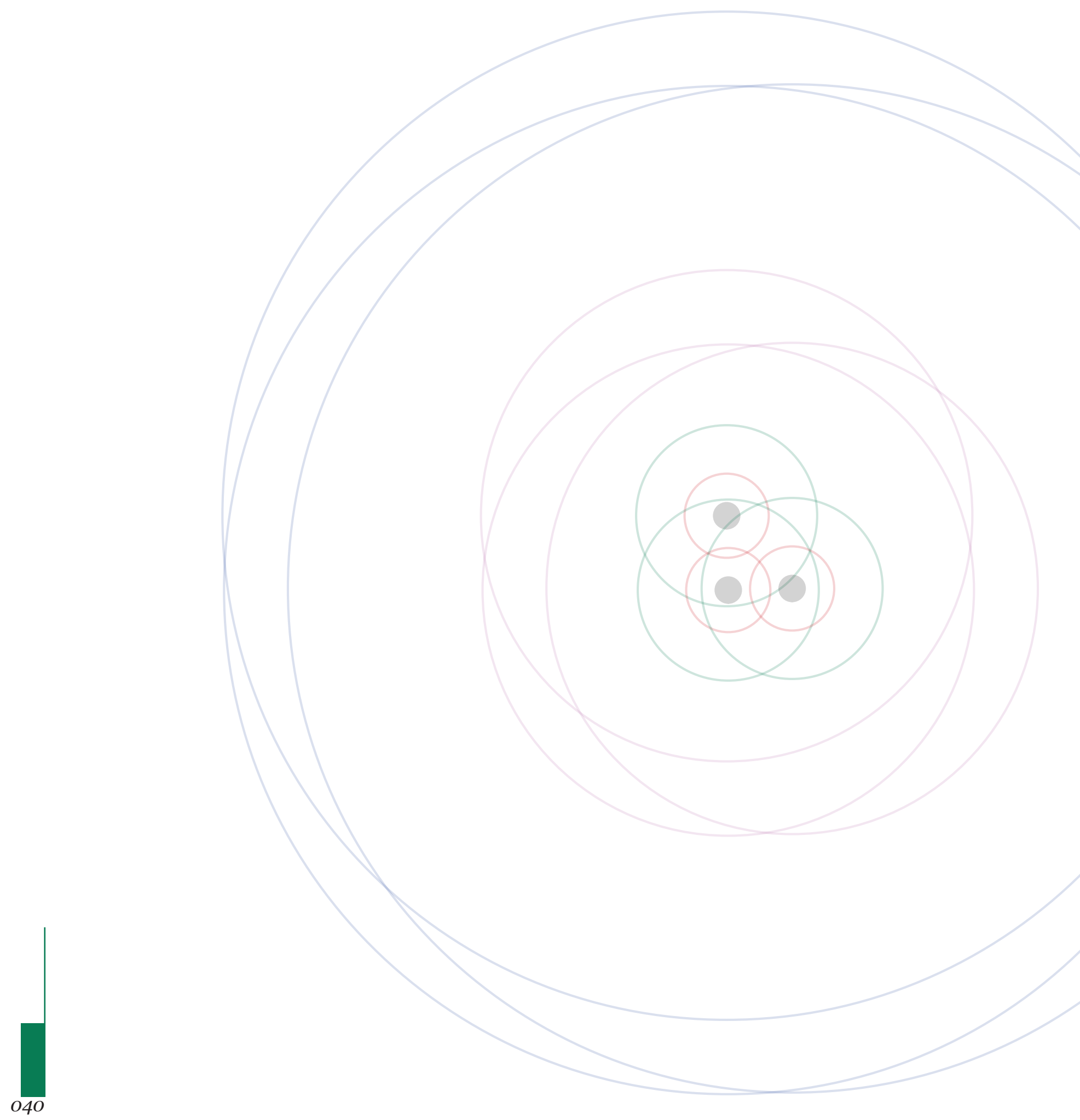




\section{Proxemic test}

The idea of proxemics is important to consider in the design of office space specifically when designing for the individual in a flexible space. This test begins to explore how far the size of an office can be pushed before it becomes unusable, through the exploration of overlaying the idea of airplane seat proxemics. The airplane seat was chosen as it is an example of a space in which a person is pushed to the proxemic extremes for extended periods of time. The airplane seat also is an example of a space that has visual, physical and environmental controls for the individual. Through the exploration of an economy, premium economy and business class seat on Air New Zealand, a series of digital models are mocked up to explore how the differing levels of comfort in a confined space are valued. This ability to have a series of three differing examples of comfort in a space is unique. The test will look at what techniques are used to allow privacy and comfort. These models will then be overlaid on to a floor plan and examined with a proxemic diagram to understand the points of comfort and privacy and the points of discomfort and exposure. 


\section{Airplane proxemics}

This content is unavailable

Please refer to master version 
This content is unavailable

Please refer to master version

This content is unavailable

Please refer to master version

Figure.. 2.7

A series of analysis of an economy, premium economy and business class seats on Air New Zealand. The analysis explores the proxemics of the space where people's comfort is pushed to the extreme. 


\section{Economy desk}

\section{Desk size}

Width 7oomm

Length 10oomm

\section{Minimum distances from another}

Opposite 650mm

Between 10oomm

Floor area $\mathbf{5 2 7 . 2 m 2}$

Occupancy 186

Area per person $\mathbf{2 . 8 m 2}$
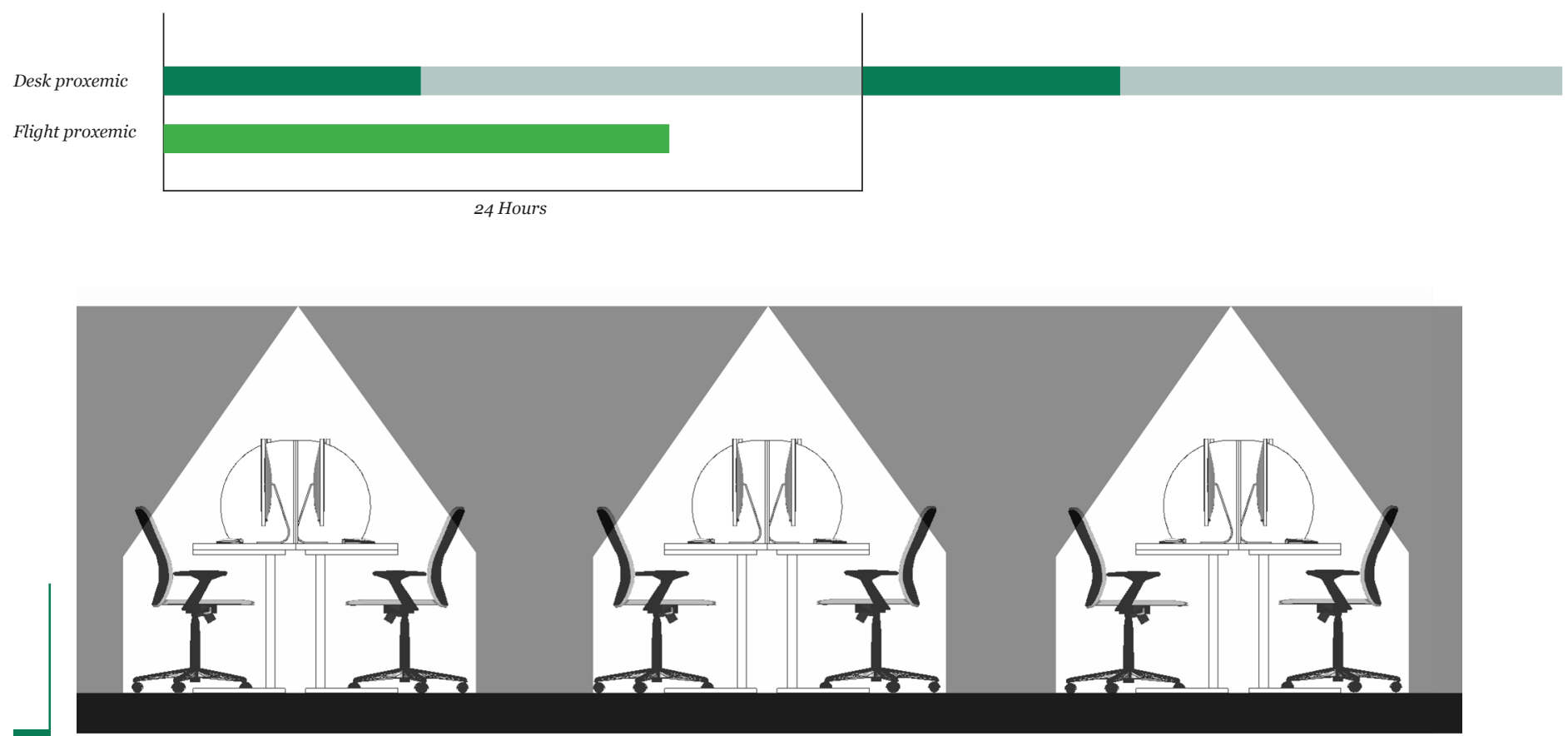

044 Figure. 2.8

An elevation of the economy desk, showing the use of the visual, physical and environmental tests through the use of partitions between, the use of directional lighting over top. 


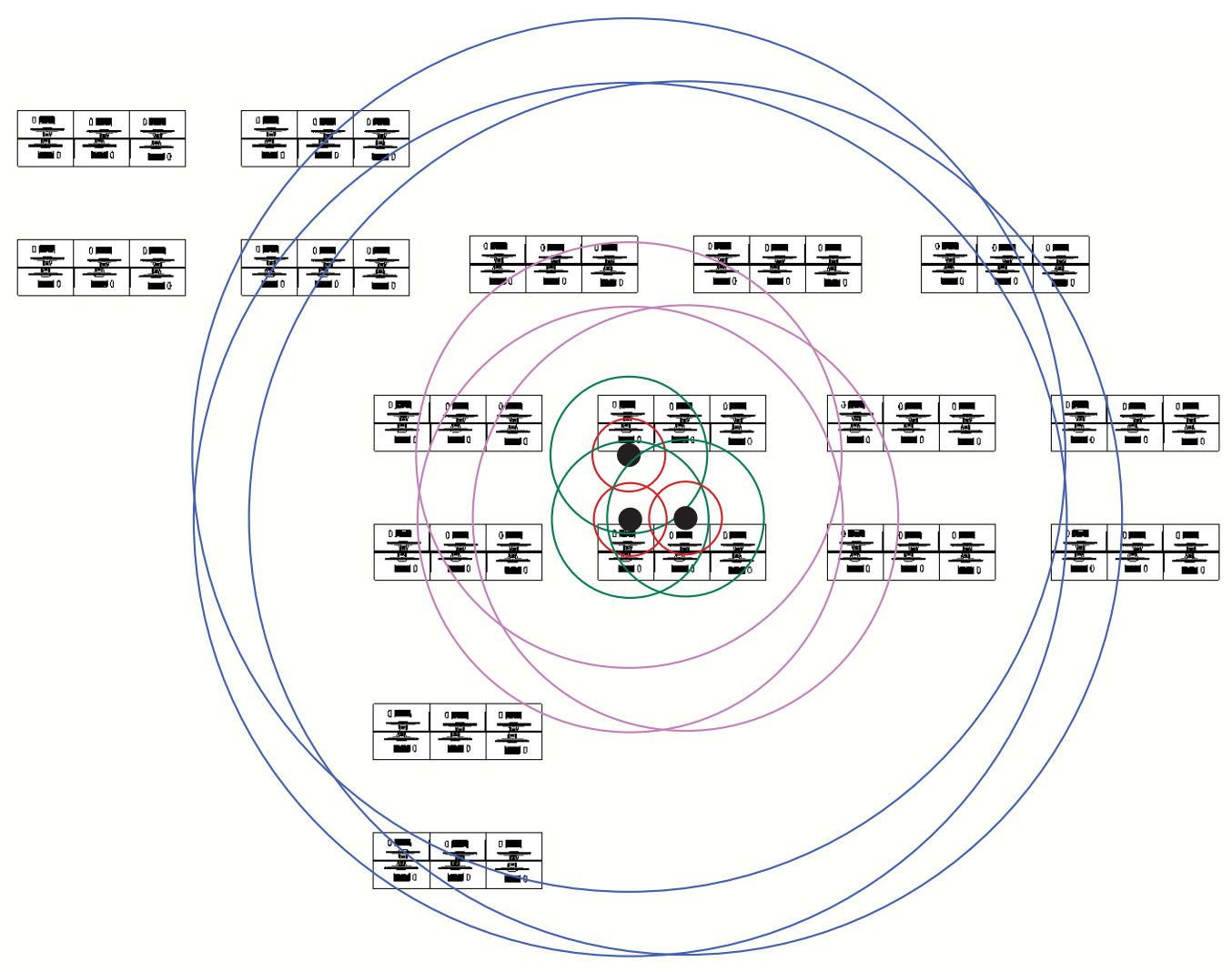

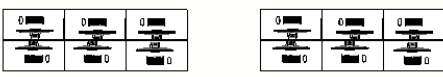

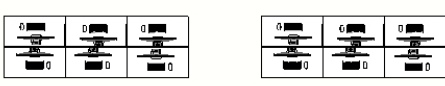

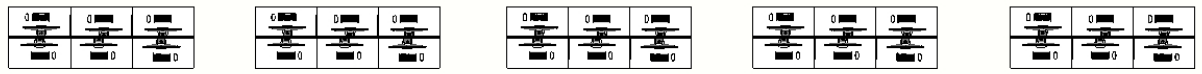

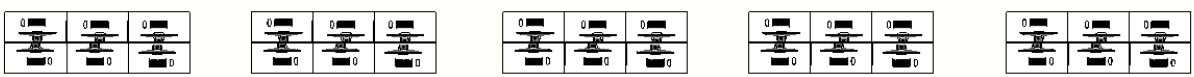

Figure. 2.9

A plan view showing the exploration of the economy layout of desks within a floor plate. The plan shows how close together the desks are to one another. This is further enhanced by the proxemic bubble diagrams showing the overlapping intimate and personal spaces which will be problematic. 


\section{Premium \\ economy desk}

Desk size

Width 8oomm

Length 1300mm

\section{Minimum distances from another \\ Opposite 910mm \\ Between 2000mm}

Floor area 527.2m2

Occupancy 96

Area per person $\mathbf{5 . 5 m 2}$
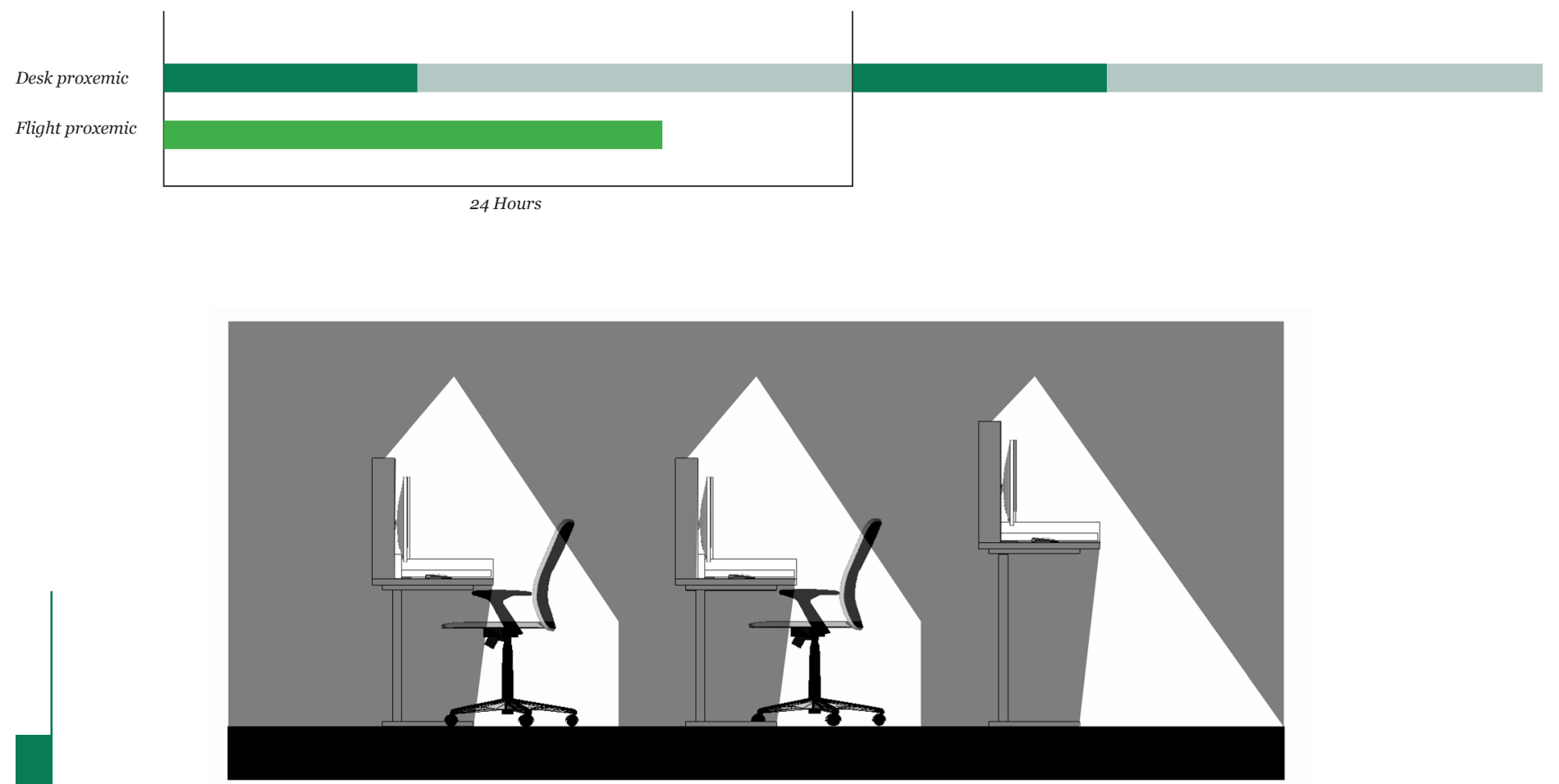

Figure. 2.10

An elevation of the economy desk, showing the use of the visual, physical and environmental tests through the use of the desks that do not back on to one another, this allows for visual privacy. Partitions between, the use of directional lighting over top. 

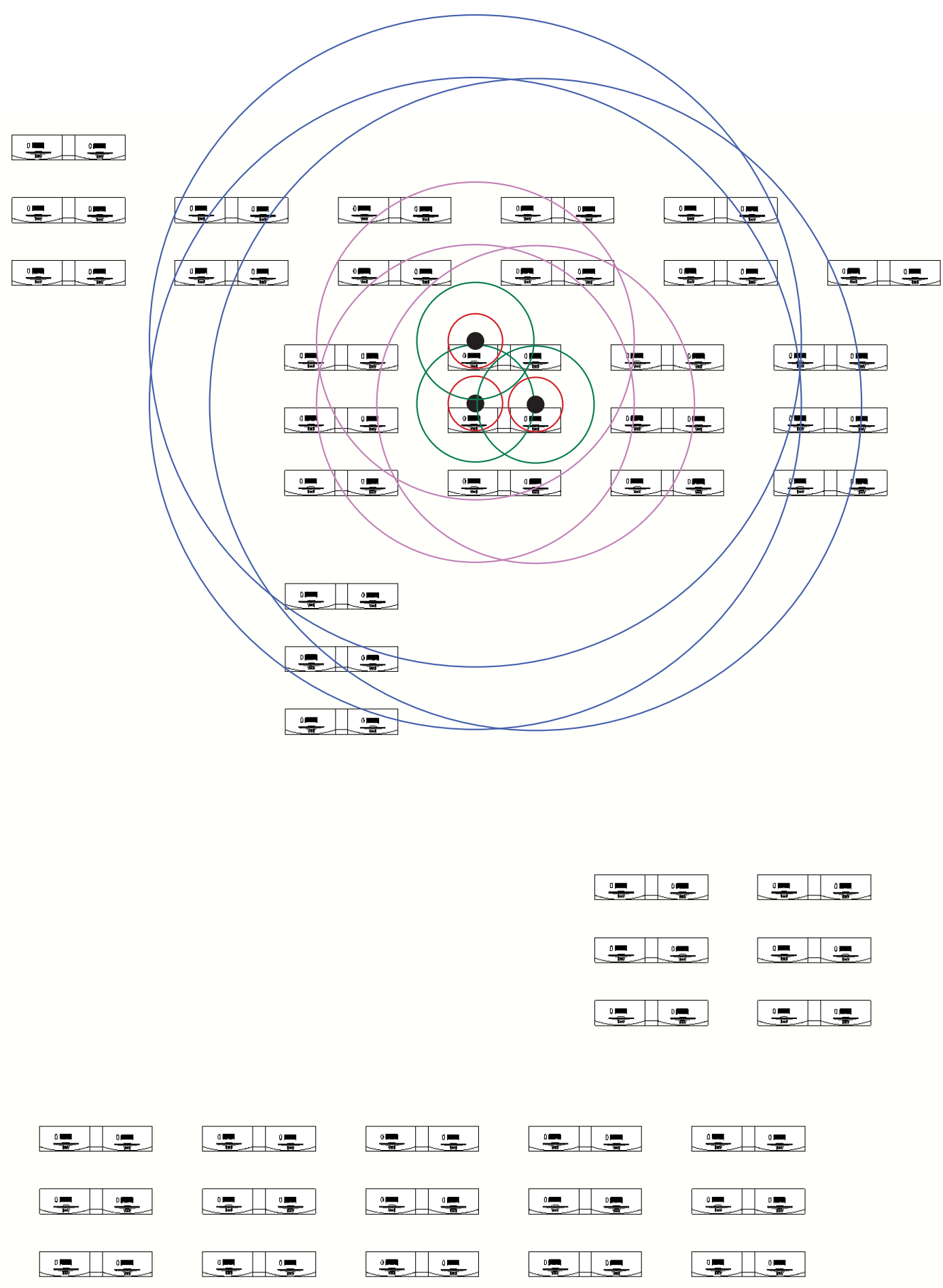

Figure. 2.11

A plan view showing the exploration of the economy layout of desks within a floor plate. The plan shows how close together the desks are to one another. This is further enhanced by the proxemic bubble diagrams showing that none of the intimate spaces overlap however the personal space all still overlap. 


\title{
Business desk
}

\author{
Desk size \\ Width $\mathbf{9 o o m m}$ \\ Length 1500mm \\ Opposite 1250mm \\ Between 950mm \\ Floor area 527.2m2 \\ Occupancy $\mathbf{6 1}$ \\ Area per person $\mathbf{8 . 6 m 2}$
}

Minimum distances from another

Desk proxemic

Flight proxemic
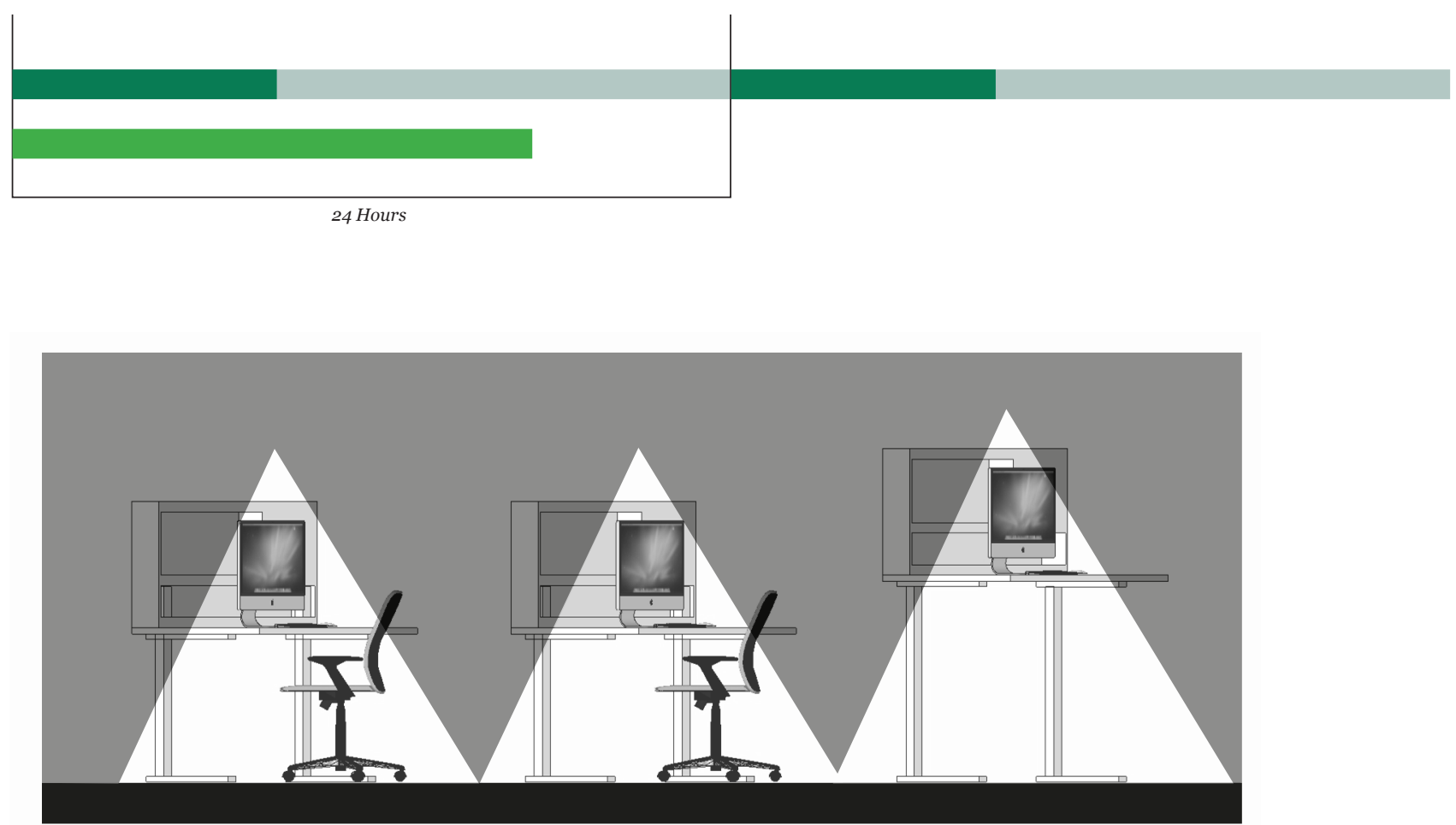

Figure. 2.12

An elevation of the economy desk, showing the use of the visual, physical and environmental tests. As can been seen the desks are now placed on the angle to allow for no peripheral visual distraction. Also the ability of a standing desk. The desks also have high backs for privacy paired with directional lighting. 


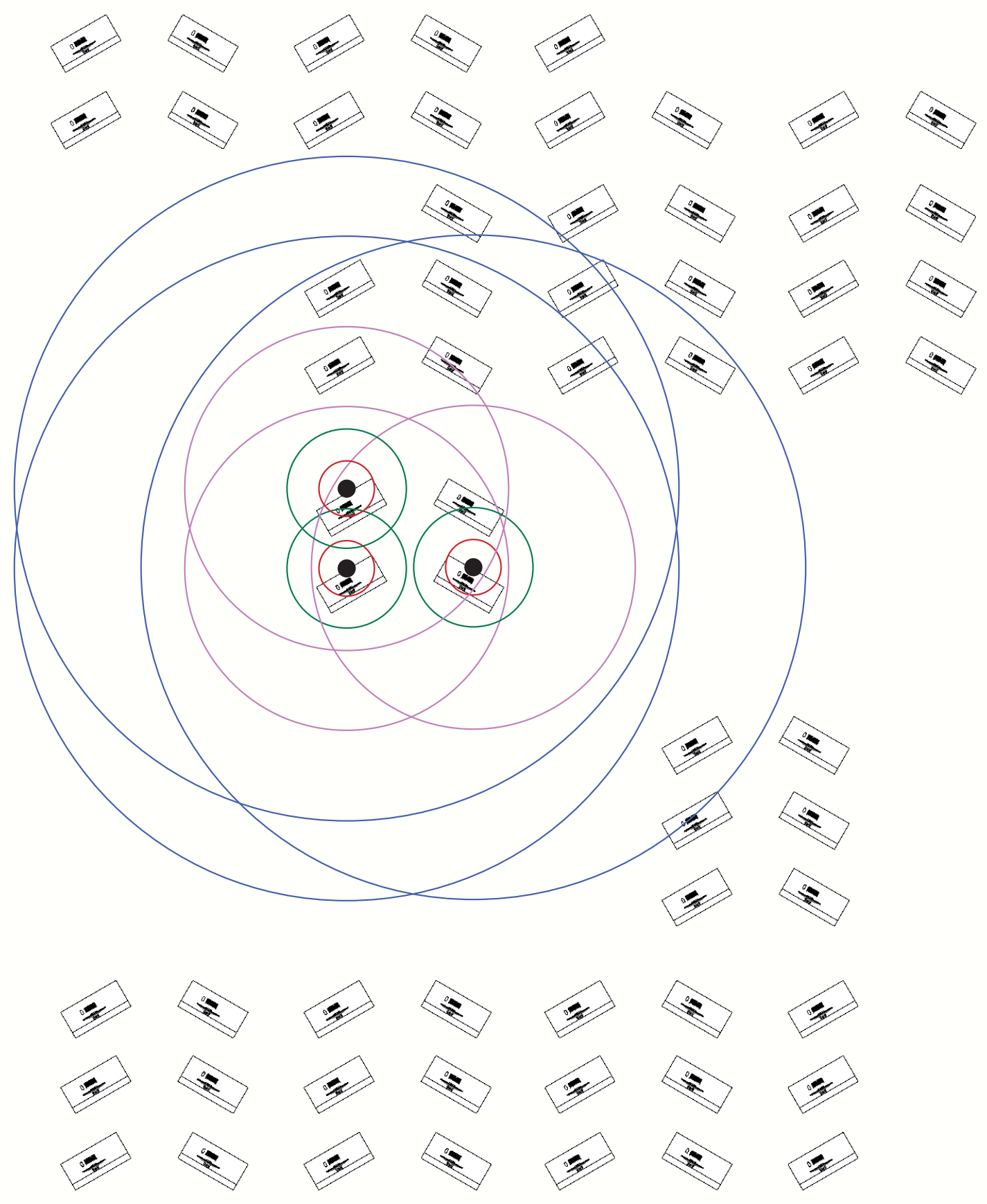

Figure. 2.13

A plan view showing the exploration of the economy layout of desks within a floor plate. The plan shows how close together the desks are to one another. This is further enhanced by the proxemic bubble diagrams showing that none of the intimate spaces or personal spaces overlap also the angles of the desk allows for more visual privacy. 


\section{Proxemic Analysis}

The proxemic test where an analogy was drawn between the classes of airplane travel and different kind of open plan office configurations was successful in identifying the situations which were most appropriate for people to be able to work comfortably with little to no distractions. It was unsurprising that the Business model performed most successfully, however the Premium economy option also performed very well as to allow no crossover of Intimate and personal spaces.

It can be seen in figure 2.9 the intimate spaces and personal spaces of all six people from a block of desks overlap. This will result negatively for the workers making them feel constricted within a space. Another issue with the economy example of desks is the lack of privacy, although there are privacy screens between each workstation the lack of space between people will be an issue for not only visual privacy and concentration but also for auditory privacy and concentration.
The Premium economy desks performed surprisingly well under the constraints. Higher partitions and only two people occupying a workstation contributed significantly to this. With slightly more desk space and a physical barrier that acted as document storage in between there was less distraction happening in the peripheral vision. A physical barrier between the desks was implemented to allow each workstation a more personal constraint see figure 2.10. Although the personal space still overlaps with the person next to you the desks have been arranged in a way there are high back which give you storage and a place for you computer to sit in while not being able to see the person in front this is shown in figure 2.11. The premium economy desk performed significantly better than expected.

As to be expected the Business class desk performed the best from the diagrams see figure 2.12. This is inherently due to the fact each of the desks are lone standing and are angled slightly as to not see anyone in you peripheral vision. None of the intimate spaces overlap and the personal space only technically overlaps with the person behind you however due to the design of the high back desks you can not see the person in front or behind see figure 2.13 .

A design that encompasses the ideas of the business desk in the constraints of the premium economy desk could prove to be very successful in an office space specifically to minimize distraction and maximise the feeling of privacy. 


\section{Critical Reflection}

Early tests of personalising the office environment were addressed to a generic, somewhat reductive model of the modern office. Specifically from the proxemic test, although this brought forth useful ideas. The main points to be taken forward will be the layout of the desk and also the proportions of partitions in a space to allow a physical separation between people, this will help to morph the proxemic perceptual zones depending on the size and shape and layout of furniture throughout a space. The next step is to define the qualities of the office to be addressed through a research through design method.
I would like to define the scope more towards creating a working environment in which one can work individually on an individual project or collectively on a collective project to encourage a more collaborative team effort and environment. This is going to be completed through a range of techniques. Such as I will no longer be applying for ethics. The workspace needs to begin encourage a more collaborative way of working that takes into perspectives the projects in which people work on. This will begin to include an exploration of the needs of spaces people need for work and will use a scale of formal to informal and individual to group. This will bring forward the idea of flexibility within the workplace. The idea of cross-programing will be explored in a way that creates flexible space that will not only work for the office environment but can invite other programs into the space.

The research will begin to explore the larger spatial relationships that happen in an office rather than just the relationship between the users their desk and the wider proxemics of people. This will be done through an exploration of the interactions people have in an office from formal work related to informal conversational. A research through design approach will be taken to explore a series of physical models to understand how these areas of flexibility can manifest. 


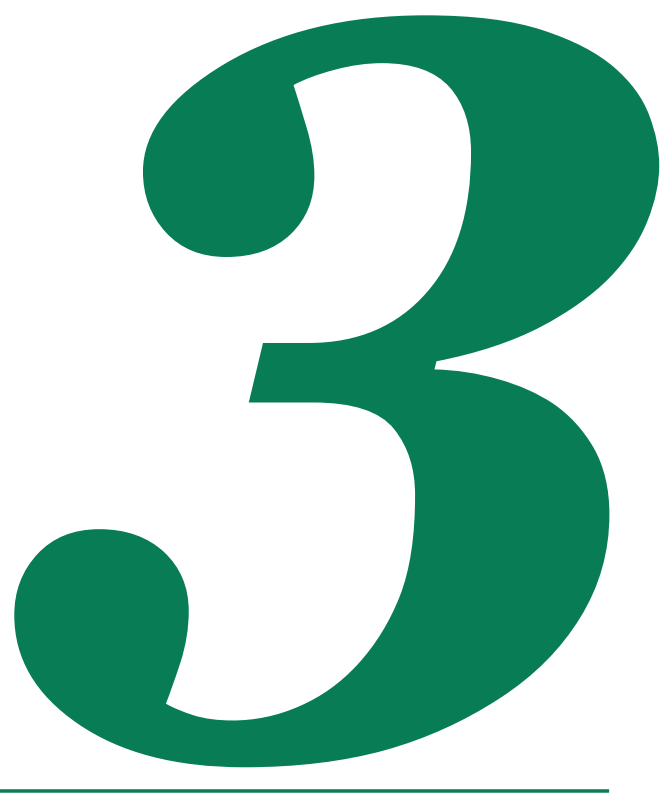




\section{Model Study}

An exploration of 3 different tests at a visual, physical and environmental scale

\section{Conceptual Modelling}

An exploration of a scale-able model exploring flexibility on a 9X9 grid. 


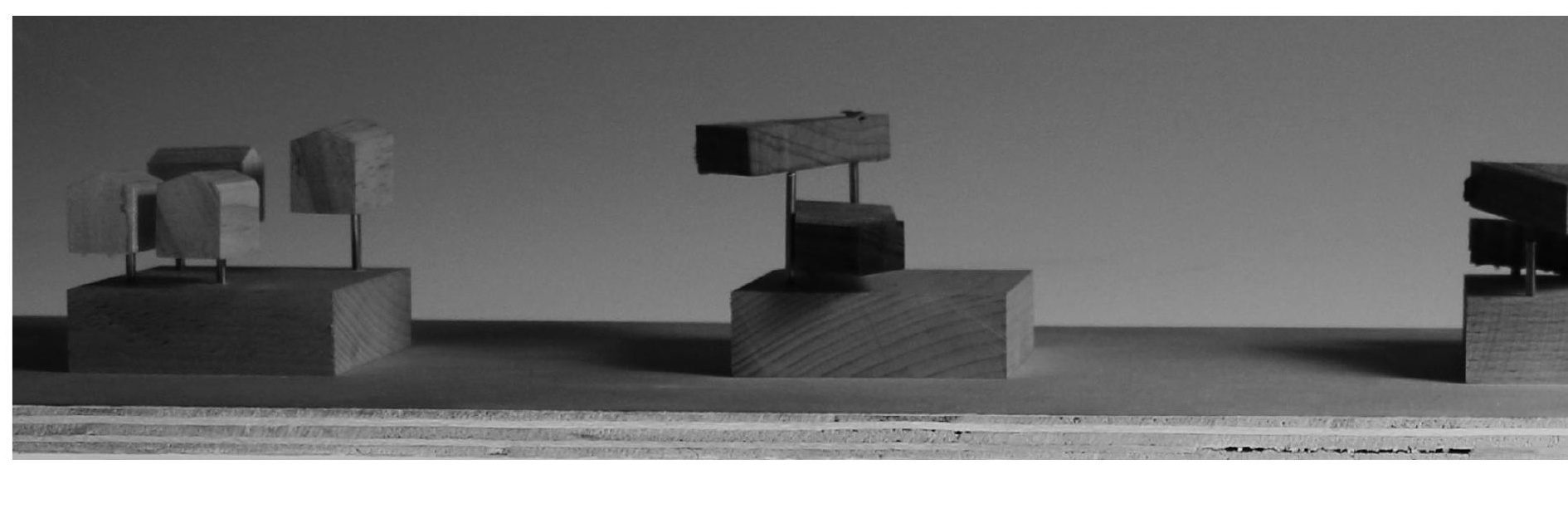




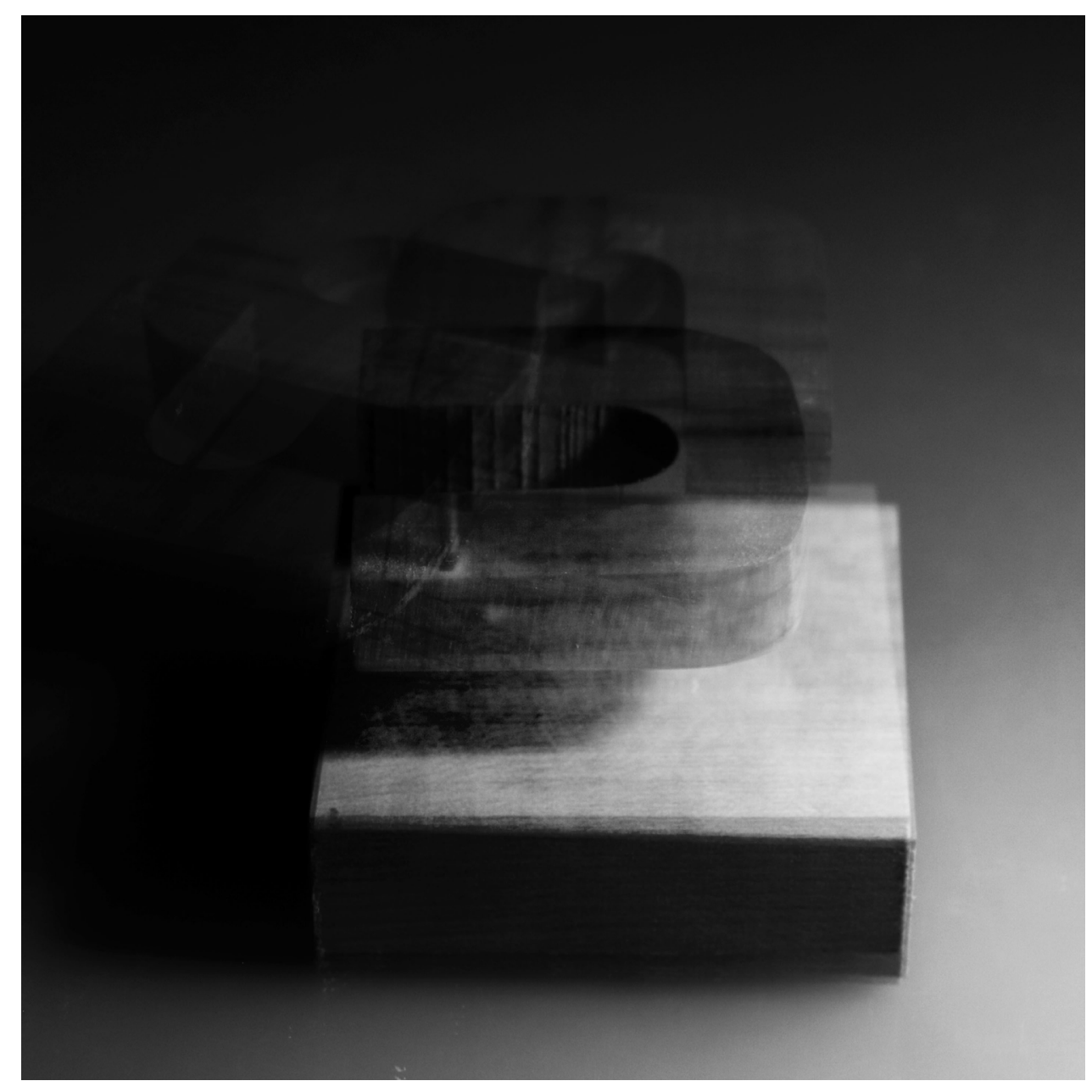

Figure. 3.2

A desk? A bench? A room? This transformative model explores the movement of curves and the space that can made within and without 


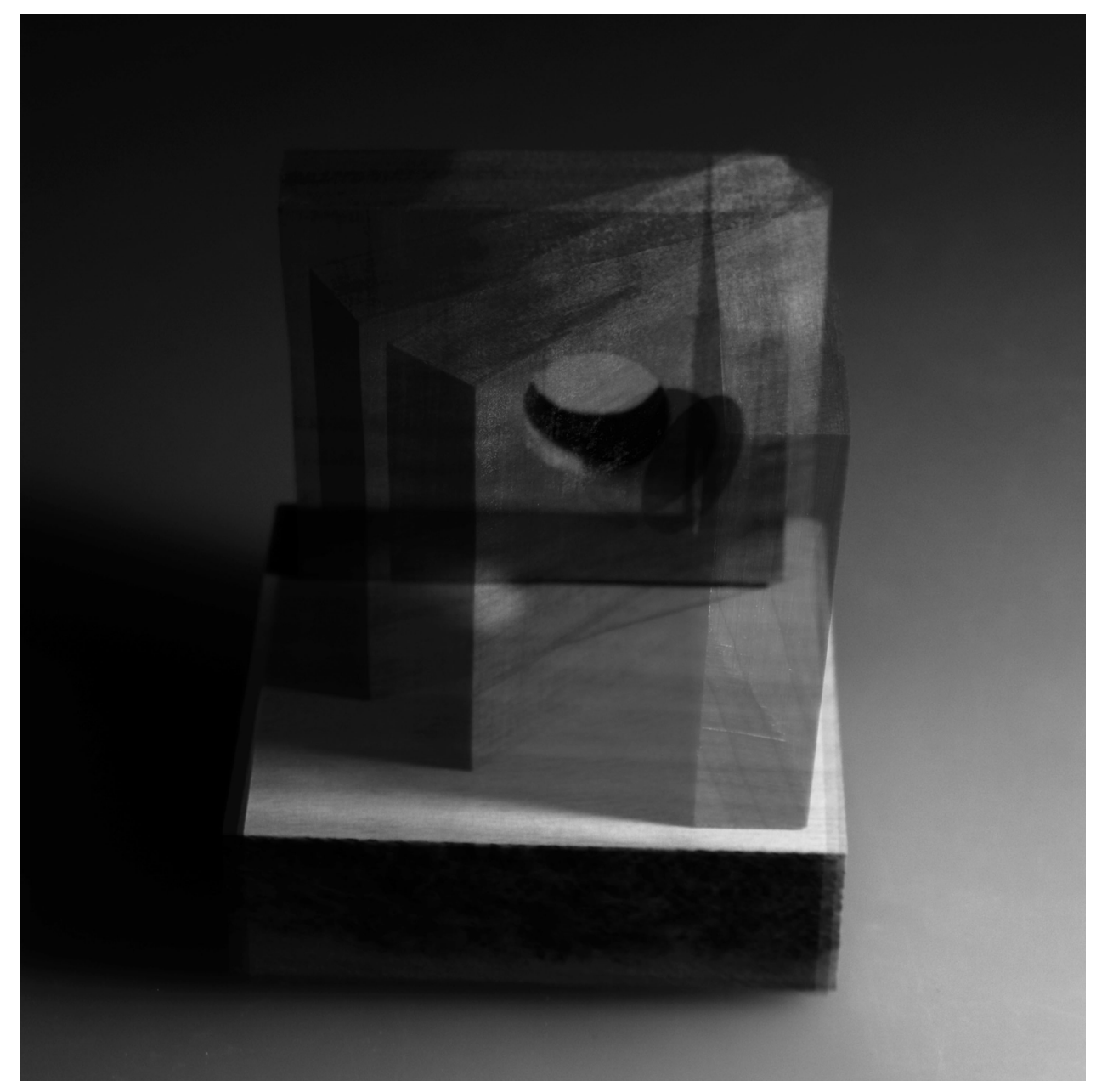

Figure. 3.3

A cupboard? A wall? An installation?

This model seamlessly glides and pivots around a single point to multiply or divide space. 


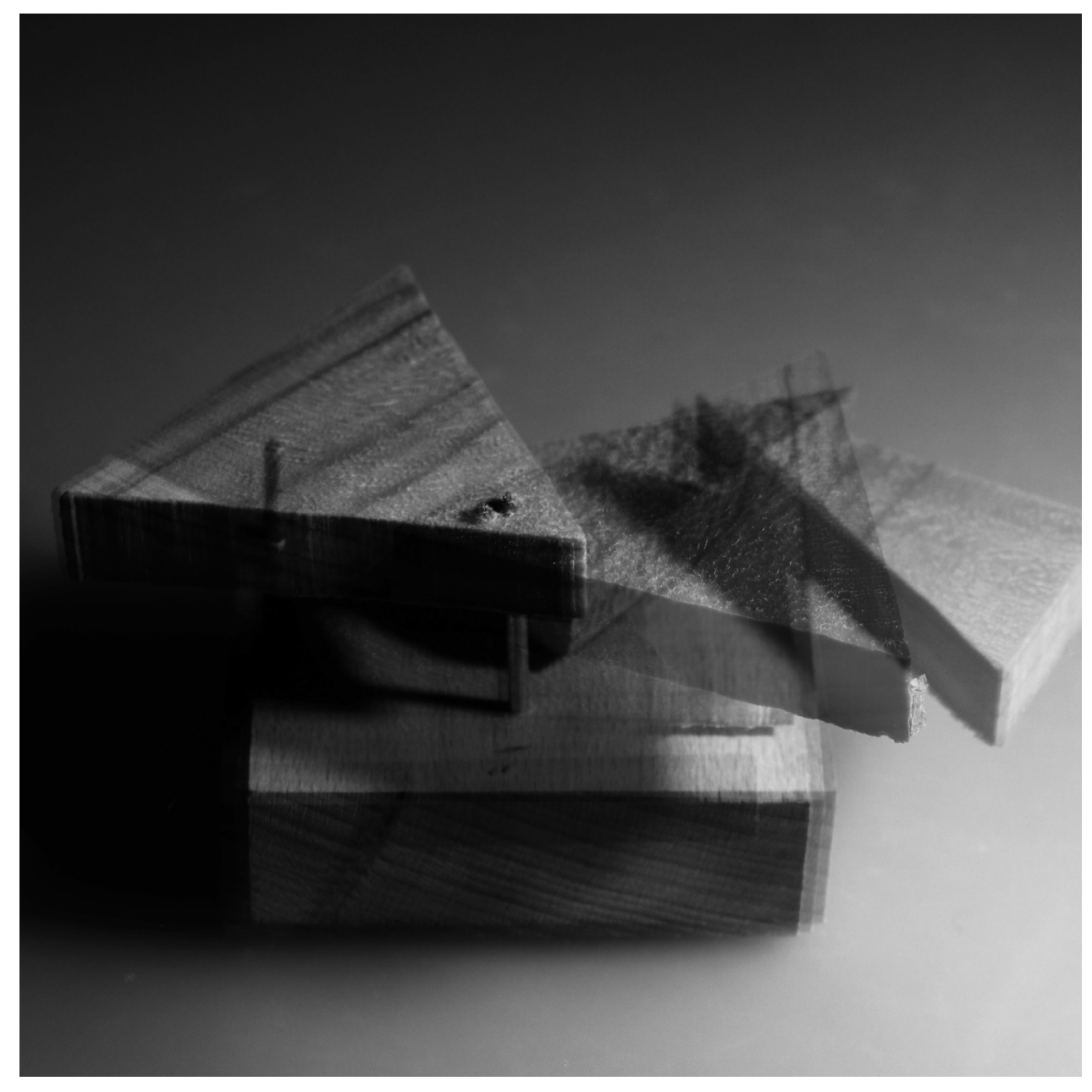

Figure. 3.4

A bench \& table? A desk? 2 separate spaces?

This model has to pivoting triangular forms that glide over one another creating split level space. 


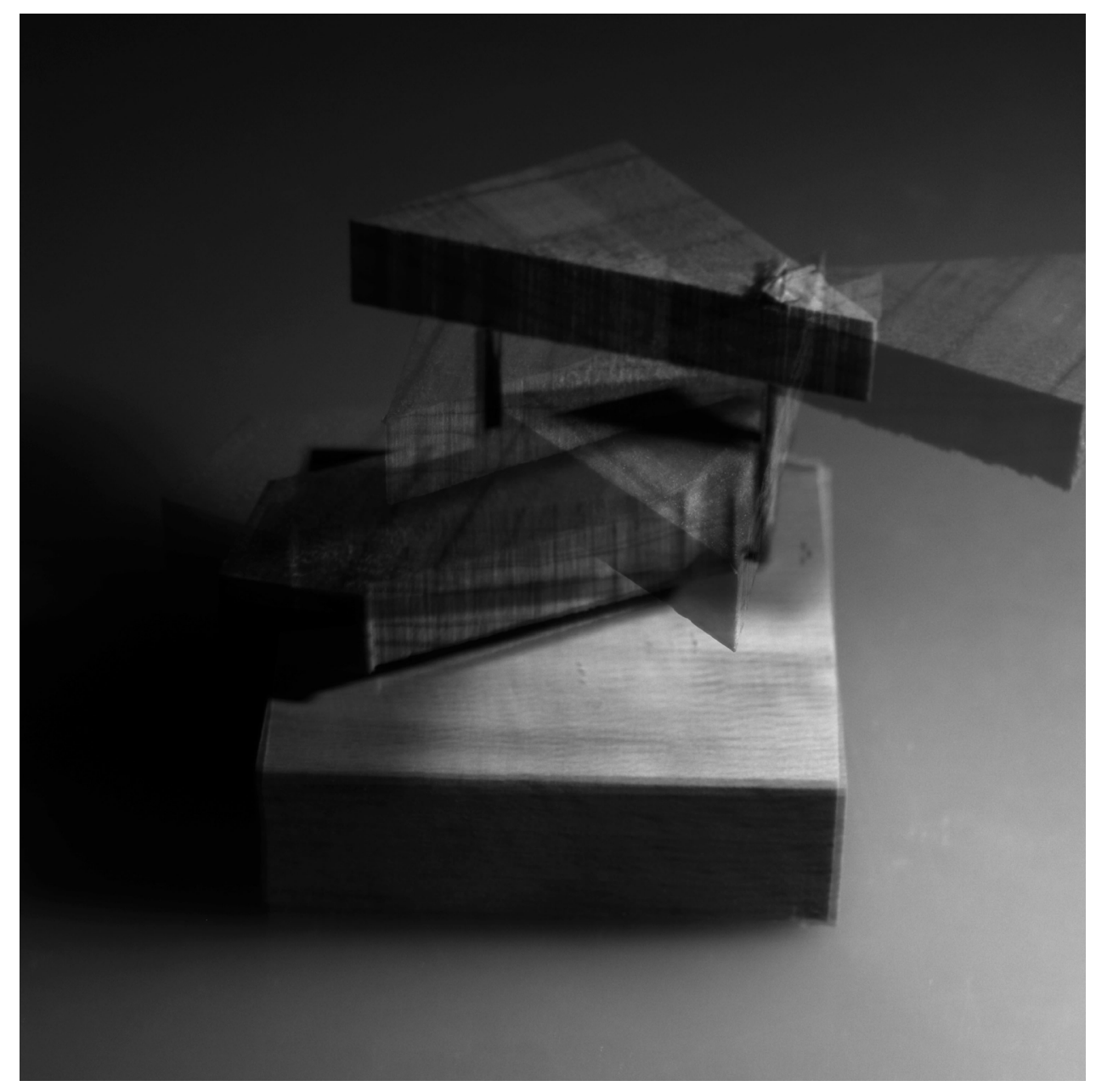

Figure. 3.5

A mezzanine? A Cabinet? A desk?

This model has two pivoting forms; that create levels that can move around each one. 


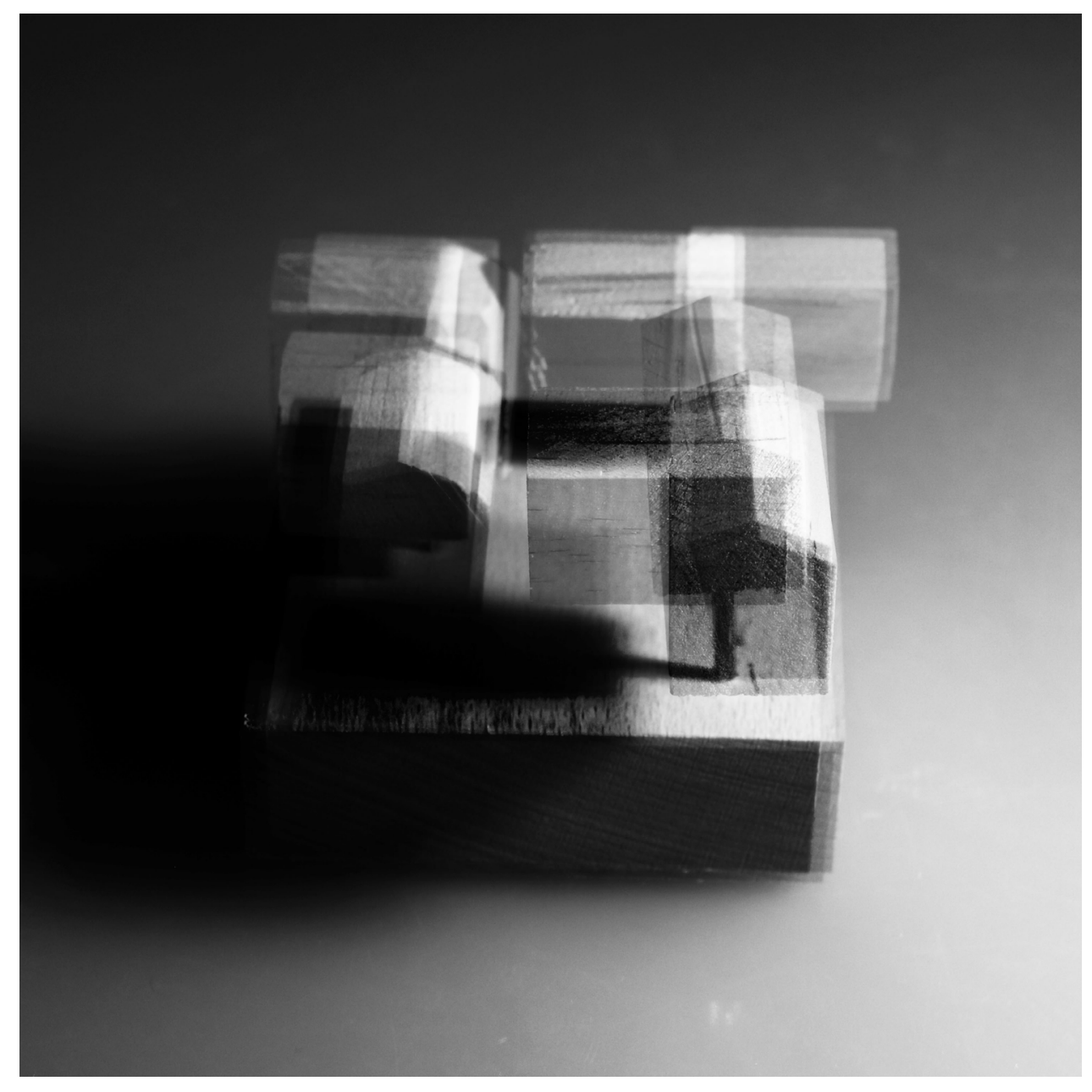

Figure. 3.6

A series of rooms? A series of desk? A seat? A series of pivoting rooms that can connect through different angles. Opening and closing spaces. 


\section{Conceptual model 1}

These models began to explore a series of pivoting walls to begin to layer spaces. The ability to add or subtract the space along with the square base began to explore a level of scalability to the models creating a more complex system. The use of layering the partitions. over one another added a translucency that brought forth the idea of using fabric to create curtain partitions, The use of fabric in the modeling was made to look solid to contrast this and explore the rich texture the material provides.
To add another layer of complexity and richness to the model explorations, the next stage was again beginning to explore the idea of scalability. To understand the true depth of each of the model iterations. This was done with the use of scaled figures each figure represents a different scale and therefore a different language is expressed.

The model was also explored from a plan perspective through the use of curves and single pivot walls, the model began to create spaces that can expand and shrink depending on what is required. 


\section{Figure. $3 \cdot 7$}

Model one explores the layering of spaces over one another creating a complex space that can multiply or subtract. This ability to have flexibility in a space is unique due to the 2 pivot points where walls move through the space. 
This content is unavailable

Please refer to master version

Figure. 3.8

Model one explored through the use of scaled people. This begins to create a more complex understanding of the space. The area could be multiple floors or a bench seat to have meetings on. 


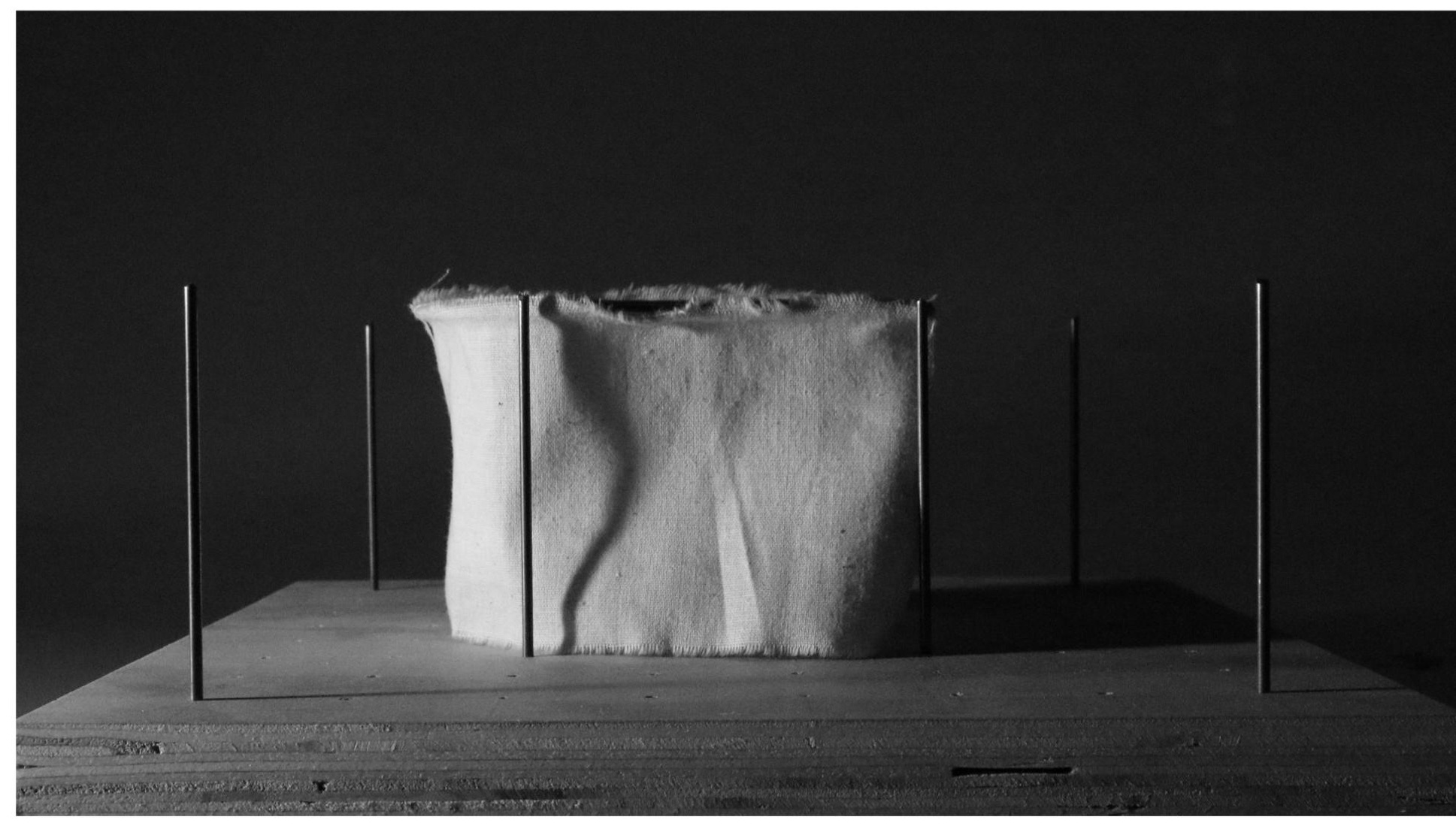

Figure. 3.9

In model two the use of fabric and curves are contrasted by the pillar structures and the square base. This contrast between soft and rigid brings forth the idea of flexibility molding into a space. 


\section{This content is unavailable}

Please refer to master version

Figure. 3.10

With the use of scaled figure in model two the idea of flexibility is explored further. The space feels differently with each figure you observe. Mid height partition walls divide a space, a staircase connects to above. 


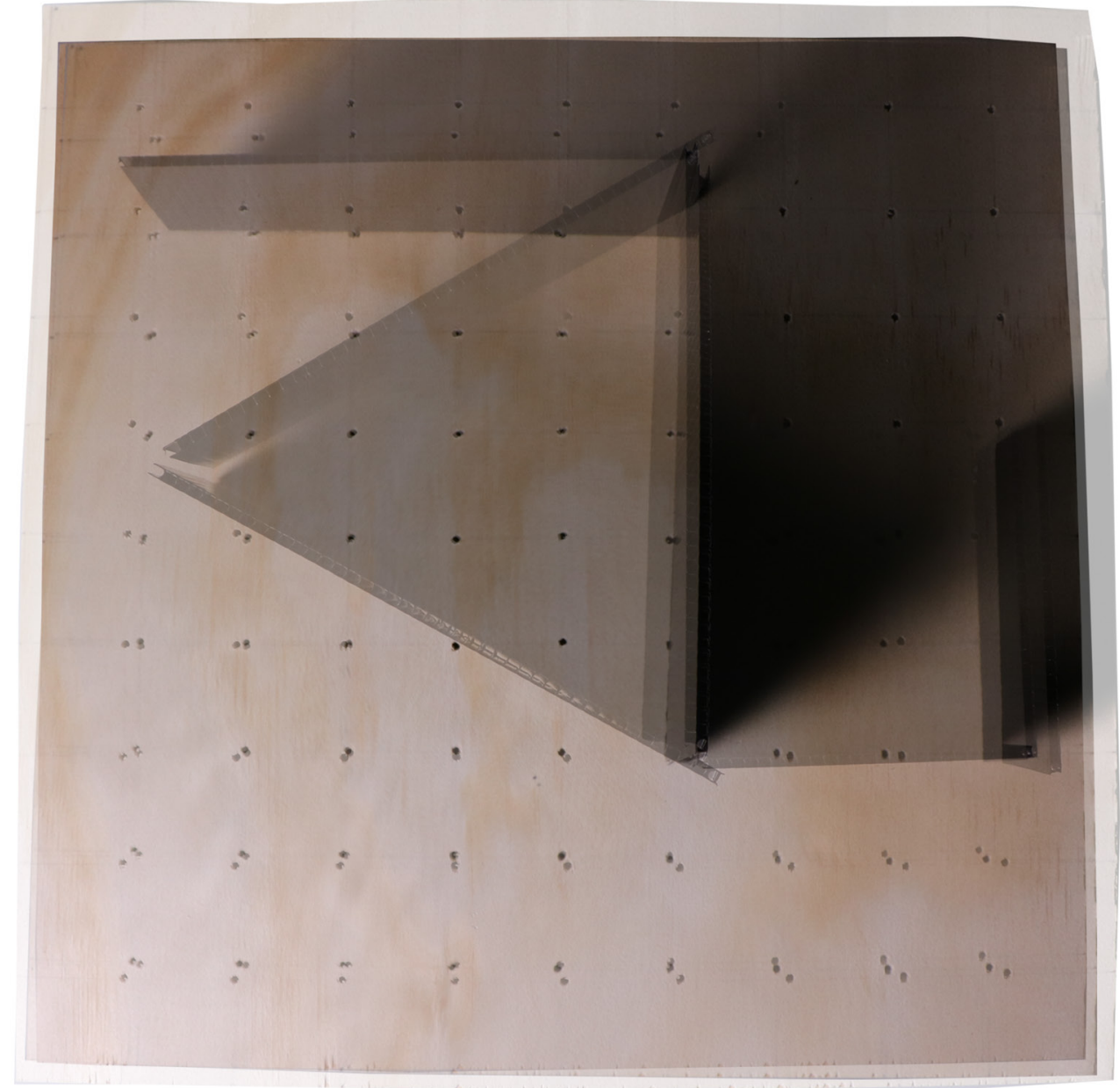

Figure. 3.11

A plan view of model one exploring how the spaces expand or contract, multiply or divide. 


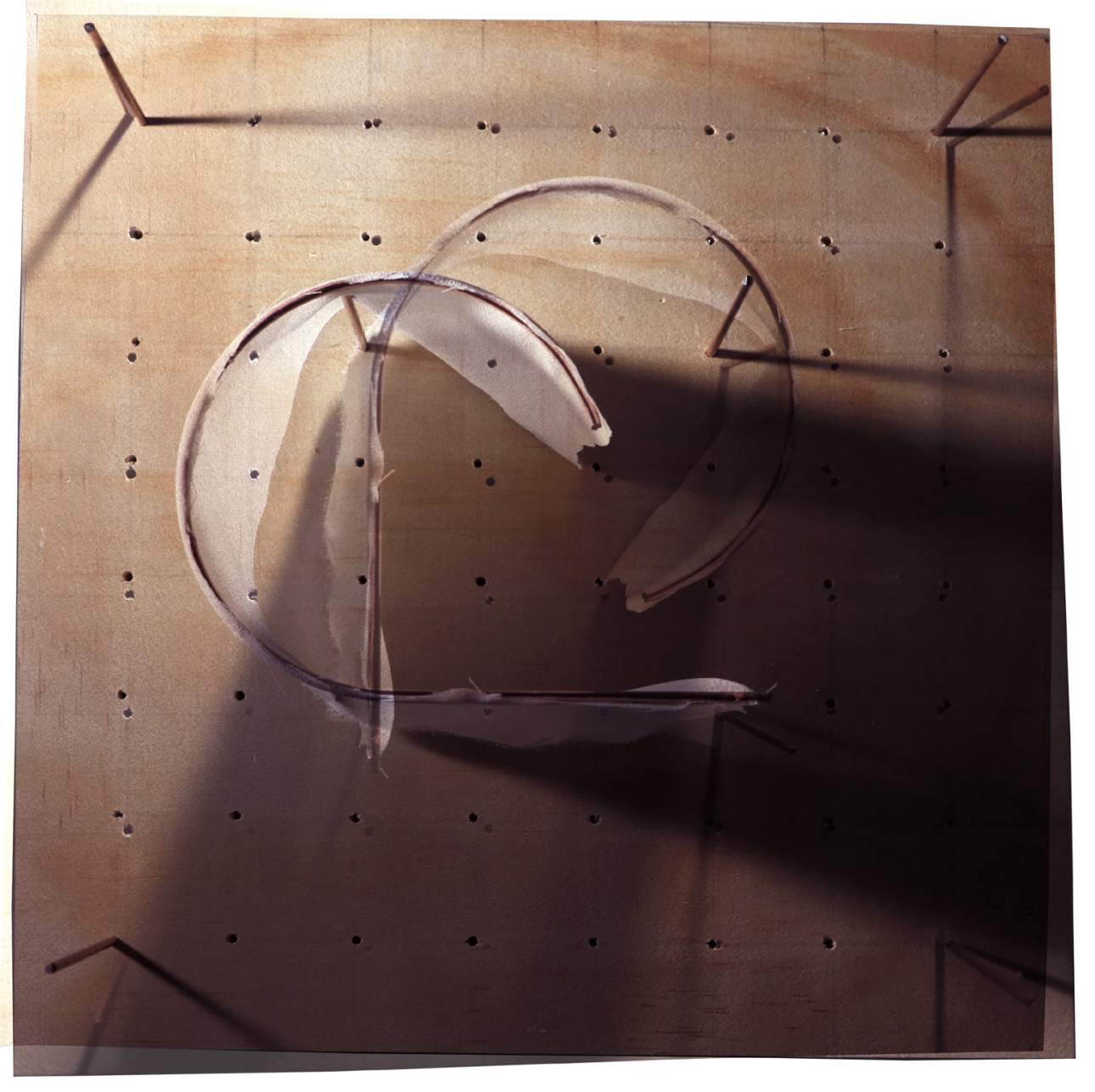

Figure. 3.12

A plan view of model two exploring the use of curves and fabric in a flexible fluid way. 


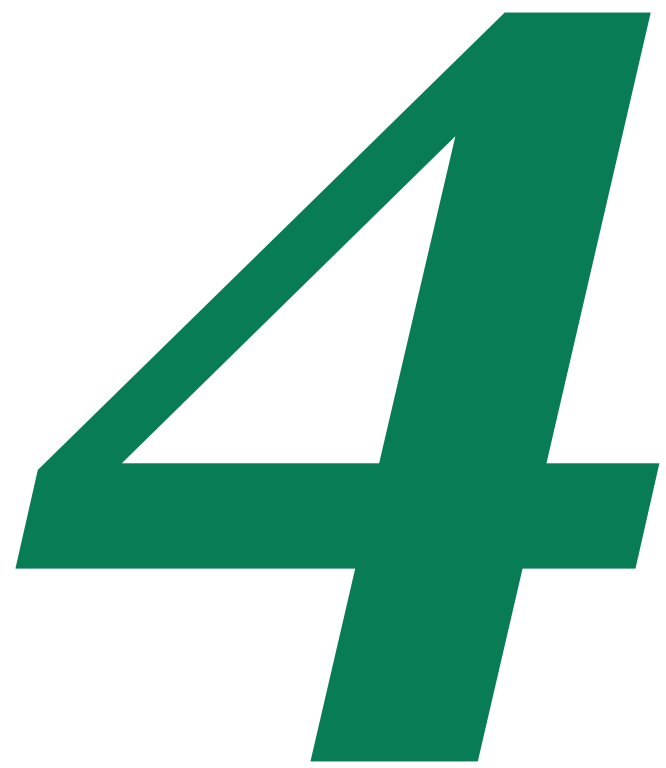




\section{The Site}

An introduction to the chosen site.

\section{Conceptual Model 2}

A second conceptual model test exploring the layering of models over the original site drawings.

\section{Conceptual Model 3}

A third conceptual model test exploring the layering of models over the original site drawings.

\section{Critical Reflection}




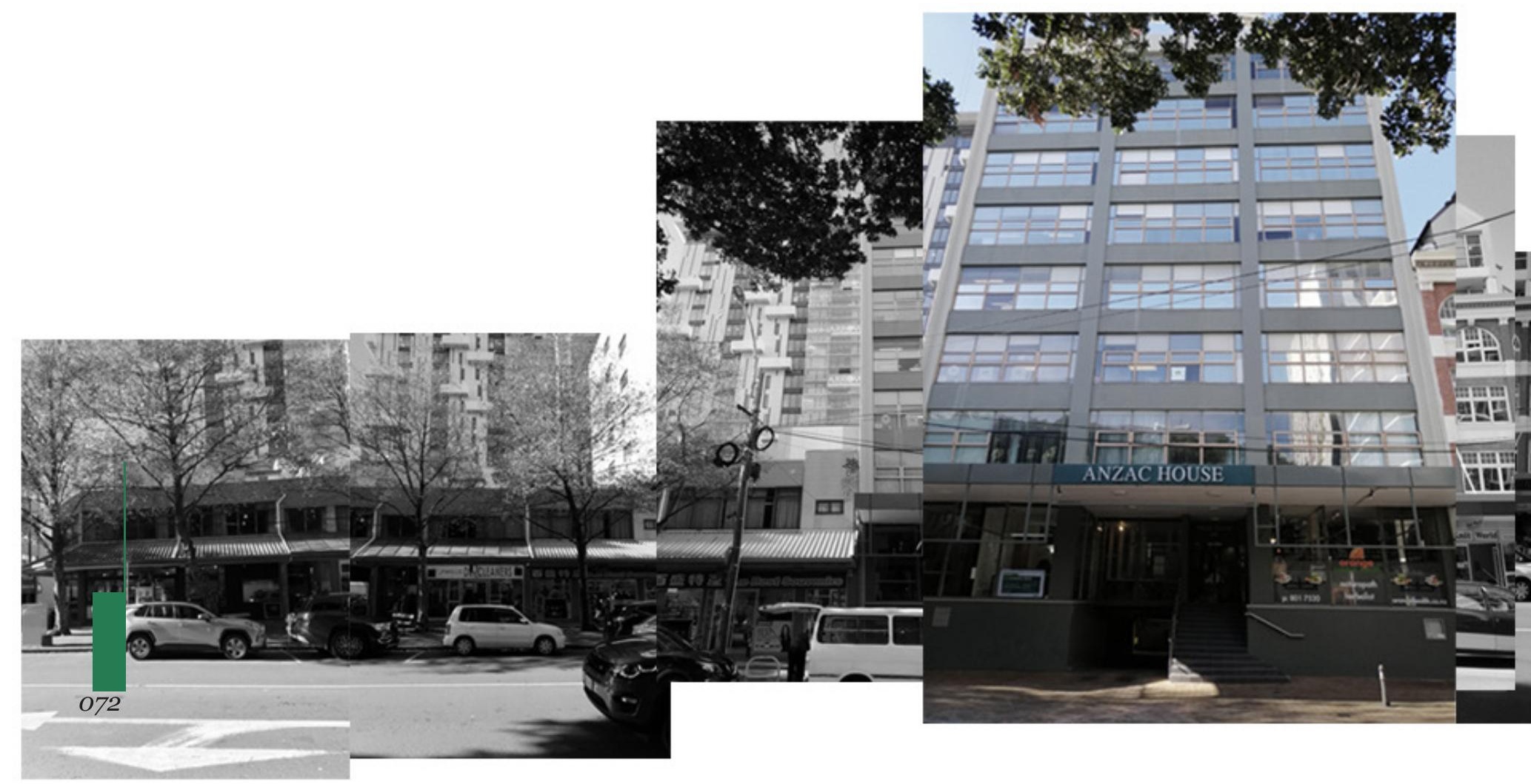




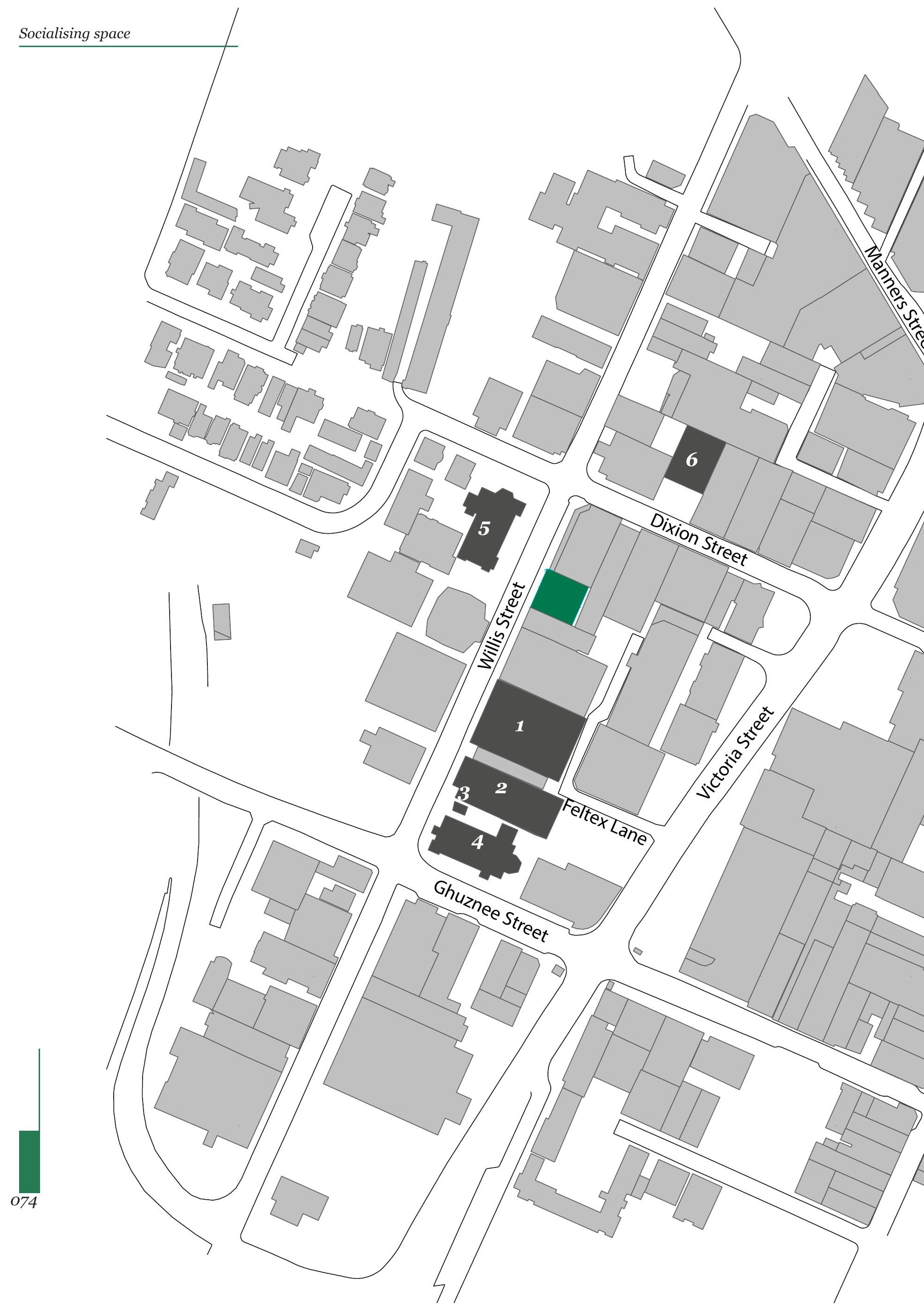




\section{Site Map}

Site - 181 Willis St. Anzac House.

1 Work \& Income NZ.

$2 \quad$ Salvation Army Opportunity Shop.

3 The Free Store.

4 St Peters Anglican Church.

$5 \quad$ St Johns Presbyterian Church.

6 New Zealand CCS Disability Action. located on. Marked in green, Anzac house and then highlighted are the important social spaces within the block. 


\section{Conceptual model 2}

In the second conceptual model test, the initial conceptual model test from chapter three are collaged over the floor plans of 181 Willis Street. This tested the ideas of flexibility and partitioning at the scale of the open plan office.
These model tests explore what happens when the first conceptual model test is merged with a typical floor plan of the chosen site, this allows the placement of windows on all four faces of the building along with the placement of the central core for the elevators, staircase, and bathrooms. The nine square grid of the site and also the model allowed them to seamlessly fit together with a rich complexity of concept and space. The use of shadows in the models creates spaces that are read as open, semi-private or private. 


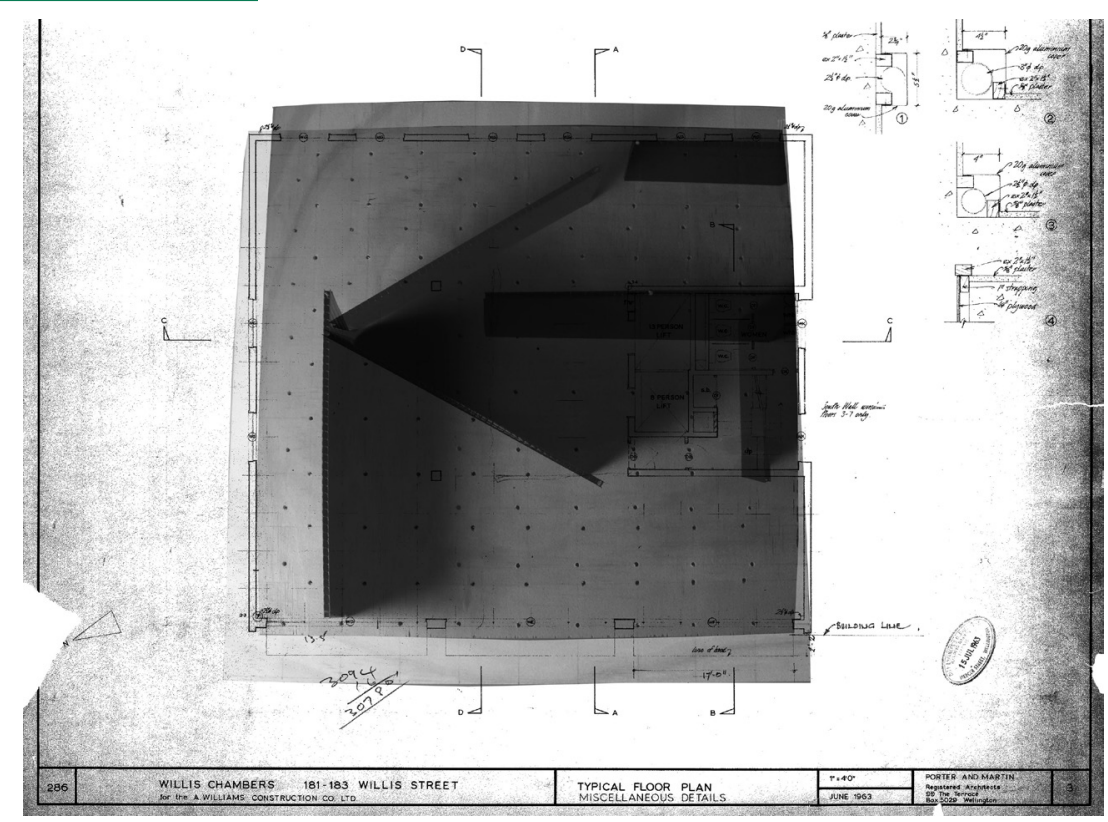

Figure. 4.3

Typical floor plan

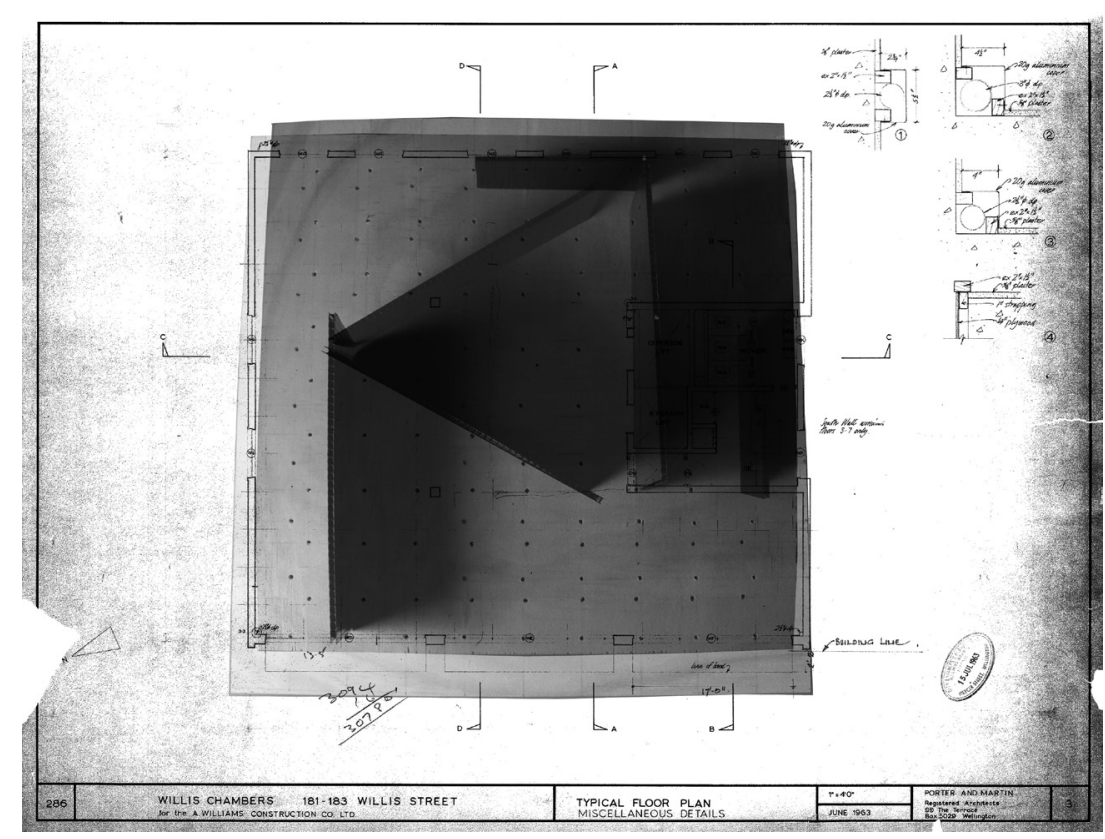

Figure. 4.4

Typical floor plan

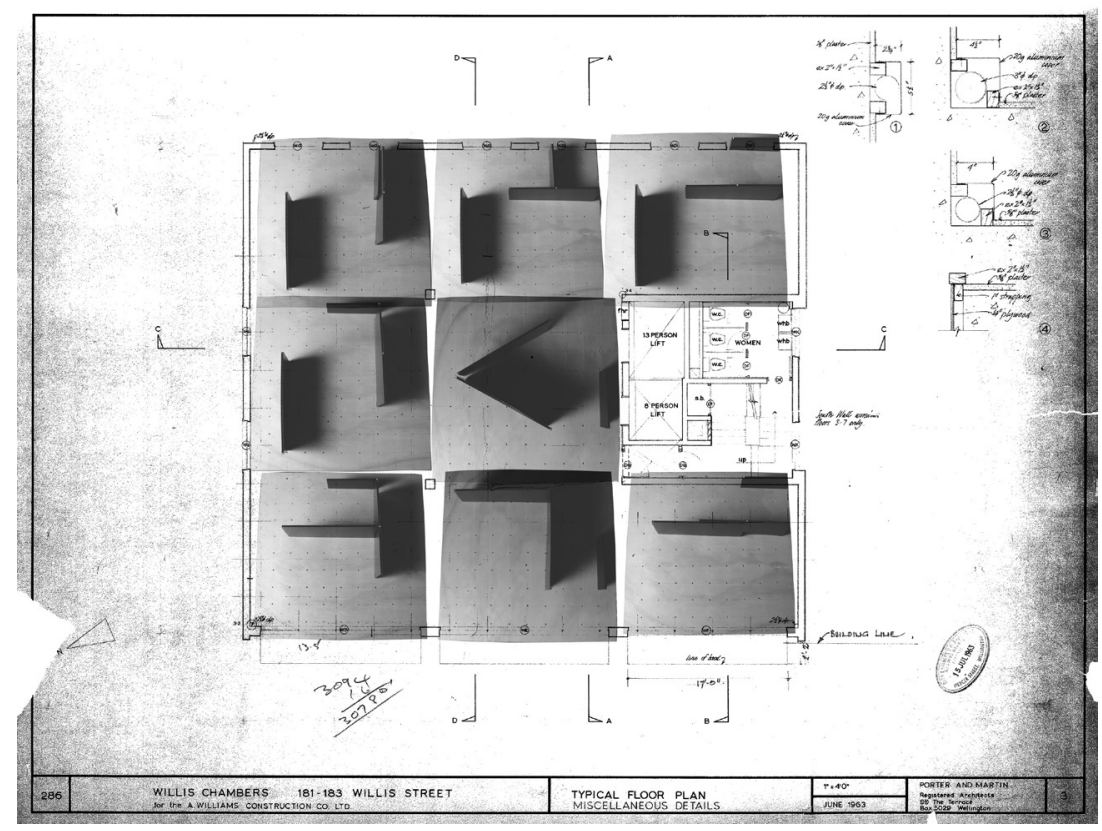

Figure. 4.5

Typical floor plan 


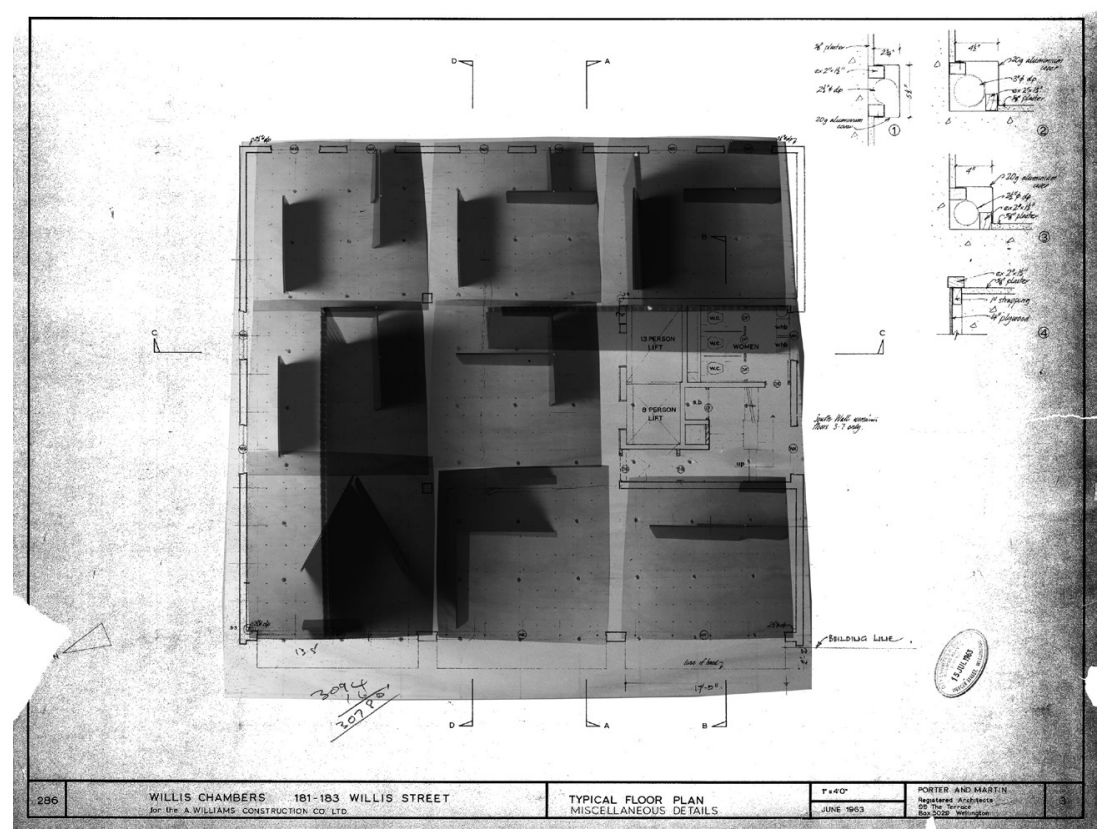

Figure. 4.6

Typical floor plan

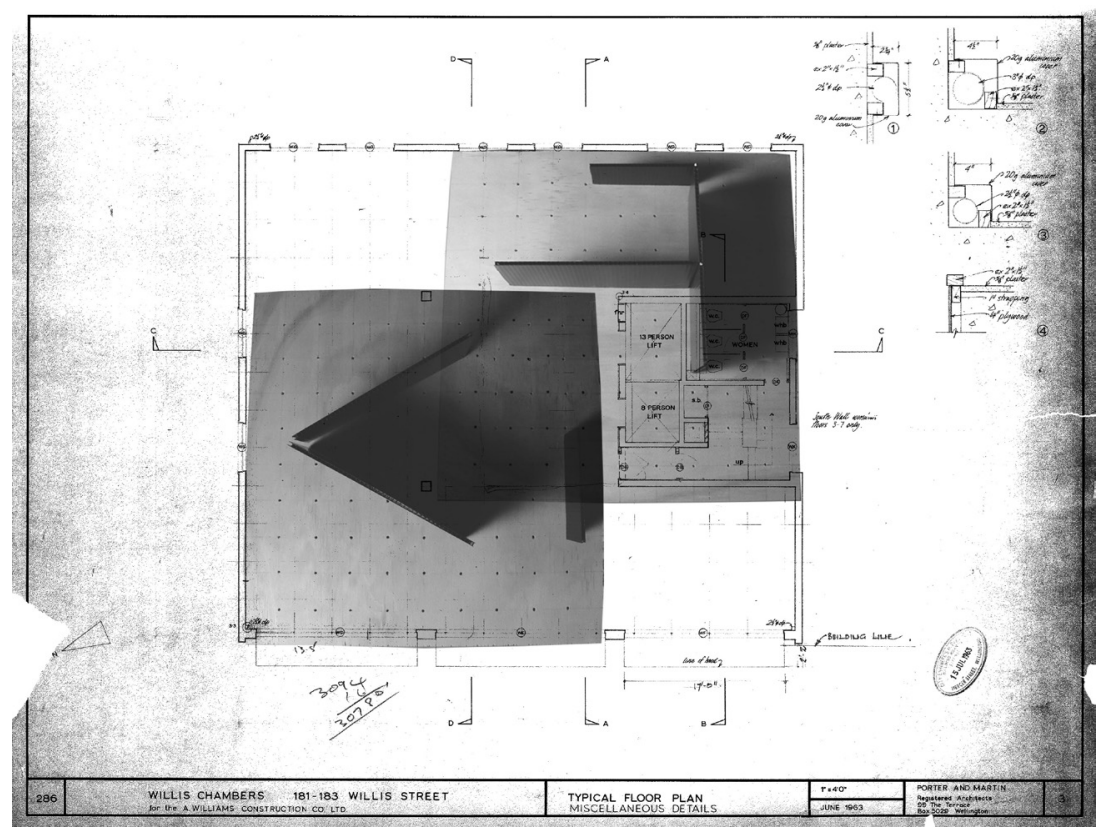

Figure. 4.7

Typical floor plan

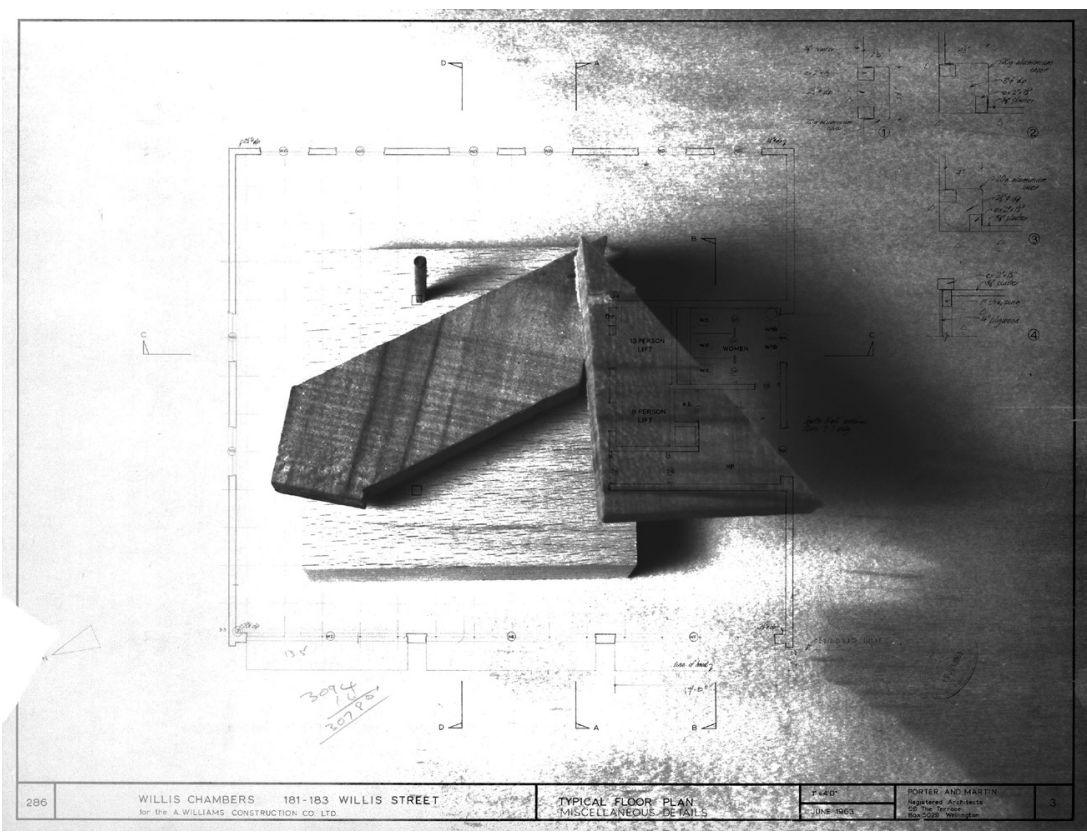

Figure. 4.8

Typical floor plan

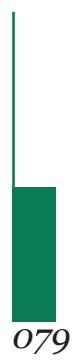



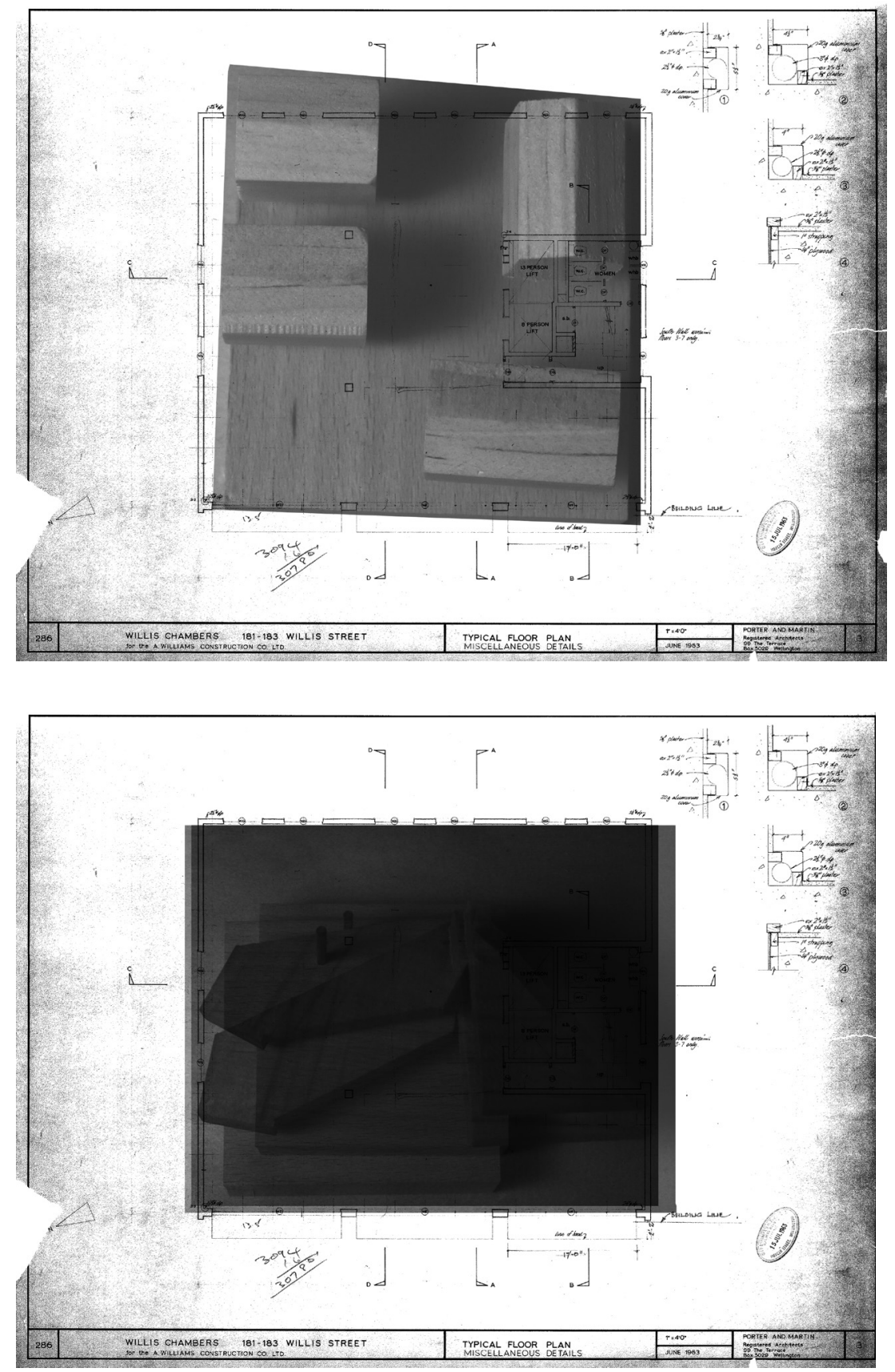

Figure. 4.10

Typical floor plan

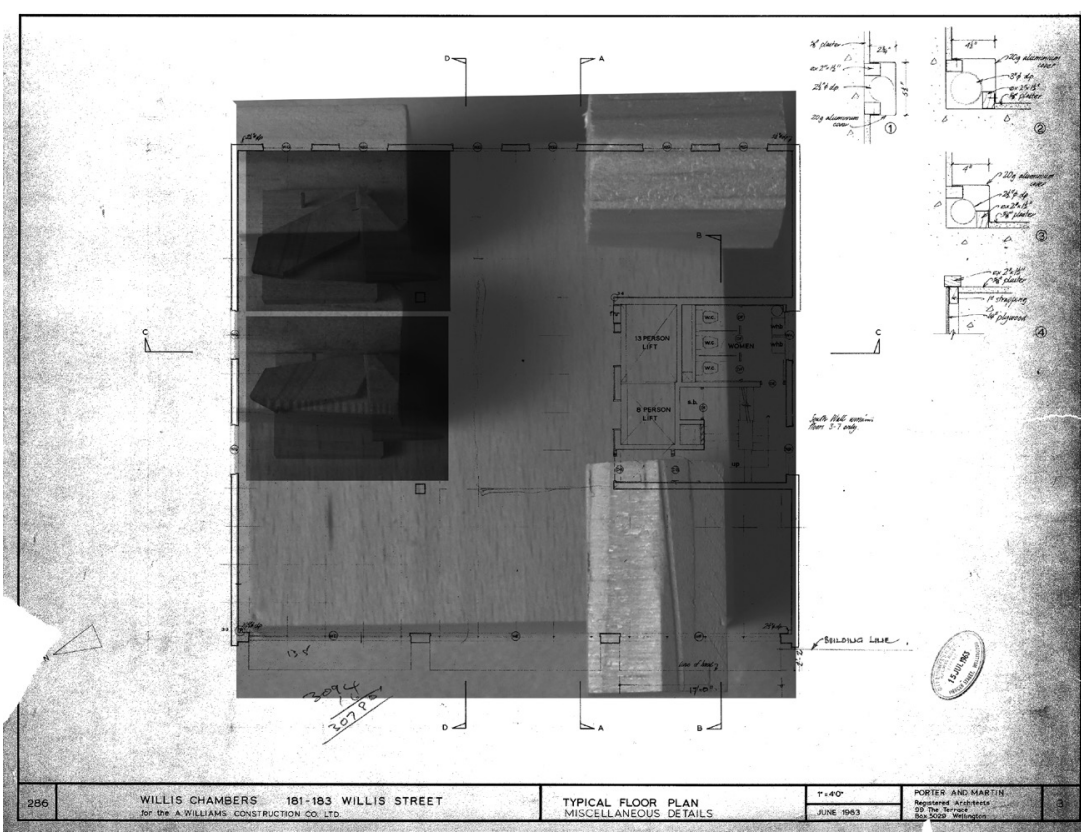




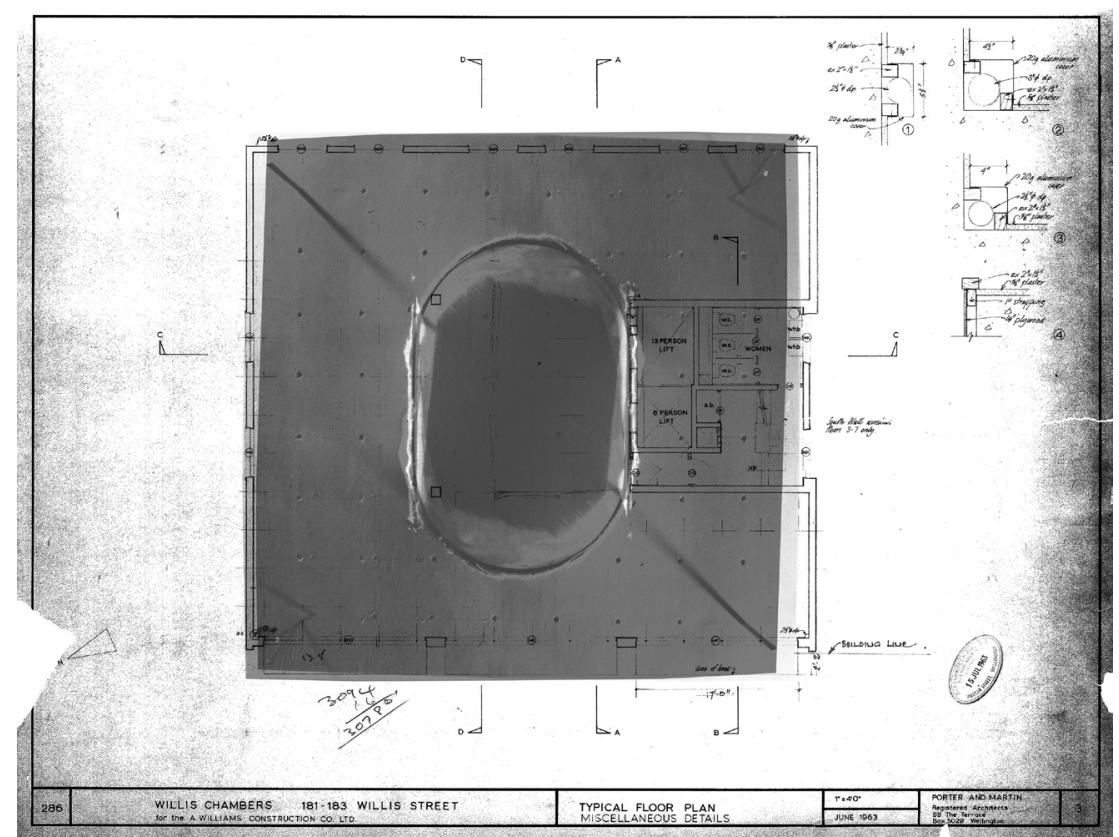

Figure. 4.12

Typical floor plan

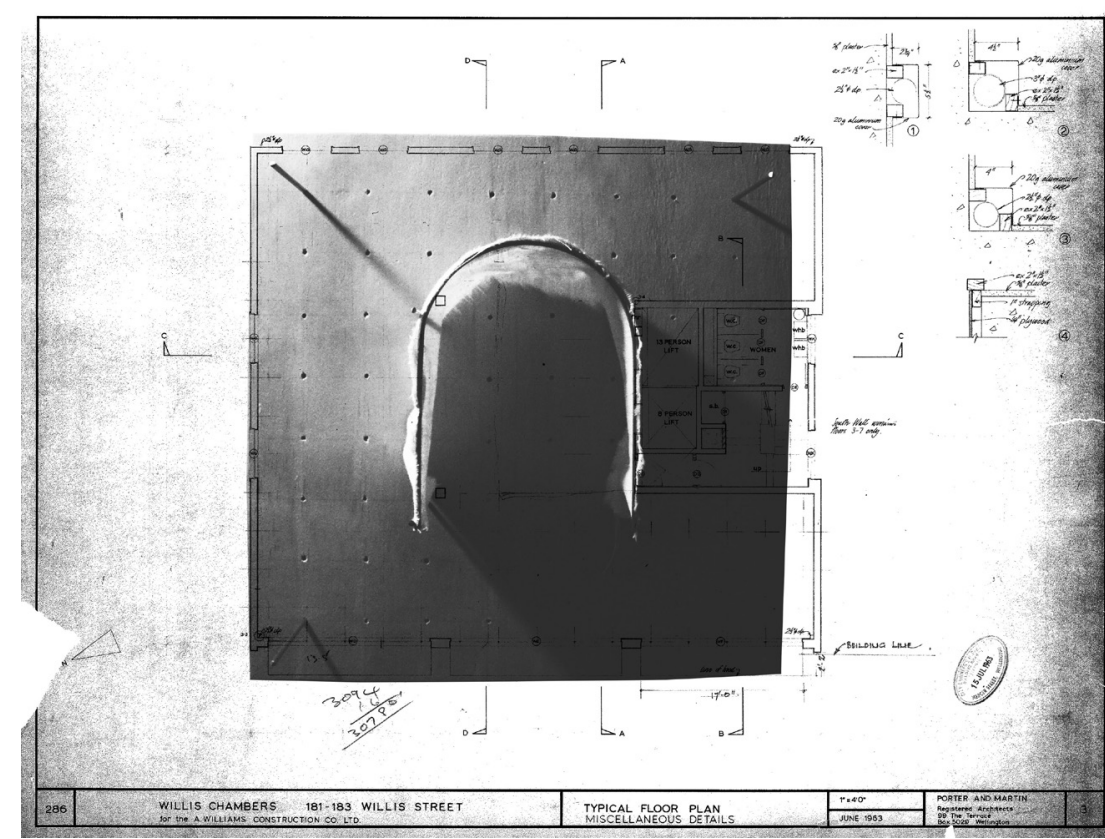

Figure. 4.13

Typical floor plan 11

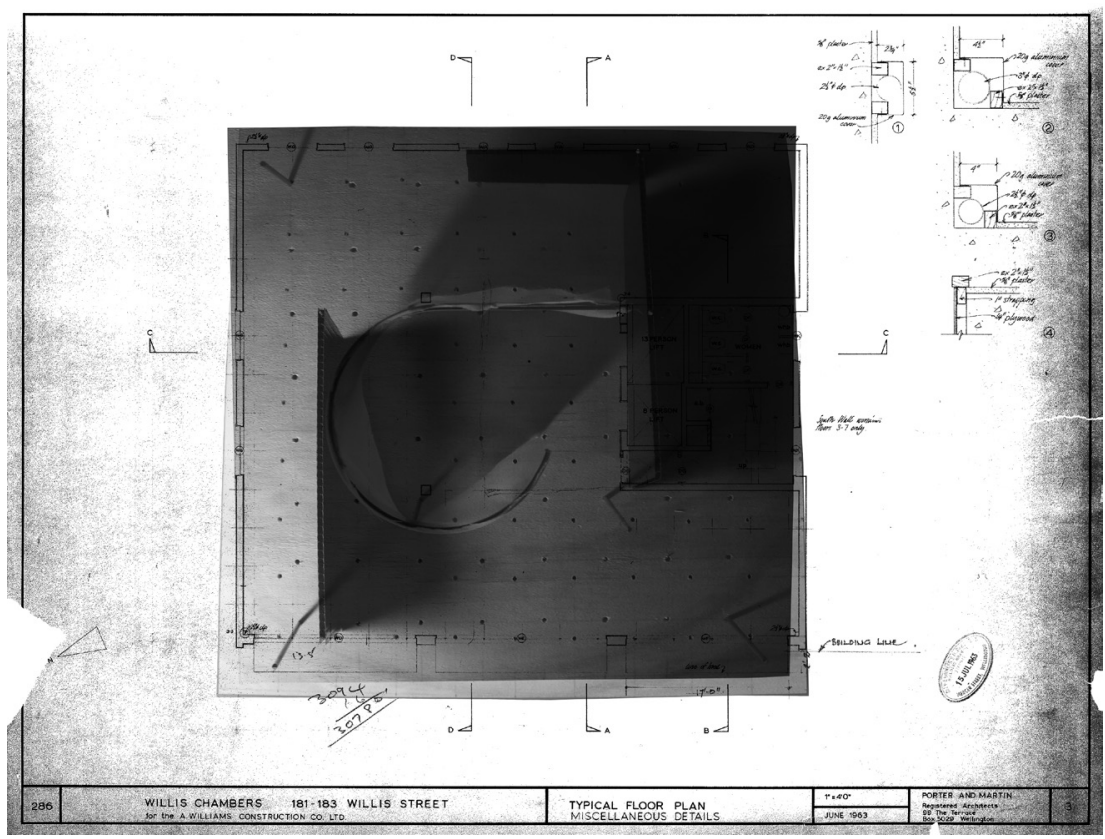

Figure. 4.14

Typical floor plan

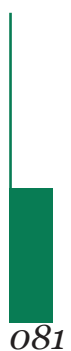




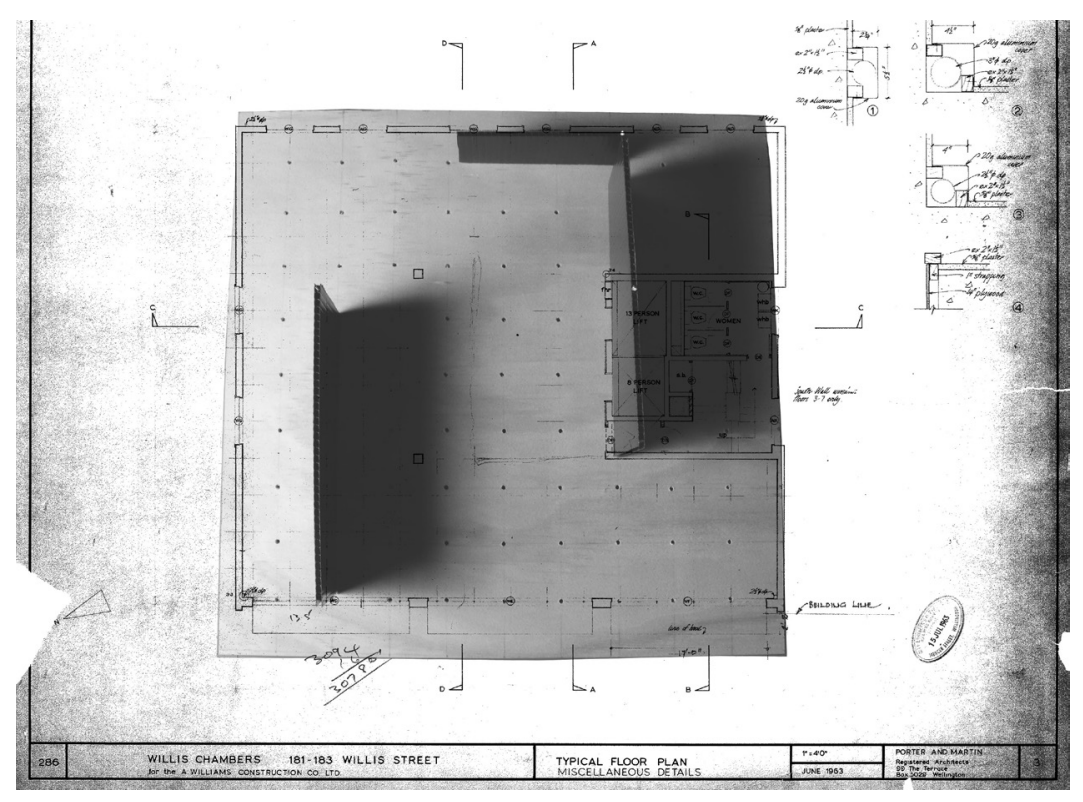

Figure. 4.15

Typical floor plan

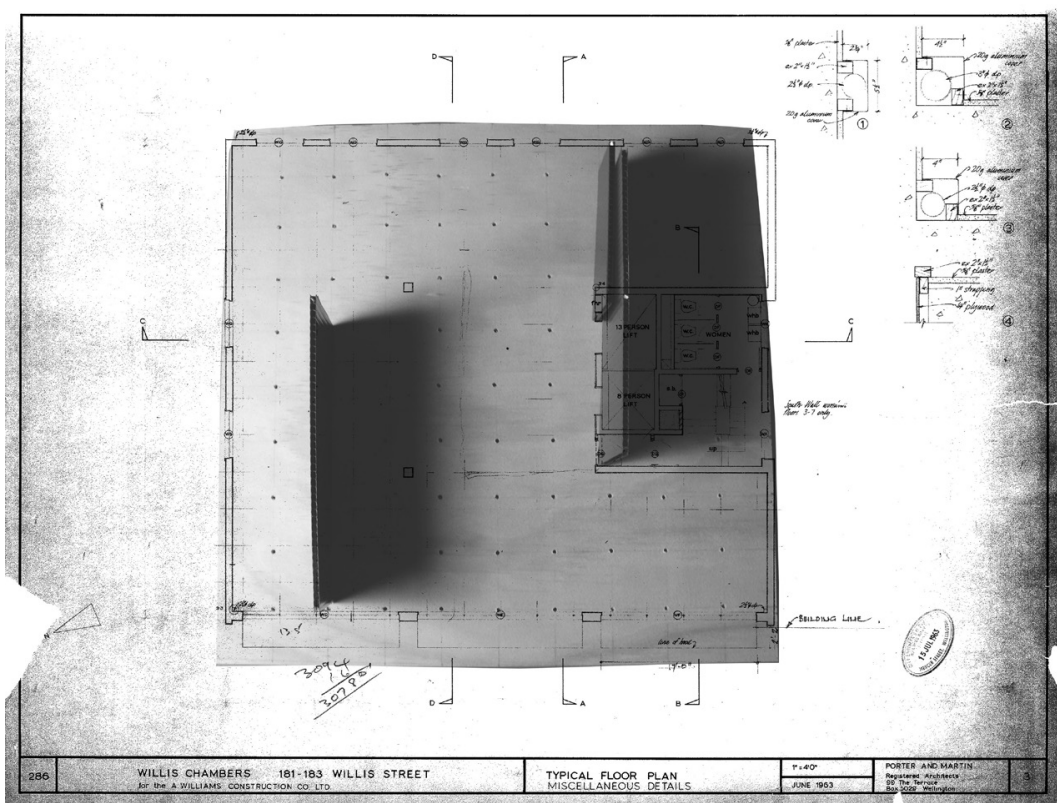

Figure. 4.16

Typical floor plan

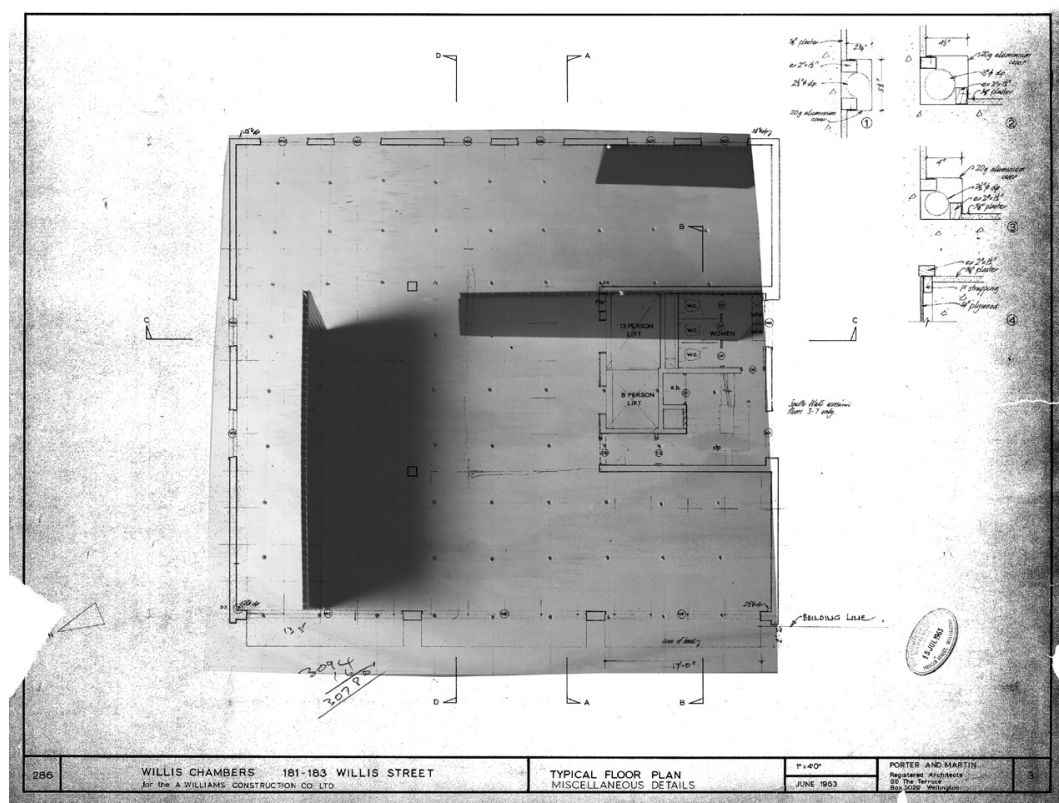




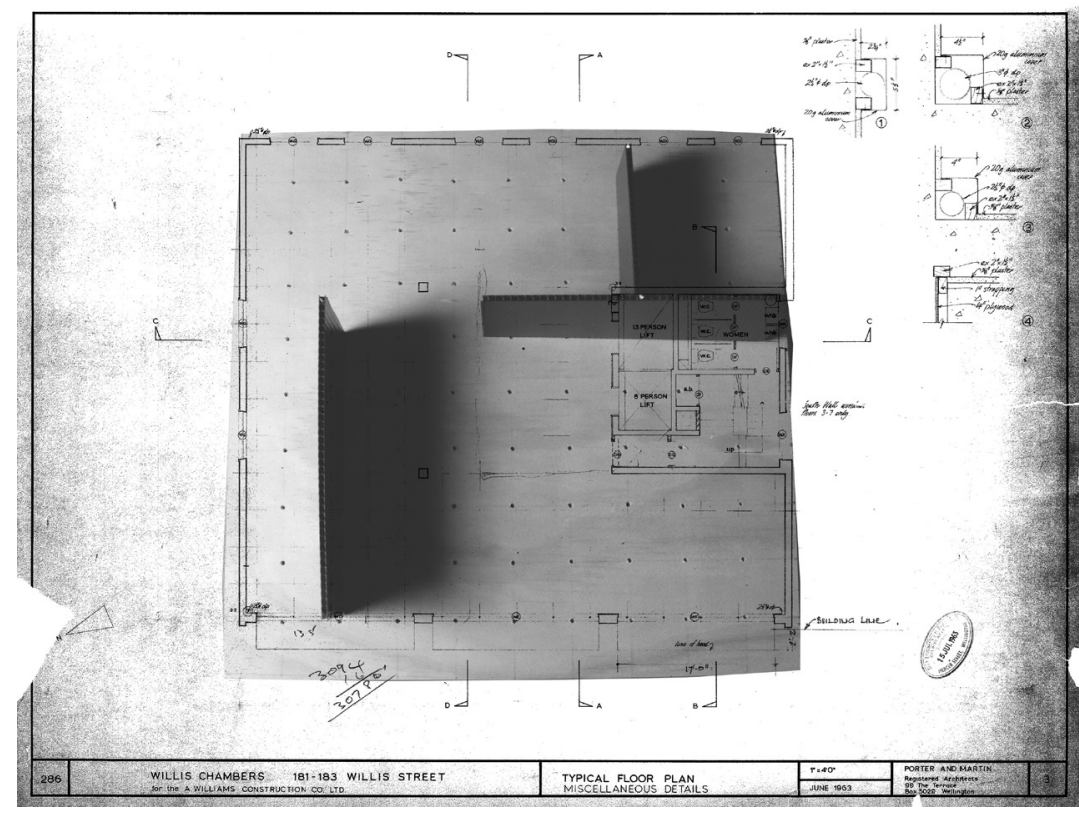

Figure. 4.18

Typical floor plan

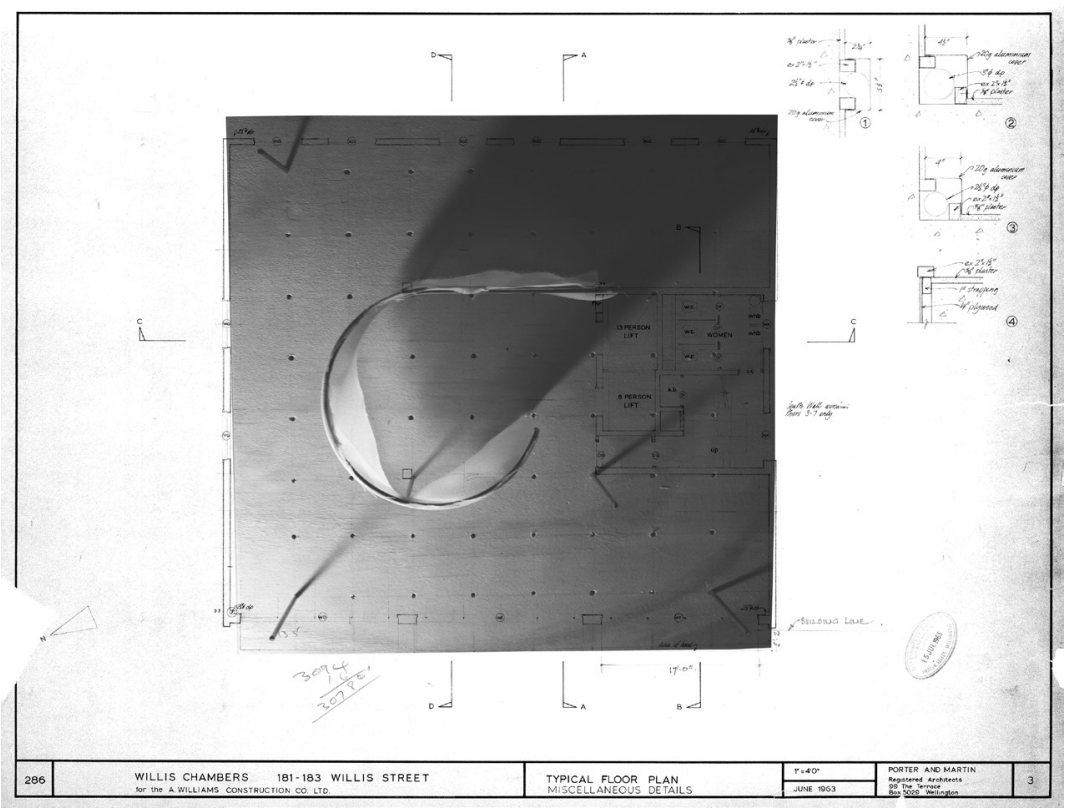

Figure. 4.19

Typical floor plan

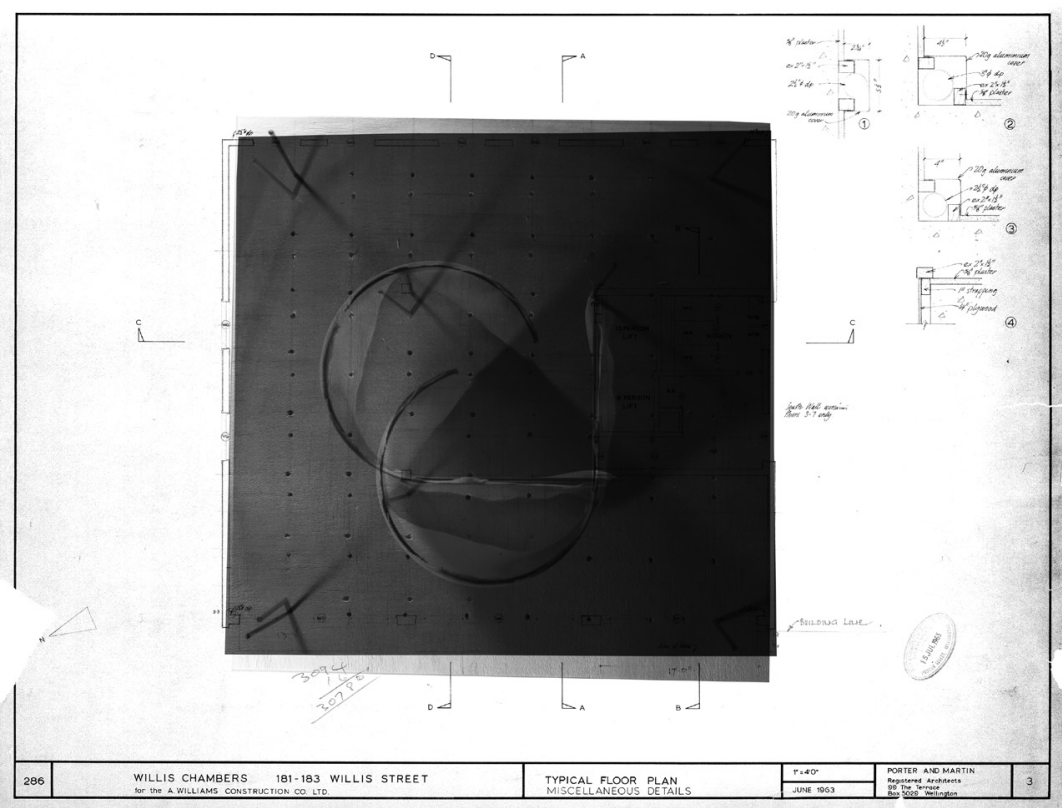

Figure. 4.20

Typical floor plan

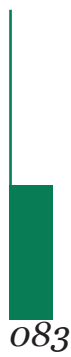




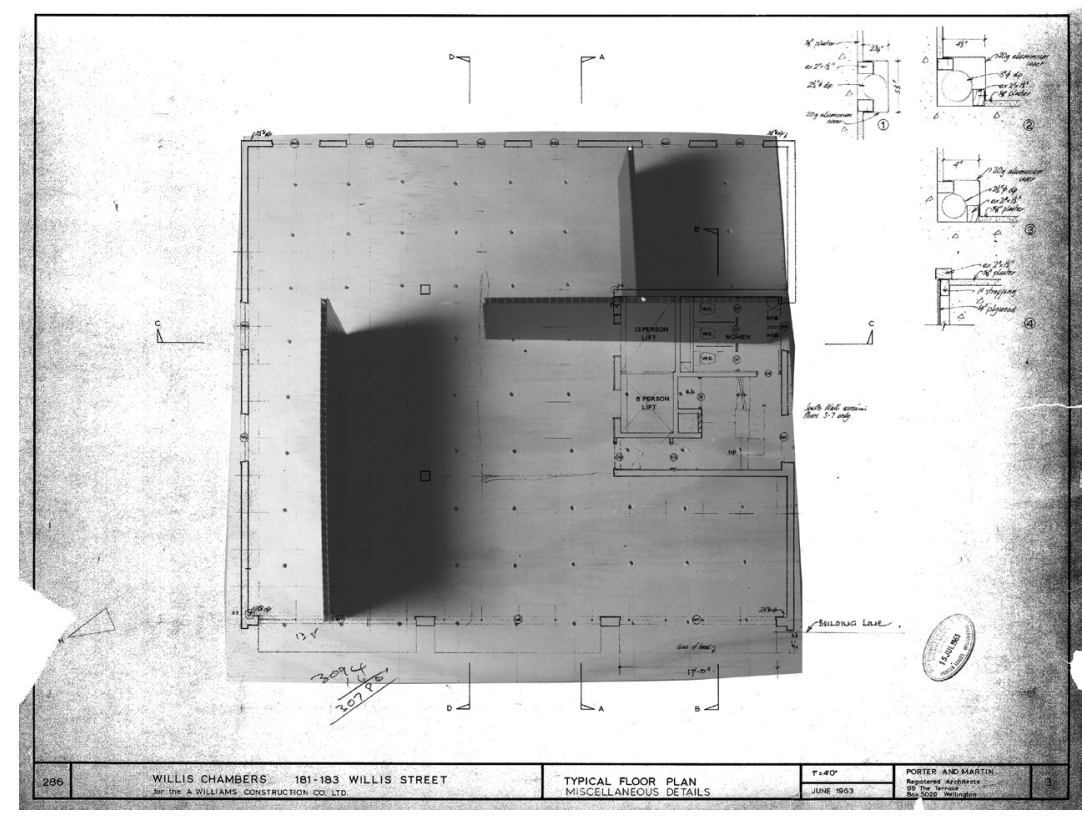

Figure. 4.21

Typical floor plan

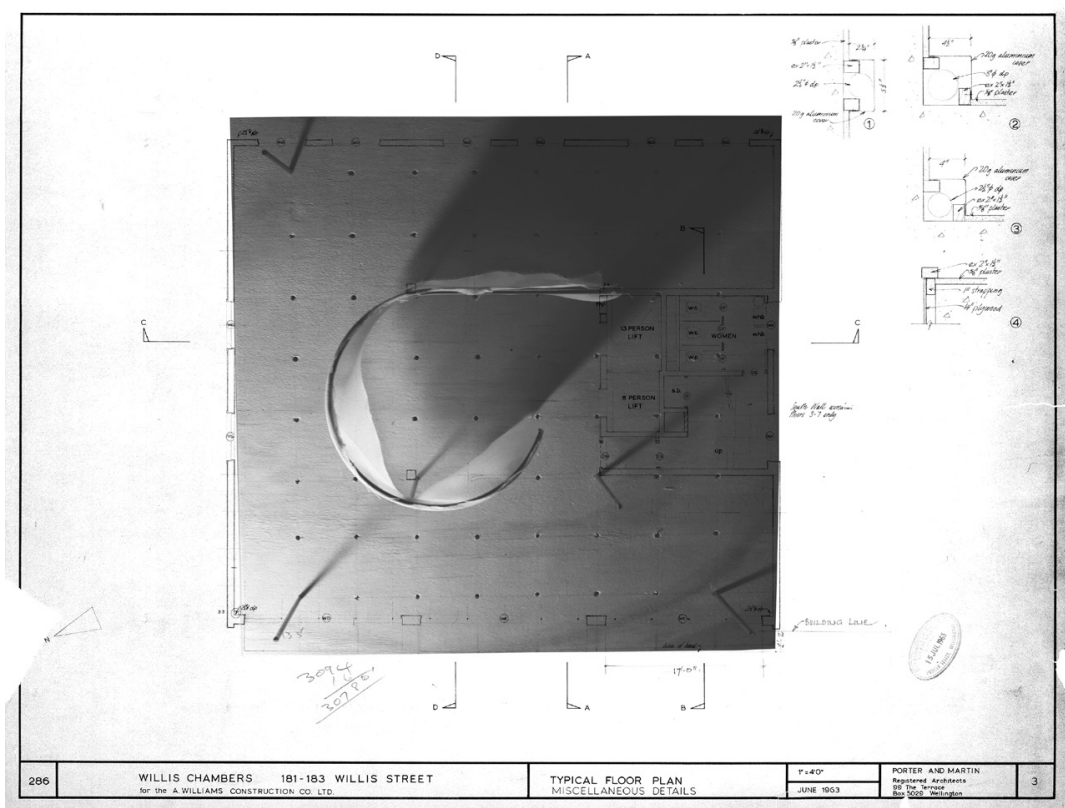

Figure. 4.22

Typical floor plan

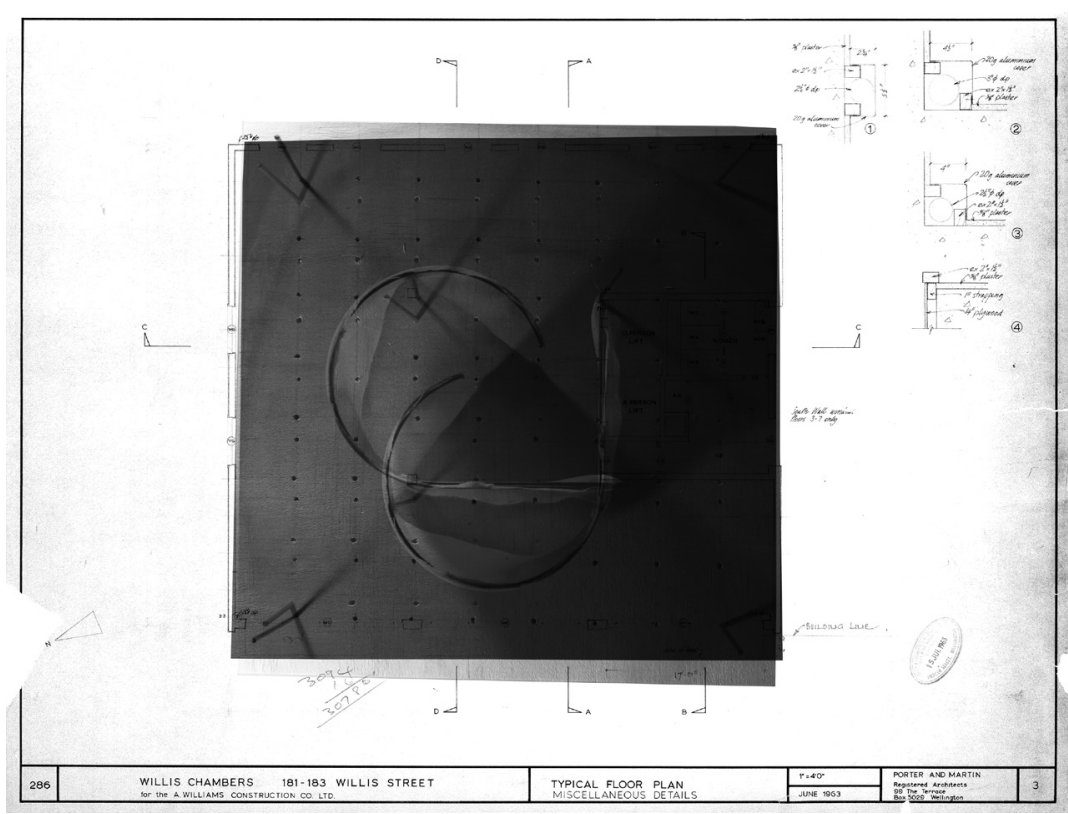

Figure. 4.23

Typical floor plan 


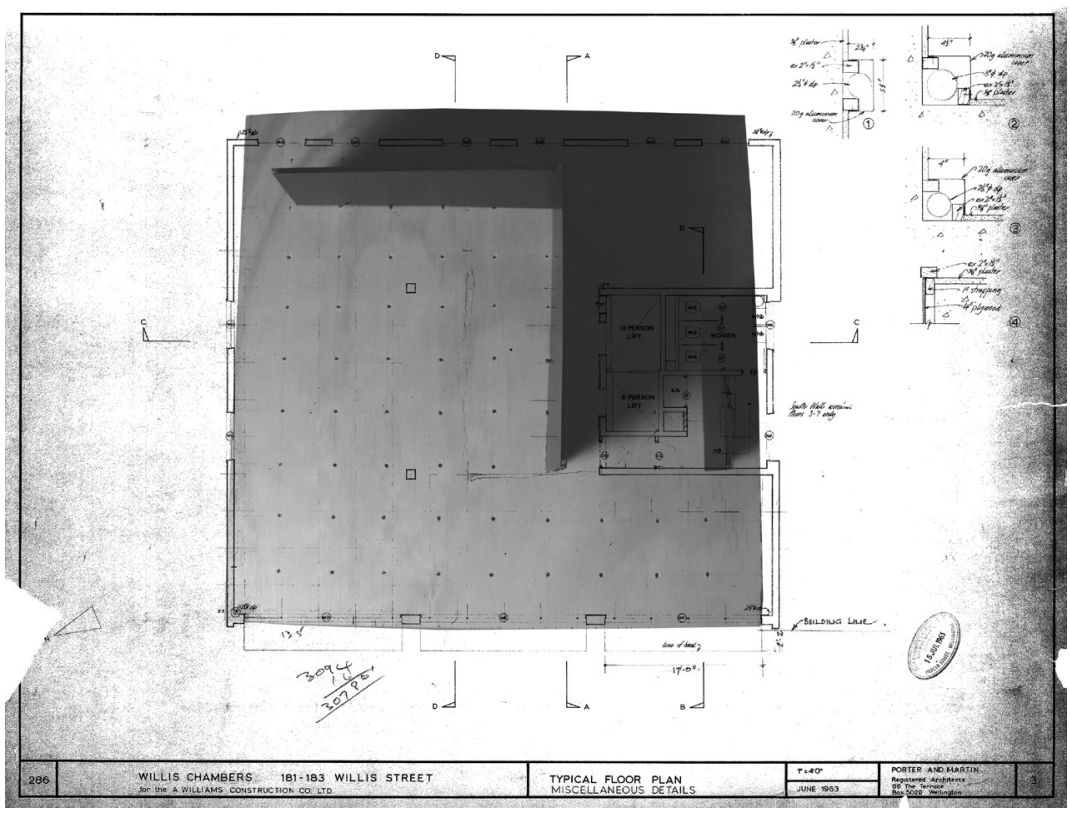

The second conceptual model test was successful in exploring the types of space that are explored through the use of shadow. Each model is an iteration which multiplies and divides space creating an architecture of flexibility. This was layered over the existing buildings original floor plans to create a further understanding of the three by three grid. 
Socialising space 


\section{Conceptual model 3}

In the third conceptual model test all of the past models from chapter three are collaged over the sections drawings of 181 Willis Street. This tested the ideas of flexibility and partitioning through a three dimensional look at the open plan office.
Conceptual model three explores the layering of models over the original drawings similarly to the second conceptual model test, however this time through the use of the original drawing sections of the building. This allows a deeper understanding of the original building and the three dimensional space. Through these drawings a connection up through the building is found with the use of half floors. The models layer up the space creating moments of openness and also moments of privacy. These models also explore the flexibility of furniture through a space and how it connects to the larger spatial arrangement of each floor through section. 

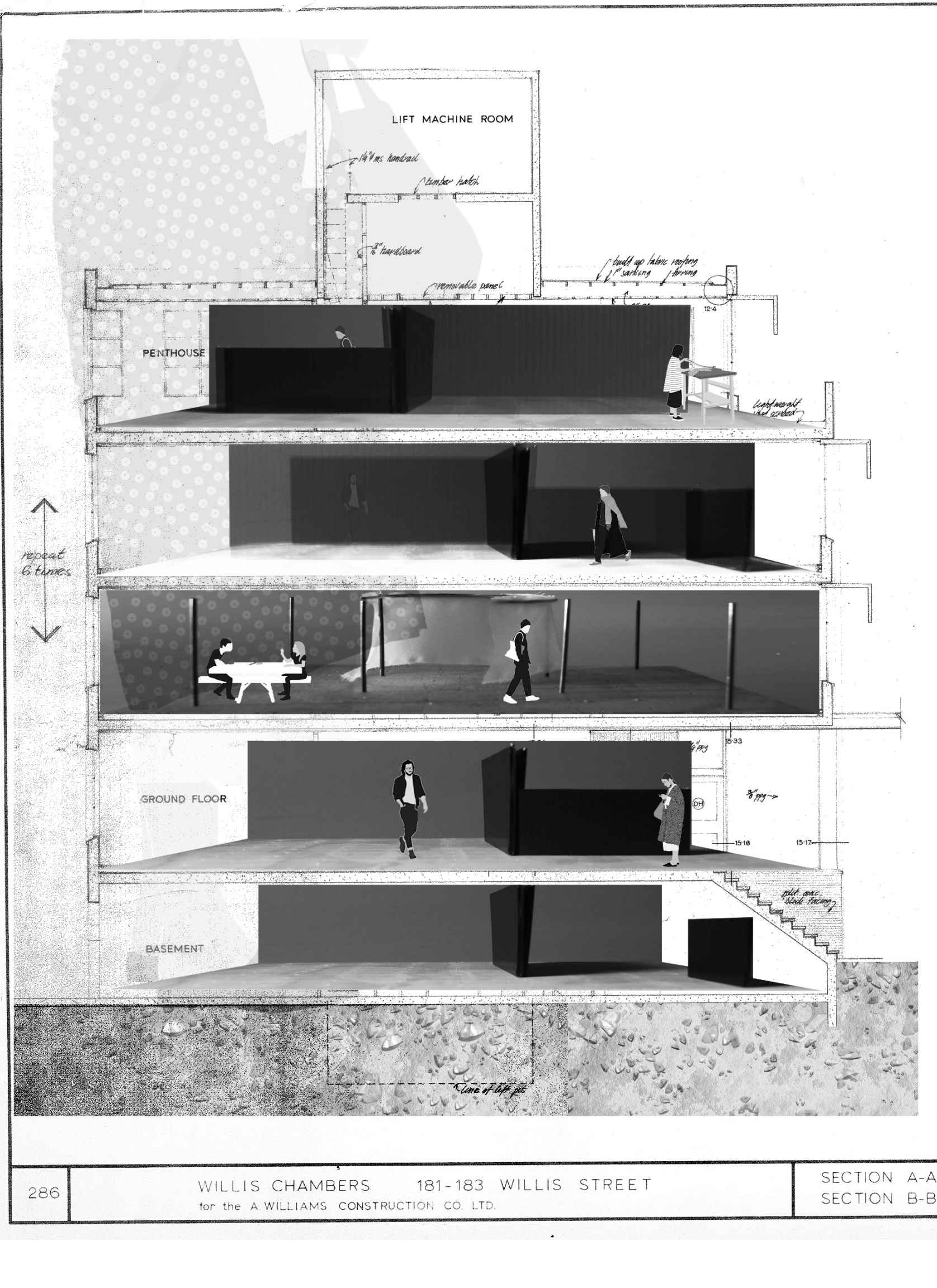

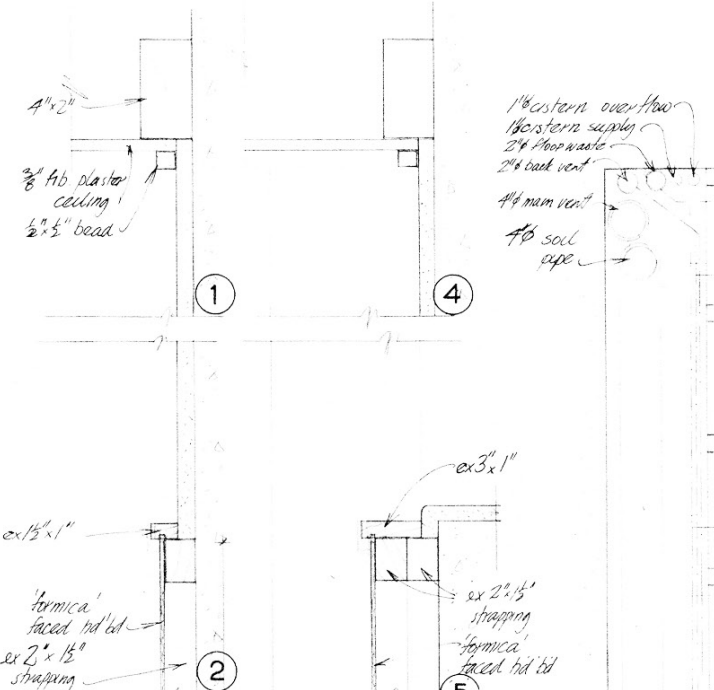

(4)

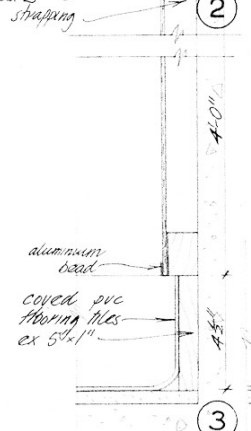

(3)

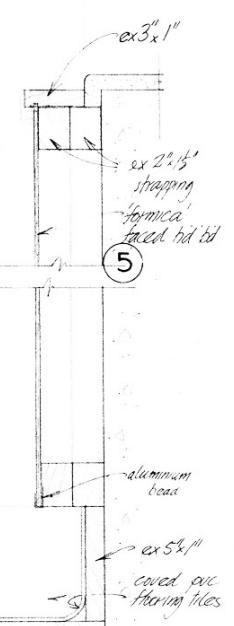

(6)
WALL DETAILS 1/4 F.S

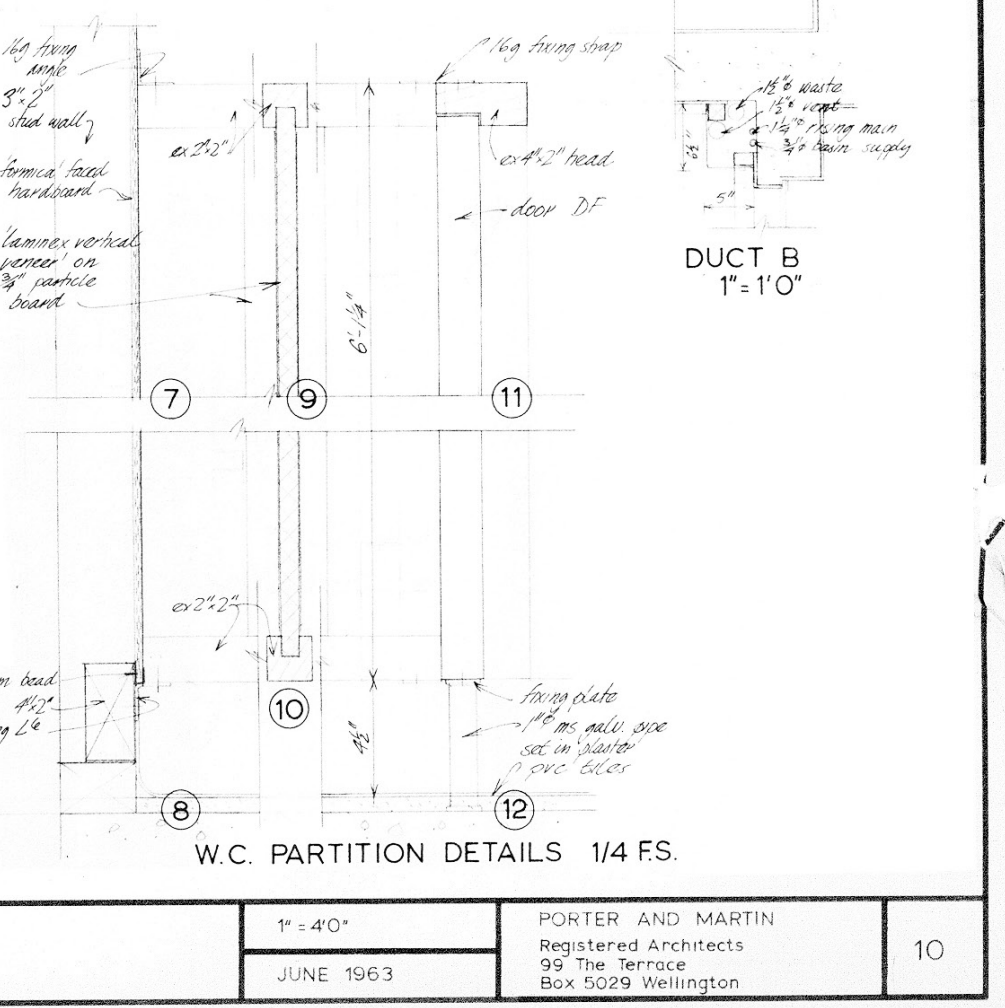

Figure. 4.25

An original building section view that has been overlaid with the conceptual models. In Section A-A the building begins to become more private and is sectioned into smaller areas the further you move up. This tightening through the building allows one to see how the open and the more private floors will work. 


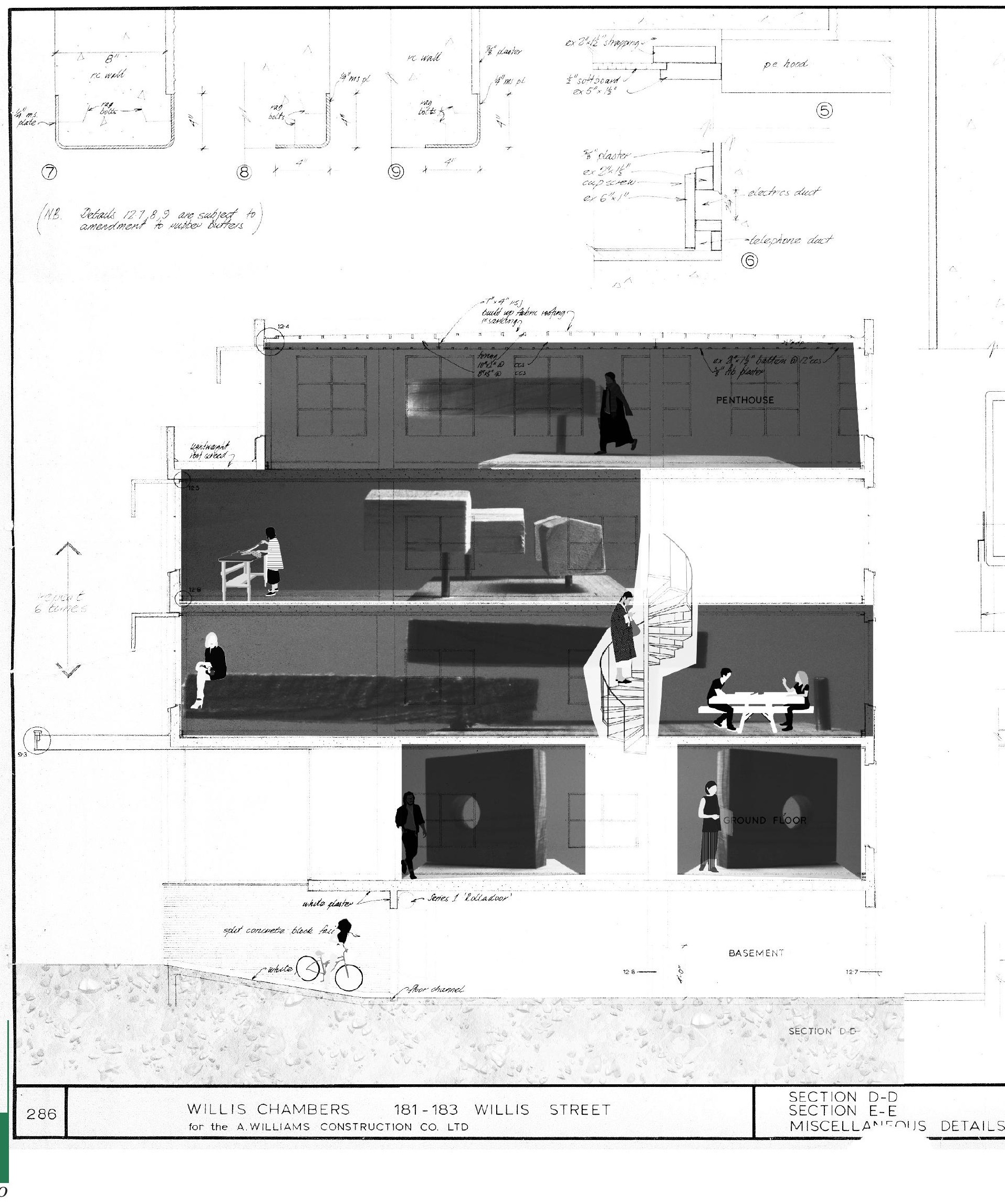


Socialising space

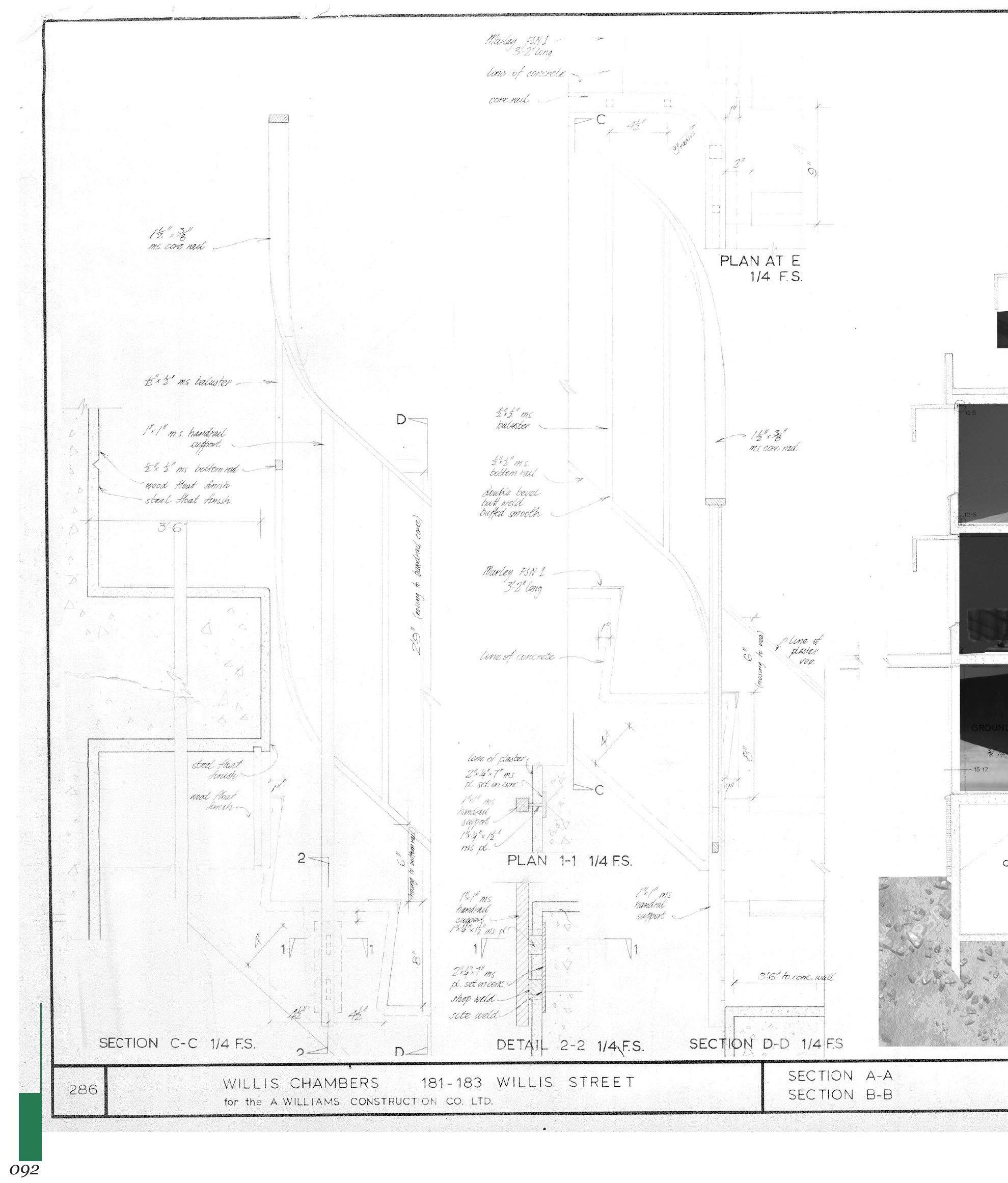




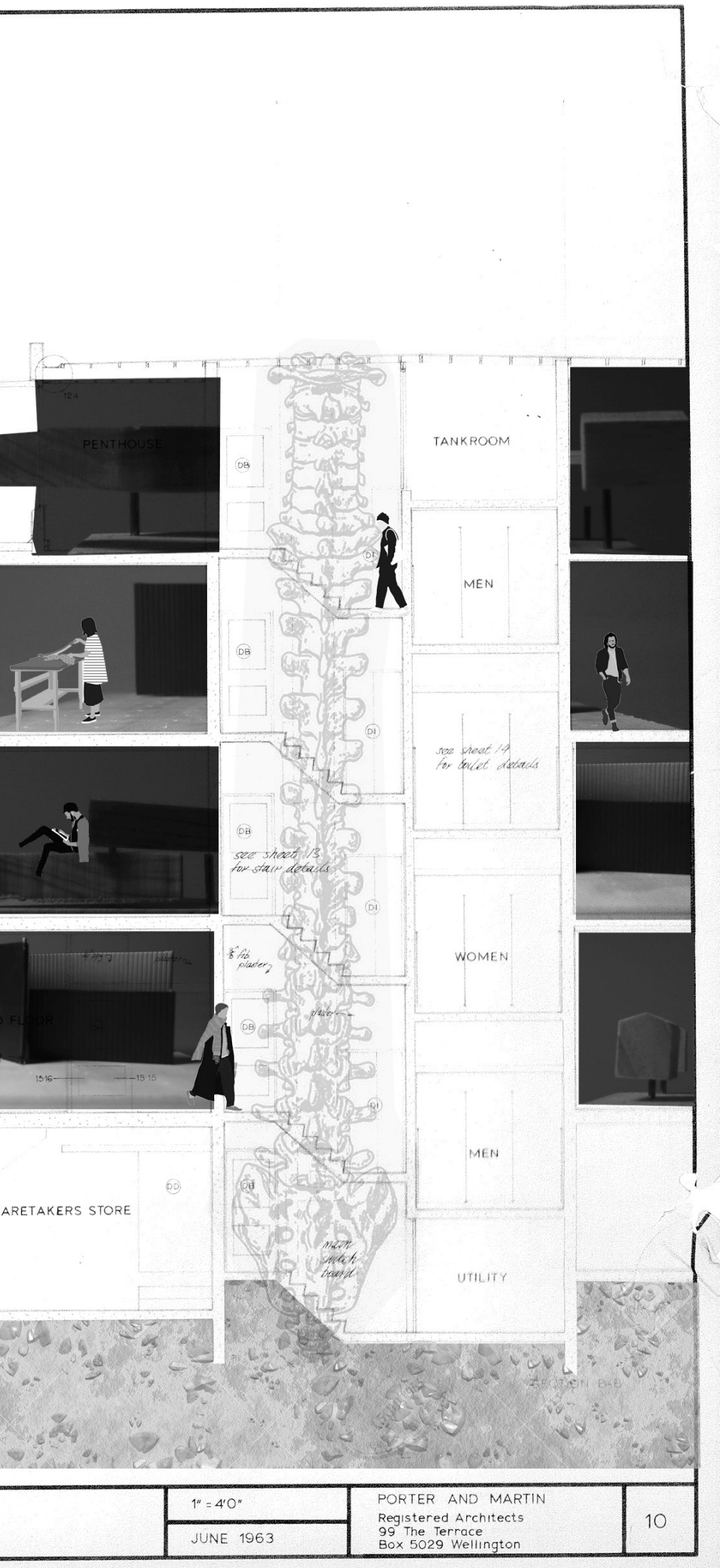

Figure. 4.27

An original building section view that has been overlaid with the conceptual models. In Section $B-B$ the main central spine of the building is accentuated. Off the spine are the floors, these act as ribs for the building provided privacy and enclosure through a way of opening and closing, this flexibility is important for those using the building. 


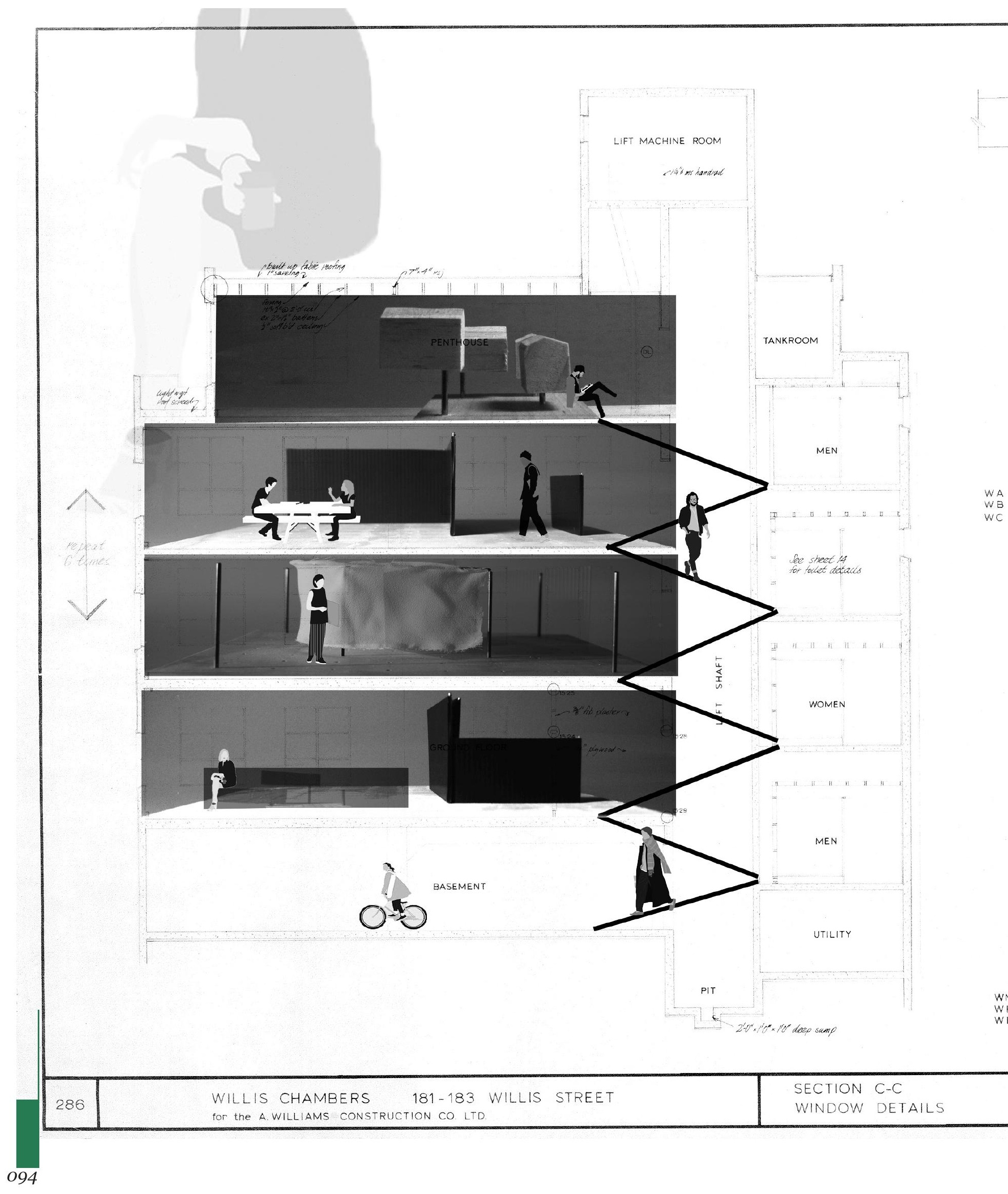



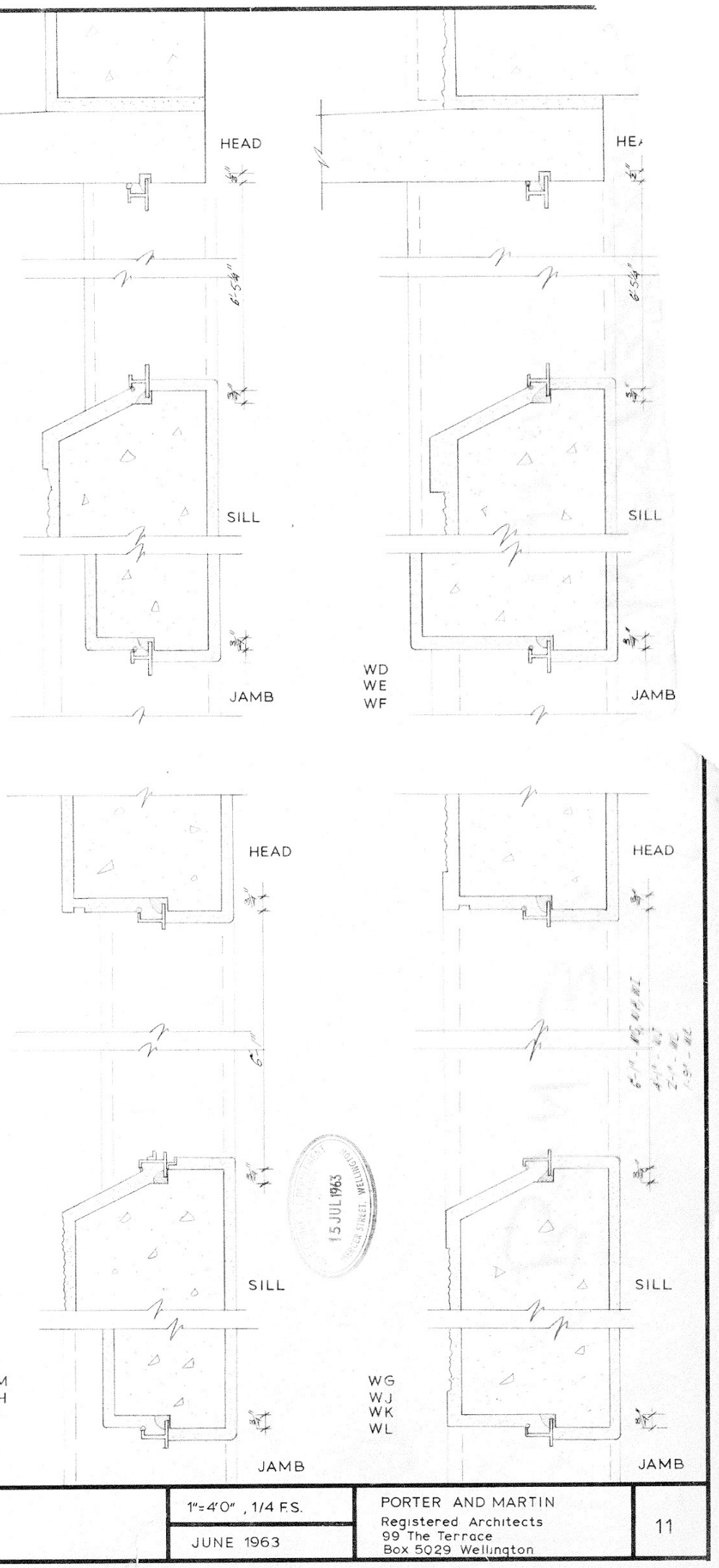

Figure. 4.28

An original building section view that has been overlaid with the conceptual models. In Section C-C the ideas of the three previous models are explored through the connection of the central staircase. How can the central staircase area connect the building in a more unifying way? How can the walls and furniture work to be flexible within the space to work in anticipation for the users? 


\section{Critical Reflection}

Using a focused research through design approach, the previous modeling tests explored space through a flexible and scalable lens. Through the introduction of a specific site the tests were explored in a three-dimensional space with real dimensions. The chosen office block, at 181 Willis Street, has a formal clarity and simplicity, being made up of open-plan office floors with internal columns set up to create a nine-square grid. This constraint helped to base the collaged models in an idea of site.

The initial model test were successful in creating suggestive spatial diagrams; exploring the relationship between flexibility and scalability through the use of movement. These vignette models were a basis for subsequent models that explored spatial relationships from the scale of a series of rooms, to a room, to walls dividing space, and furniture. Each model was left abstract however, deliberately evocative rather than directly translatable into architectural form. There is still a lack of solidness and formality in the drawings which would translate into real architecture.
The use of shadow and the effect of overlapping through the use of photography was successful in identifying areas that could be opened or closed through moving certain walls in the space. This was also highlighted through the different use of materials such as fabric which added another layer of flexibility into the models.

Through the introduction of 181 Willis Street; a building with a plan that is a nine square grid was effective as it also brought with it a complex social setting which could be explored through the idea of cross-programming the site. The site and the previous conceptual model test were successfully brought together and overlaid, beginning to understand how the implementation of the flexible walls may affect interior connections within the site. These connections were explored through a potential cross-program of a night shelter and the Wellington Free Store, however this would be explored in more depth after the modelling tests were complete.

The final conceptual model test overlaid collaged model fragment on the original section drawings of 181 Willis Street. Similar to the first conceptual model test, spaces were layered with rich complexity of opacity, allowing the spaces to open and close, expand or retract depending on what was required, whether the programme was public or private. The next step was to create a digital model of the building and begin to insert and move walls within the space to create flexibility in more precise ways. 


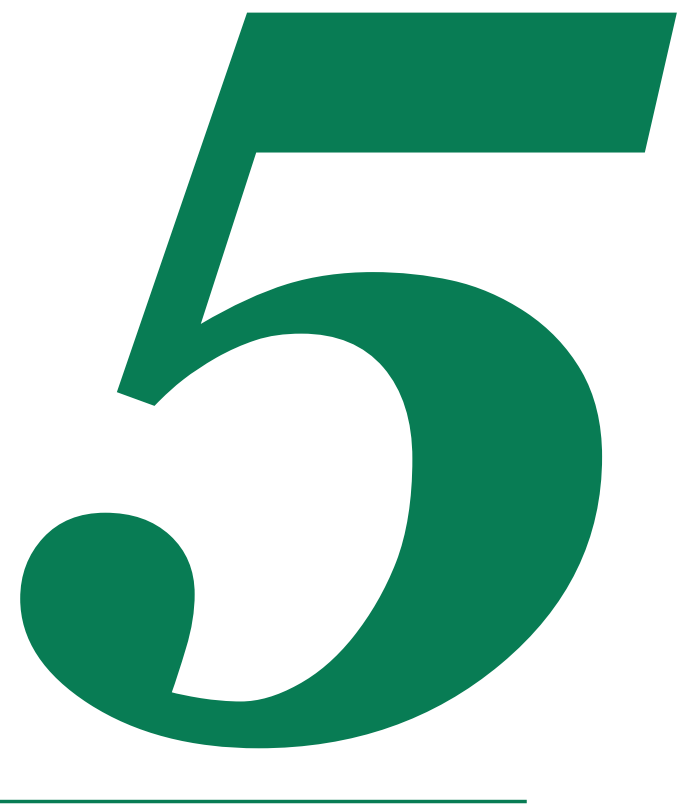




\section{Conceptual design}

A look at blending models with the digital Revit models to explore how this changes the affects of the differing spaces.

\section{Building Make-up}

A explanation of the cross-programming of the buildings. 


\section{Conceptual design}

Within the conceptual design the use of Revit begins to create the space as a whole office building. Using the conceptual model tests with Revit the spaces blend together allowing a more formal understanding of how the space is divided for flexibility. This is furthered through the use of perspectives to get a truly three dimensional understanding of the use of walls and fabric partitions at differing heights.

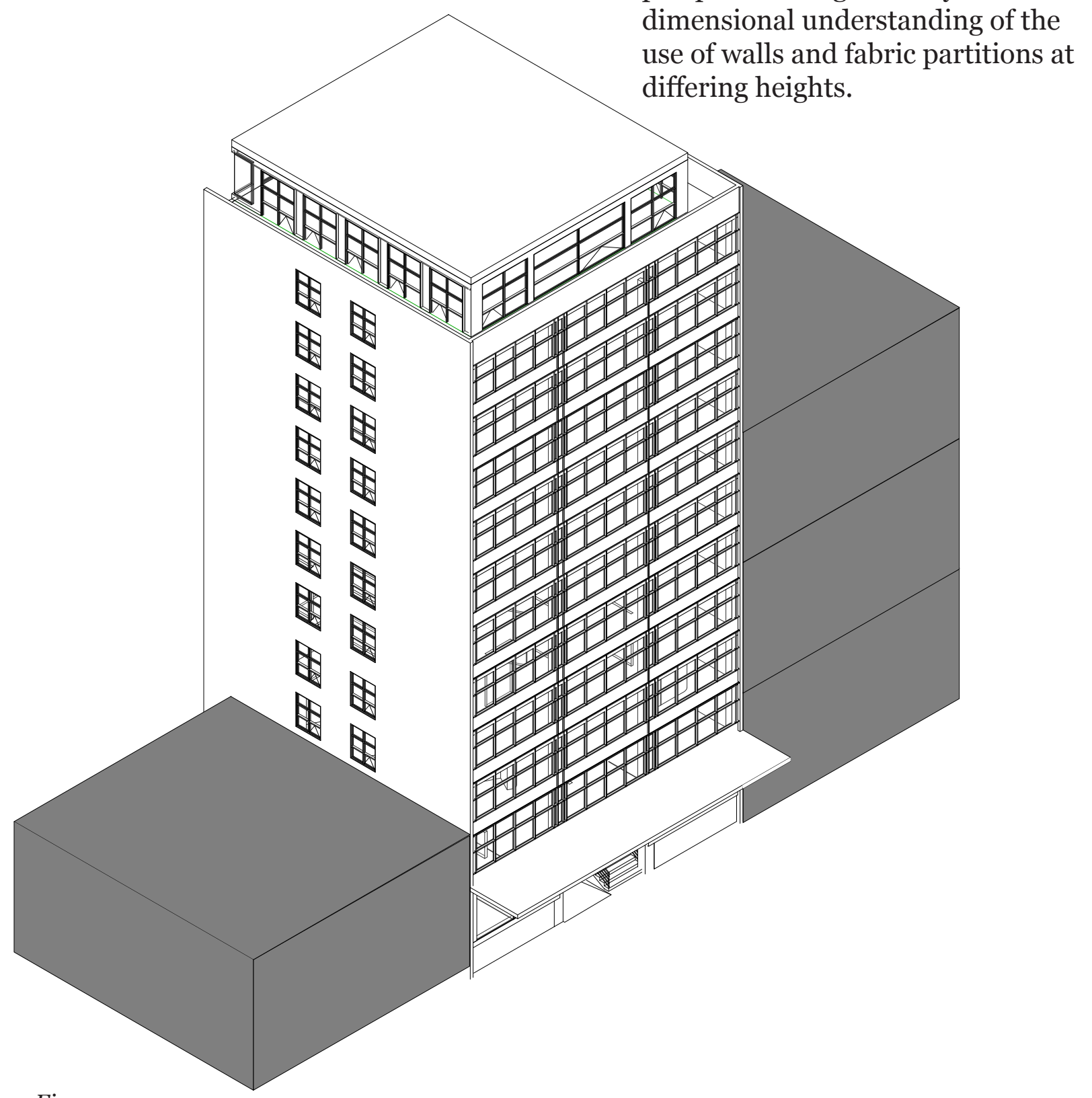

Figure. 5.1

An axonometric view of Anzac house looking at the north and west faces of the buildings. The west facing facade is a curtain wall split into 3 which follows the 9X9 grid of the building. There are 2 large windows in the middle of the north facing facade. 


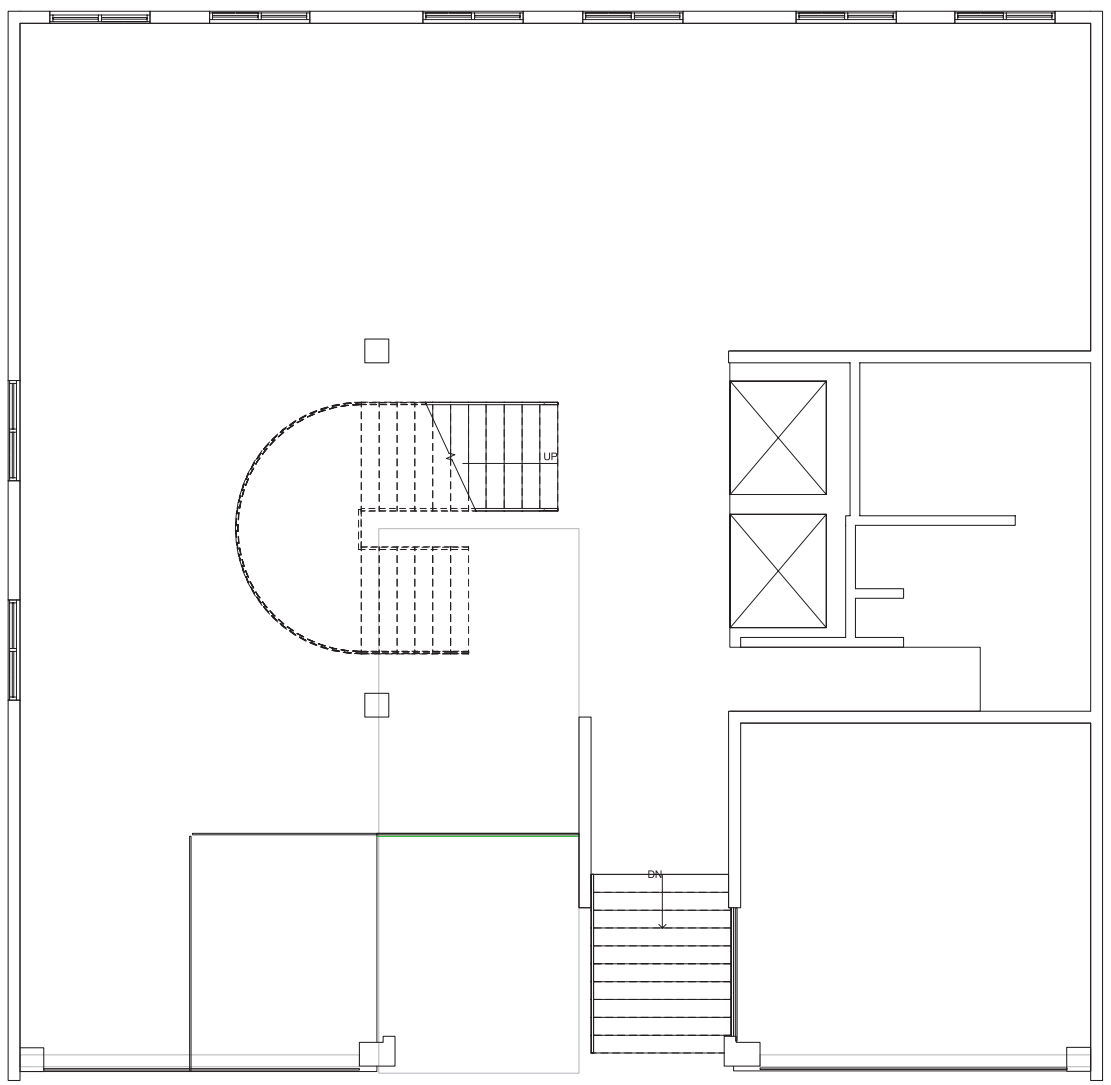

Figure. 5.2

A plan view of the ground floor with the addition of a large central curved staircase that connects with the first floor. The staircase allows a strong connection between the open ground floor and the semi private first floor.

(1) Level 1

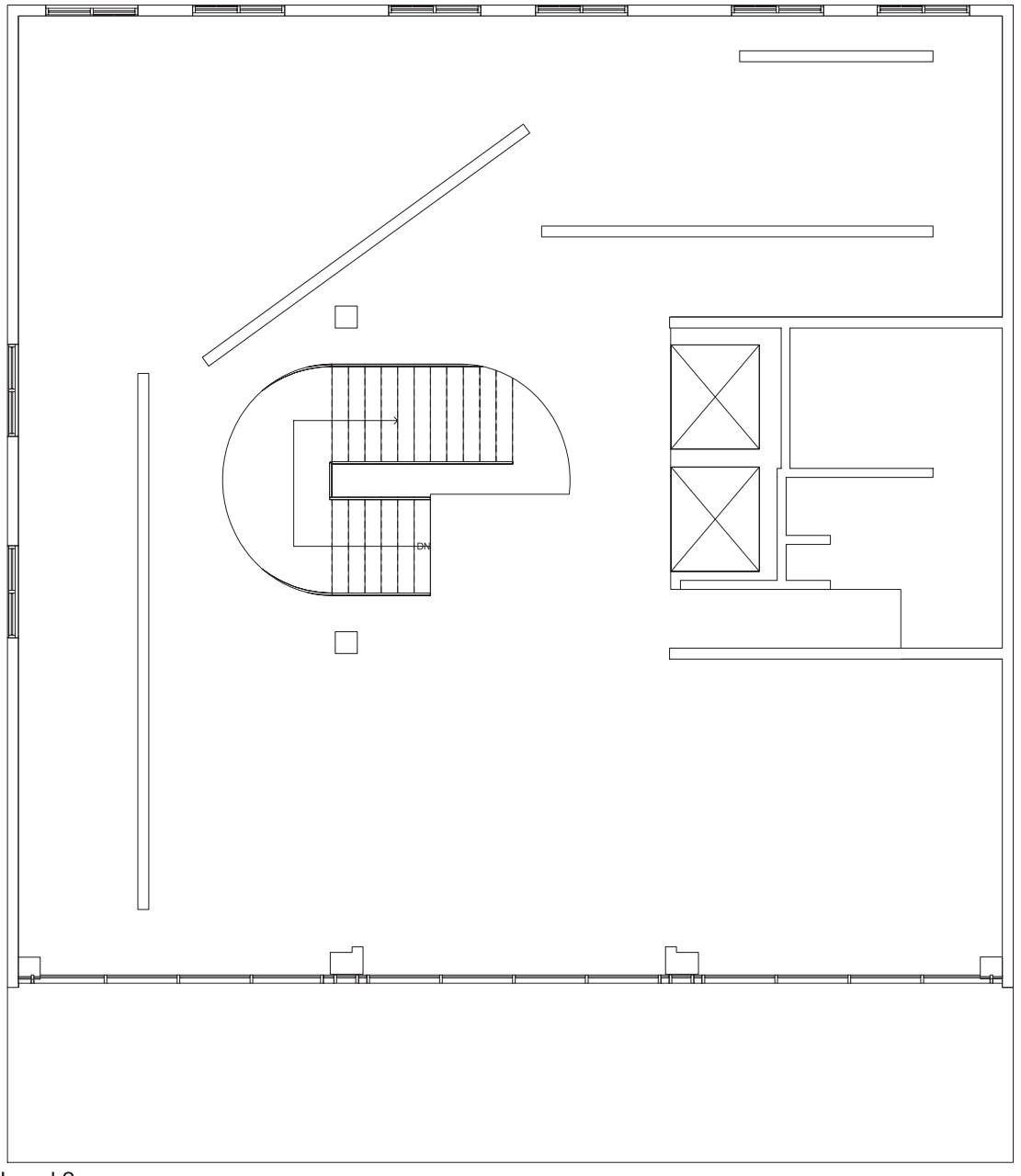

Figure. $5 \cdot 3$

A plan view of the first floor that is connected to the ground by the large central staircase. On the first floor walls at differing heights begin to section out the buildings which changes the viewpoints for people as they come up the stairs. 


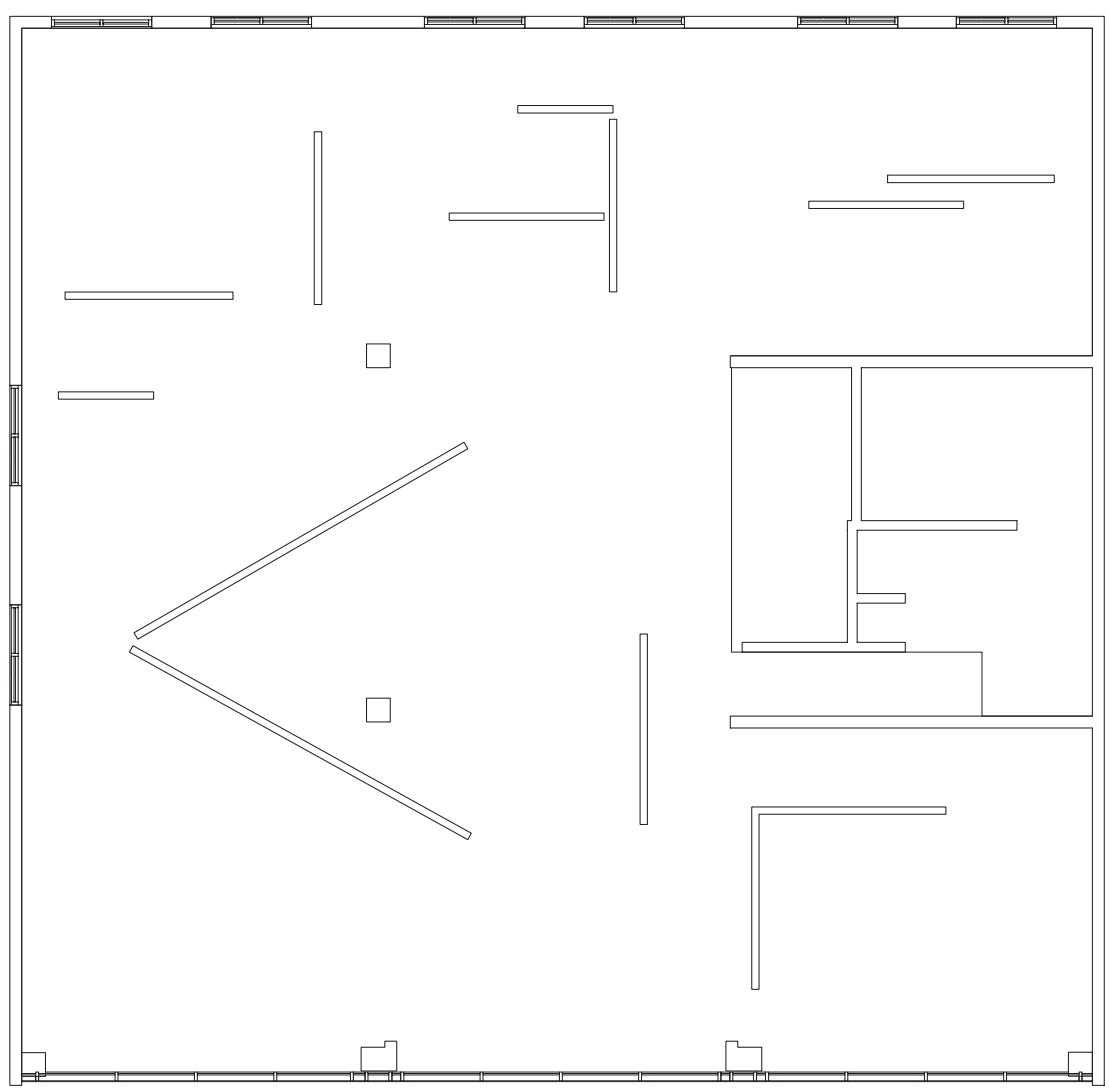

Figure. 5.4

A plan view of a typical floor. The space is divided by many different walls of different sizes and angles creating small interior spaces within the larger overall space.

(1) Level 4

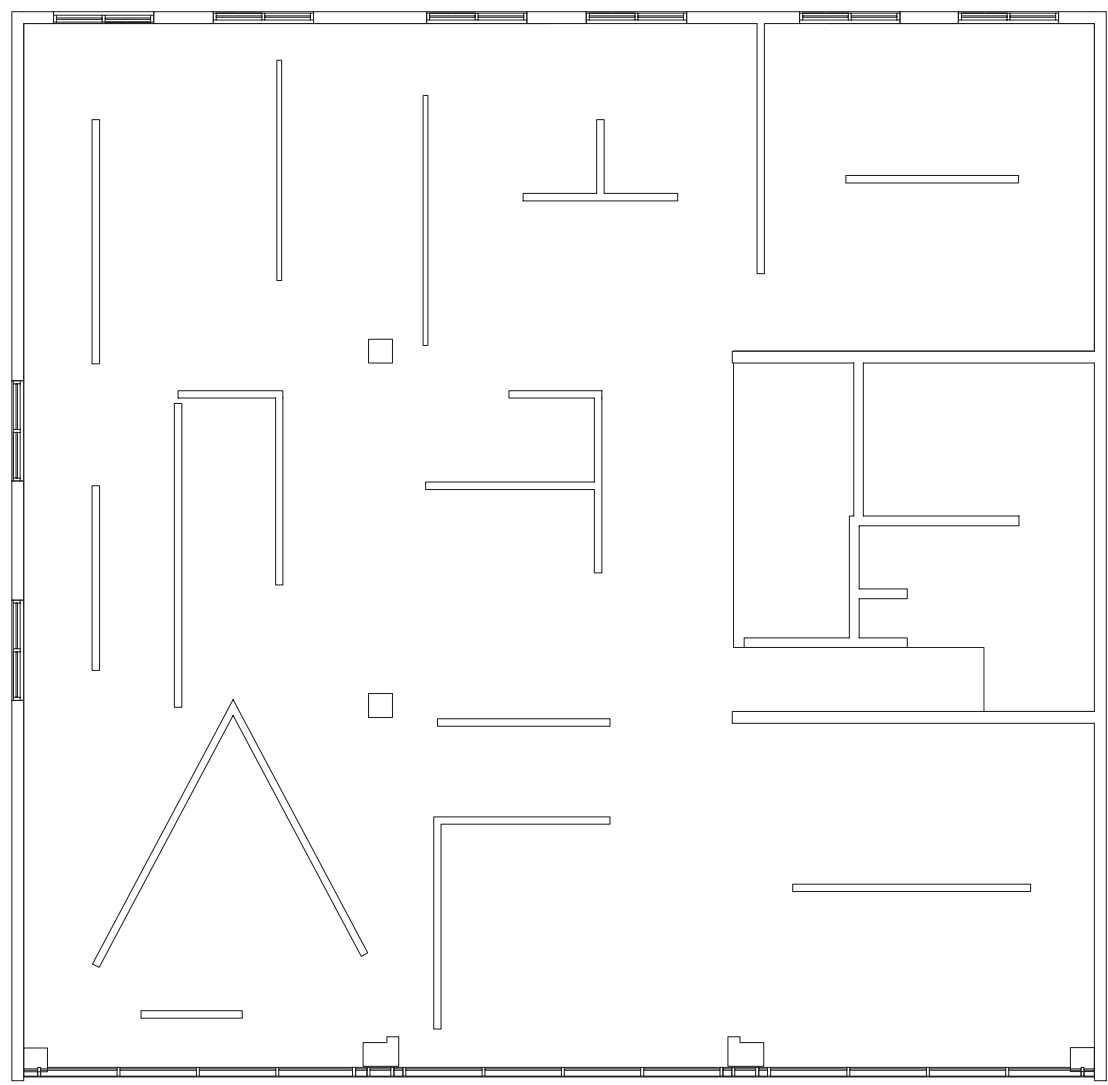

Figure. 5.5

A plan view of a typical floor. The space has many walls at right angles to one another creating a maze like space, this also creates enclosed spaces of safety and security.

(1) Level 5 


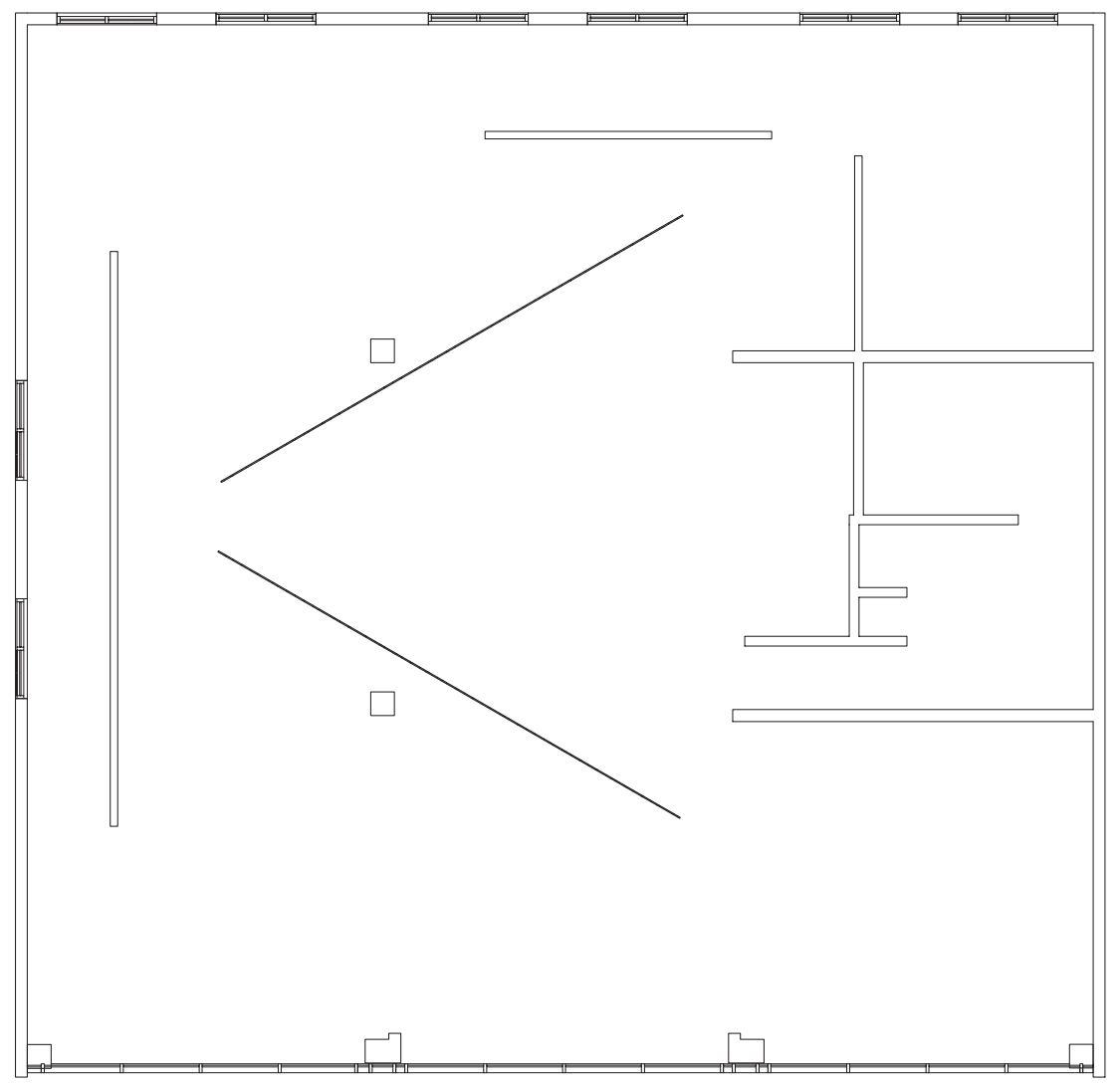

Figure. 5.6

A plan view of a typical floor. Exploring the difference between fabric and solid wall partitions, enhancing the feeling of the flexible nature of space.

\section{(1) Level 9}

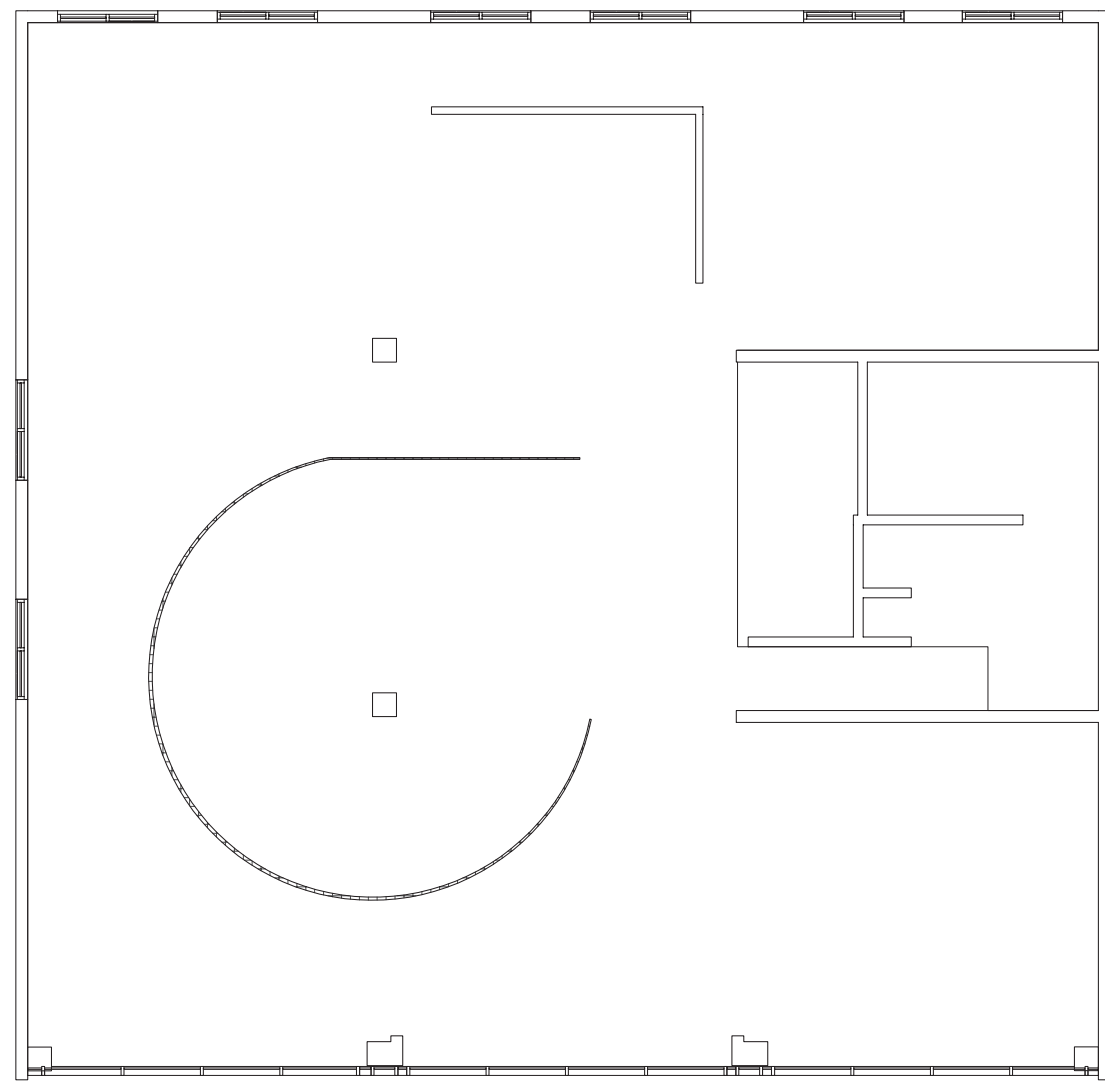

Figure. 5.7

A plan view of a typical floor. The use of curves and fabric partitions on this floor create intimate spaces within space.

(1) Level 10

$1: 50$ 


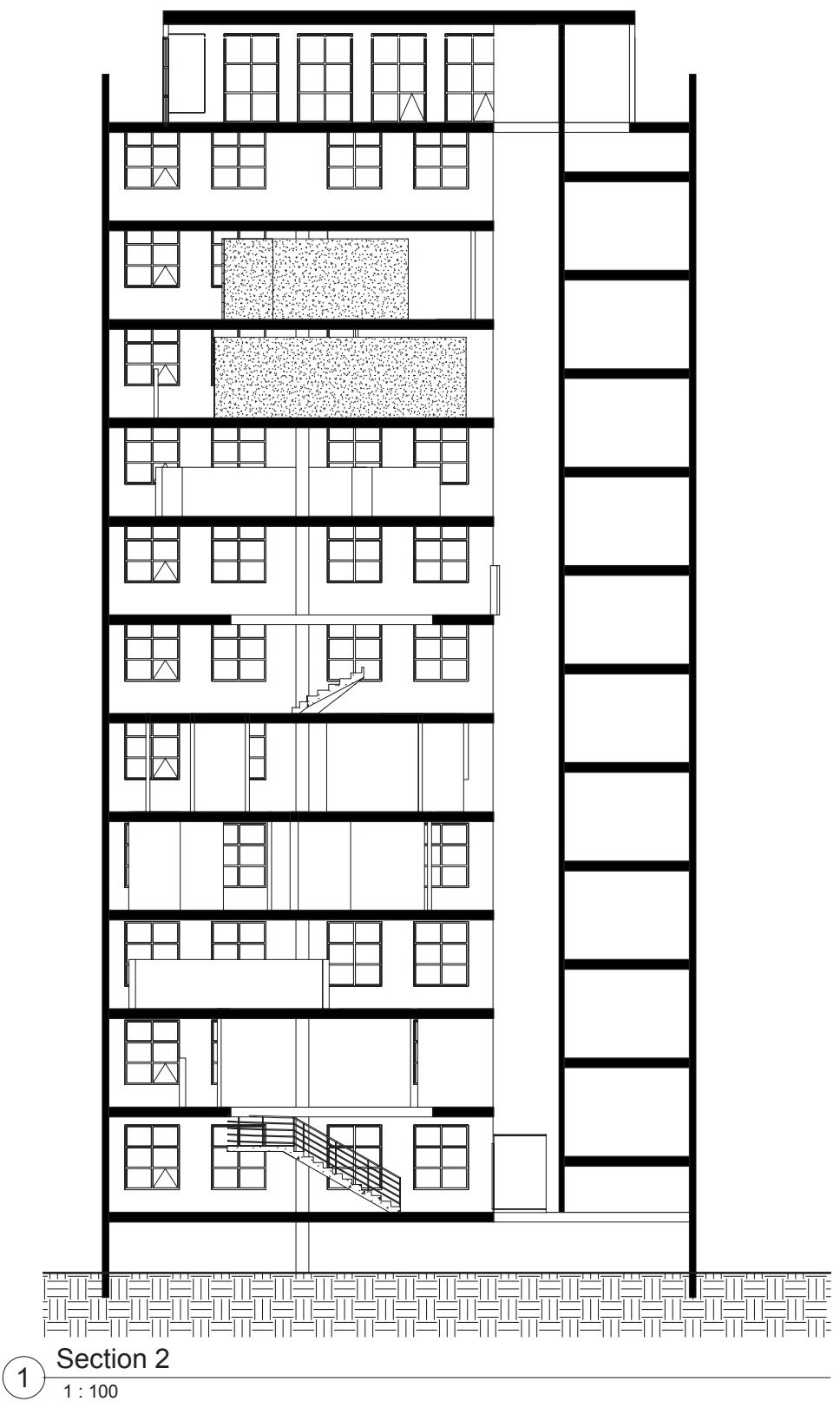

Figure. 5.8

A section exploring the connection between the ground floor and the first floor and also the sixth floor to the seventh. It also explores the use of partitions and heights of partitions to divide space. 


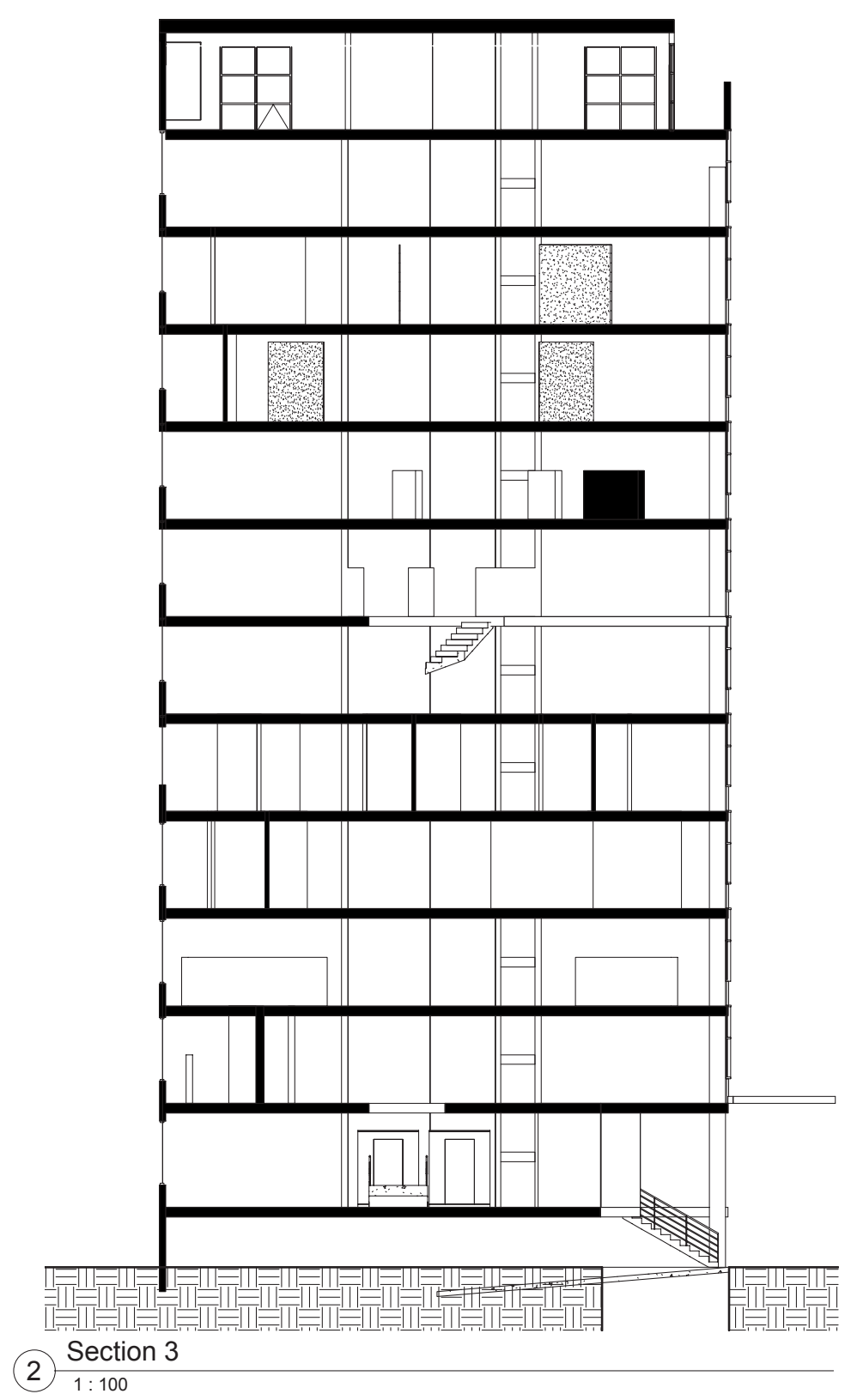

Figure. 5.9

A section exploring the connection to the street and up through the internal streets of the building. 


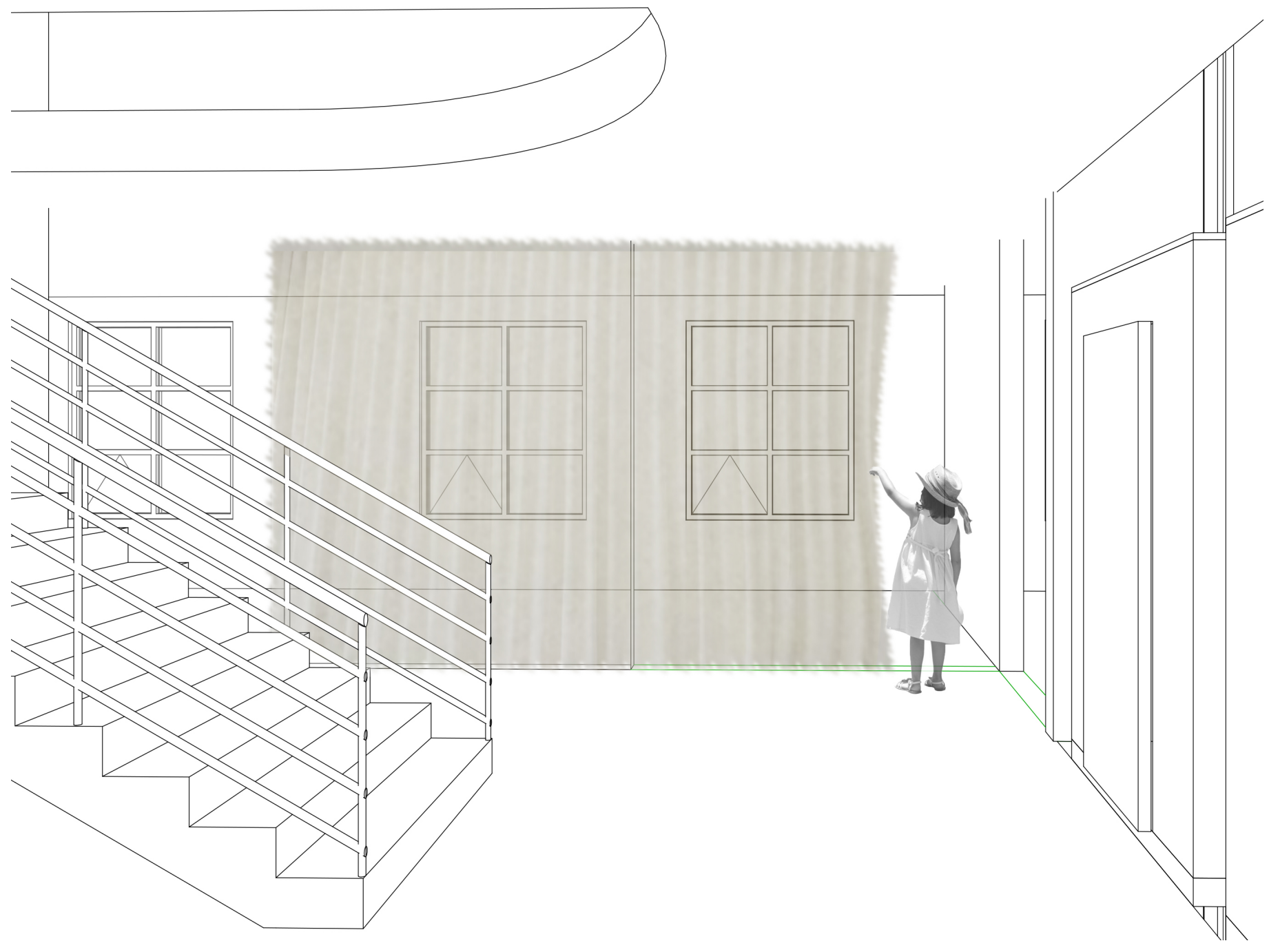

Figure 5.10

View of ground floor exploring partition curtains.

This allows spaces to be sectioned off if the space needs to be used for meetings or functions. 


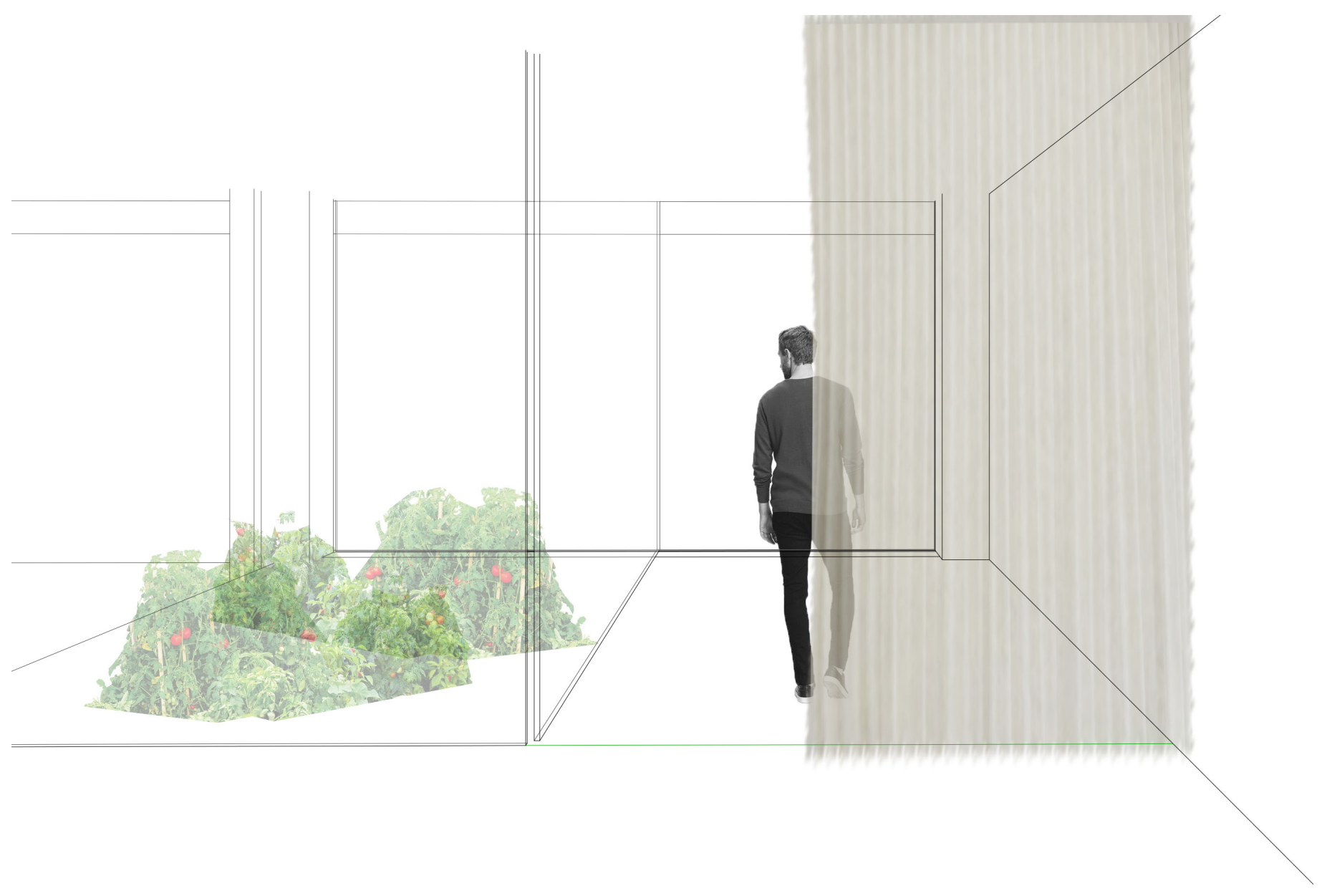

Figure 5.11

A view of the ground floor exploring the internal garden and meeting space. This also explores the terrace garden from the original drawings. 


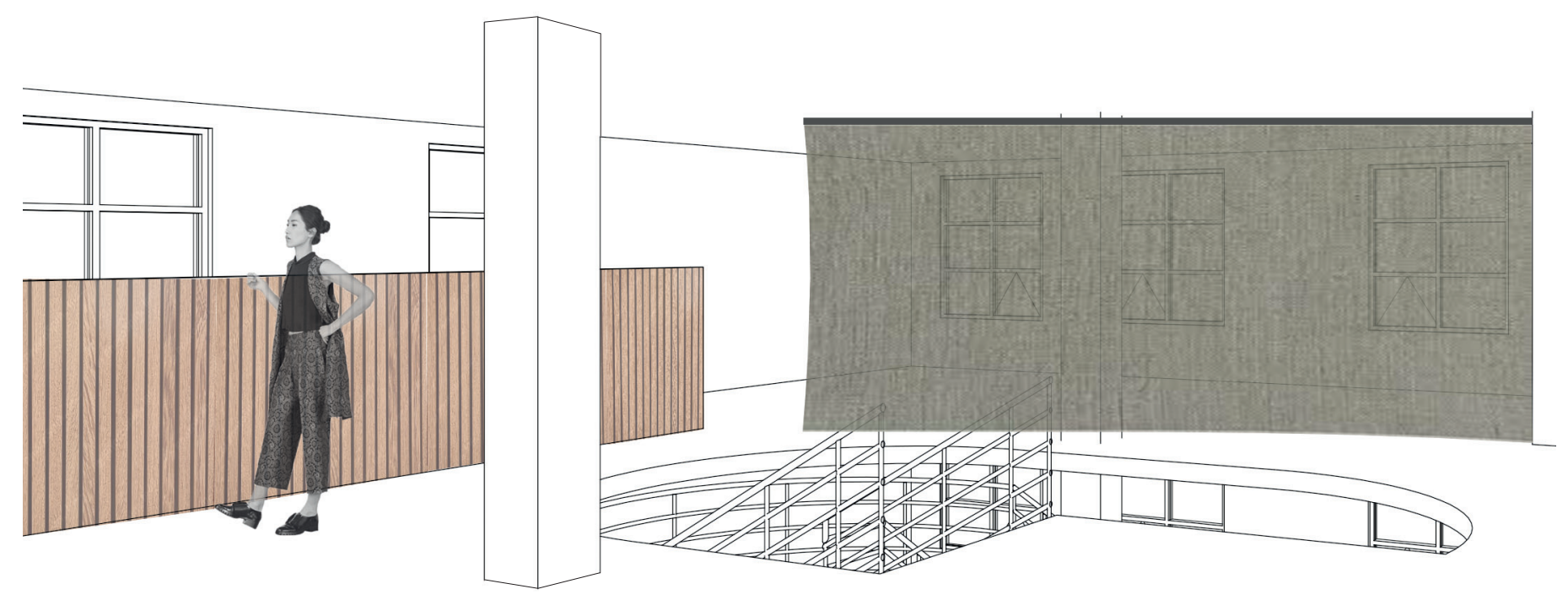

Figure 5.12

A view exploring the use of curtains and half walls to divide the space. This allows visual privacy from certain aspects within each floor which can be private. 


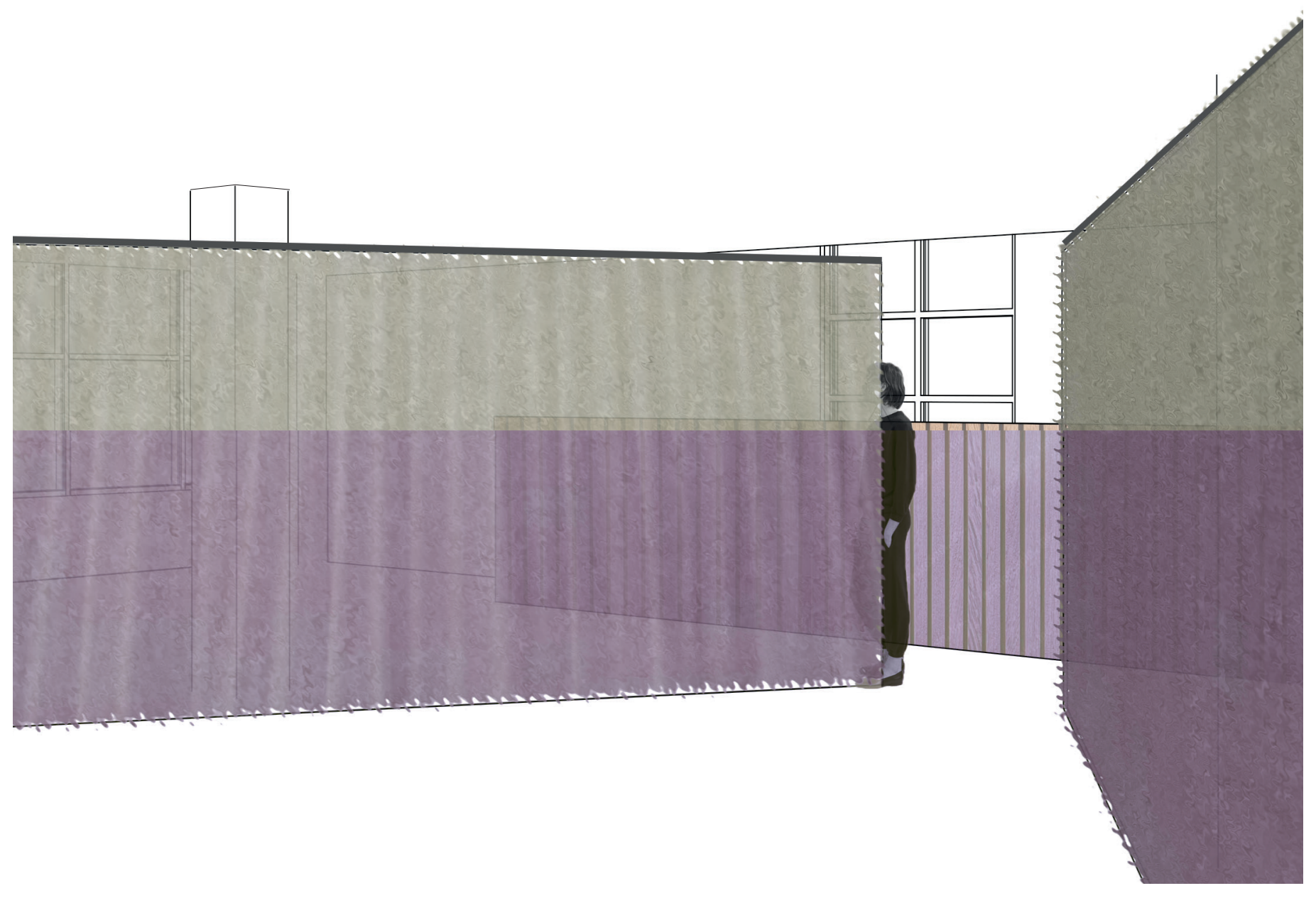

Figure 5.13

Begins to explore the use of curtains as partitions. The sense of movement the fabric forces people into creates a sense of compression and release as they move from into the office space. 


\section{Building make up}

Considering the size of the building and the way it has been configured to make the best use of the space, it will be split into three sections. Each section will have a different function for people using the space. However it is the idea that a consistent design language will be used throughout. The building will be broken into three areas, public space, sleeping space, and office space.

The first floor of the building will be open to anybody within the public, this space allows the free store (a space that collects leftover food from cafes to distribute to those in need) to work from. This space will also include a community dining space to allow people to rest for a moment and have the potential to engage in conversation. The mezzanine floor above will be connected by a large central staircase that embodies the typologies of the furniture of the space. Half walls, full walls and curtains will be used within the space to allow for flexibility and privacy whether that be a talk or a meeting.

The third, fourth and fifth floors provide immediate and emergency accommodation for members of our community in need of shelter such as rough sleepers.
These three floors will be private and offer personal sleeping space along with personal and lockable storage. Bathrooms that offer a shower vanity and toilet are fully private. The main functions of these floors are to allow people in vulnerable situations a moment of privacy and security.

The sixth to eleventh floors are dedicated to the flexible co-working space, within the makeup of the office space. Two floors will be open to one another through a cut out through the floor to enable floors more dedicated to "noiser" space where one can hold informal conversation and deter distraction from work at the formal desk. These floors will also encompass a kitchen and differing typologies of working space such as informal couches, the 'kitchen table' or just large multi-person desks. As explored in the literature review it will be important to give the people on each floor a sense of their own space as this improves their feelings of autonomy in a space (Brunia). This can be further enhanced through the balance of traditional desk space and other office furniture typologies. There will be four floors of predominantly desk space, within each floor will be areas for meeting and privacy as well as spaces to sit more informally.

Each design element is informed by the initial tests and has similarities to keep a consistent design language and create a congruent feel throughout the levels of the building, while still enhancing the flexibility and anticipatory nature of the building. 
Co-working office space

Co-working office space

Co-working office space

Co-working office space

Co-working office space

Accommodation

Accommodation

Accommodation

Workshops space/ accomodation lounge

Open floor - Free store/dinning space

Parking/ bike storage and workshop.

Figure. 5.14

Building make up diagram 


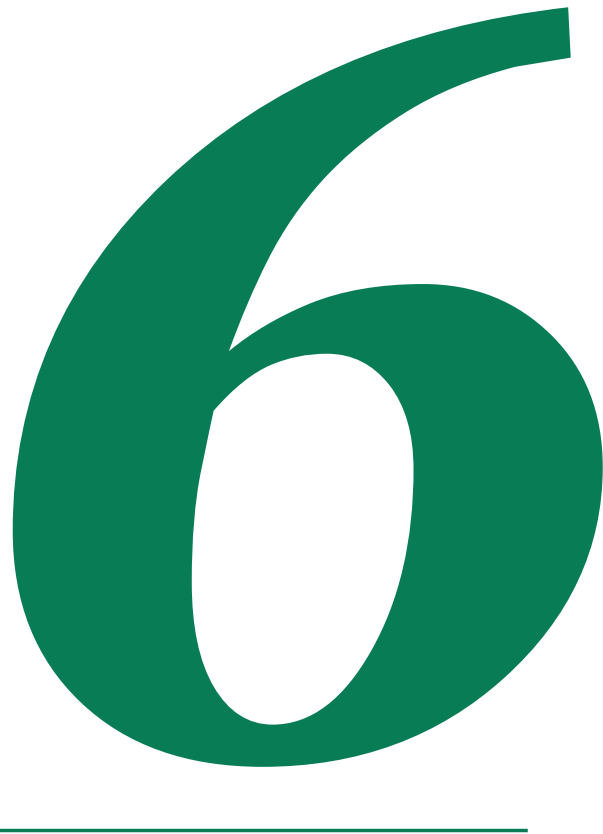




\section{Open space}

Developing design of the open space.

\section{Sleeping space}

Developing design of the sleeping space.

\section{Working space}

Developing design of the working space.

\section{Building section}

Critical reflection 


\section{Open space}

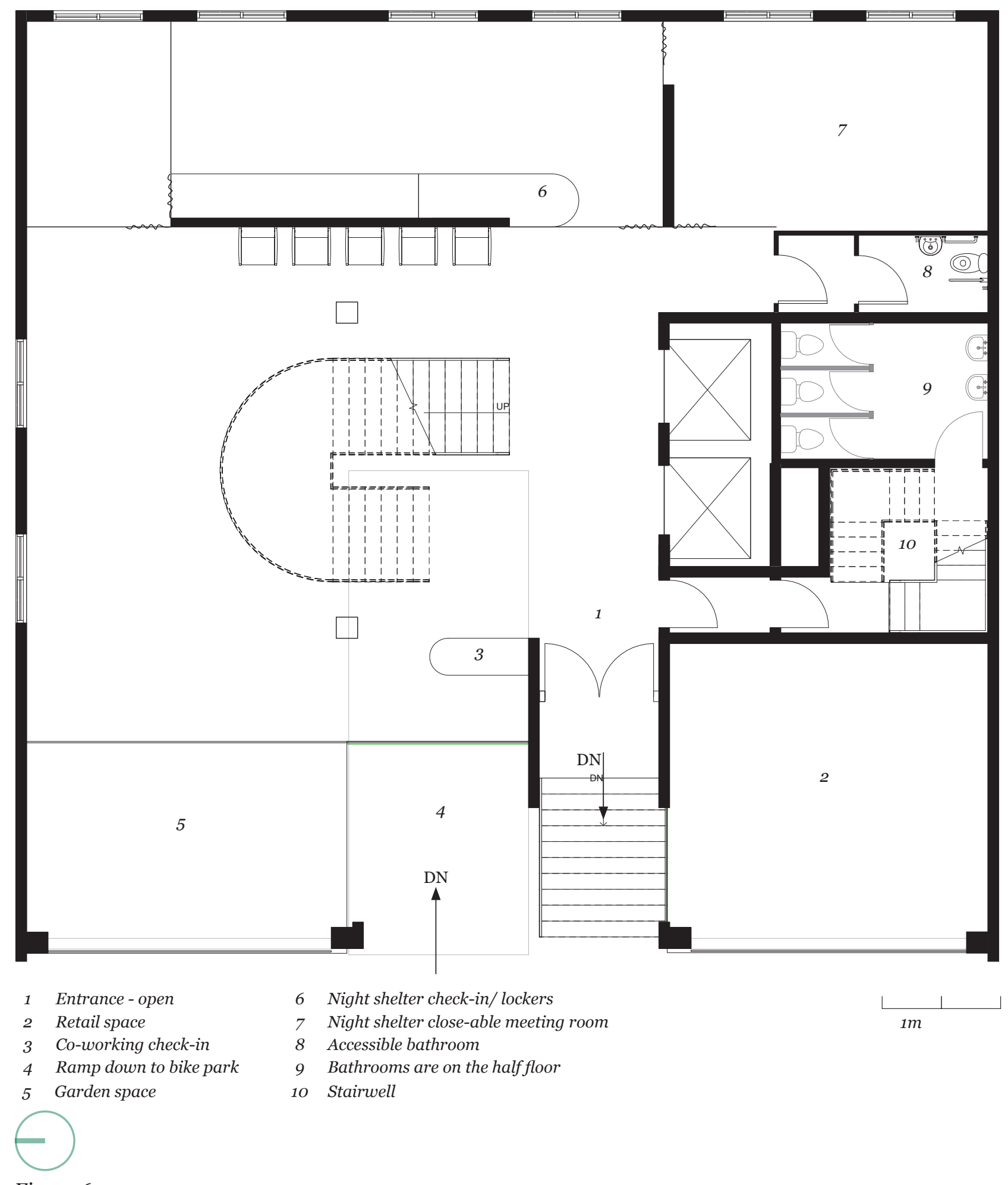

Figure 6.1

Plan view of ground floor.

Few solid walls separate the space however with the use of curtains the space 114 becomes flexible with the ability to create or remove spaces. The large central staircase connects to the first floor above. This space also has a large garden terrace (part of the original building plans). There is an accessible bathroom on this floor and other bathrooms on the halffloor 


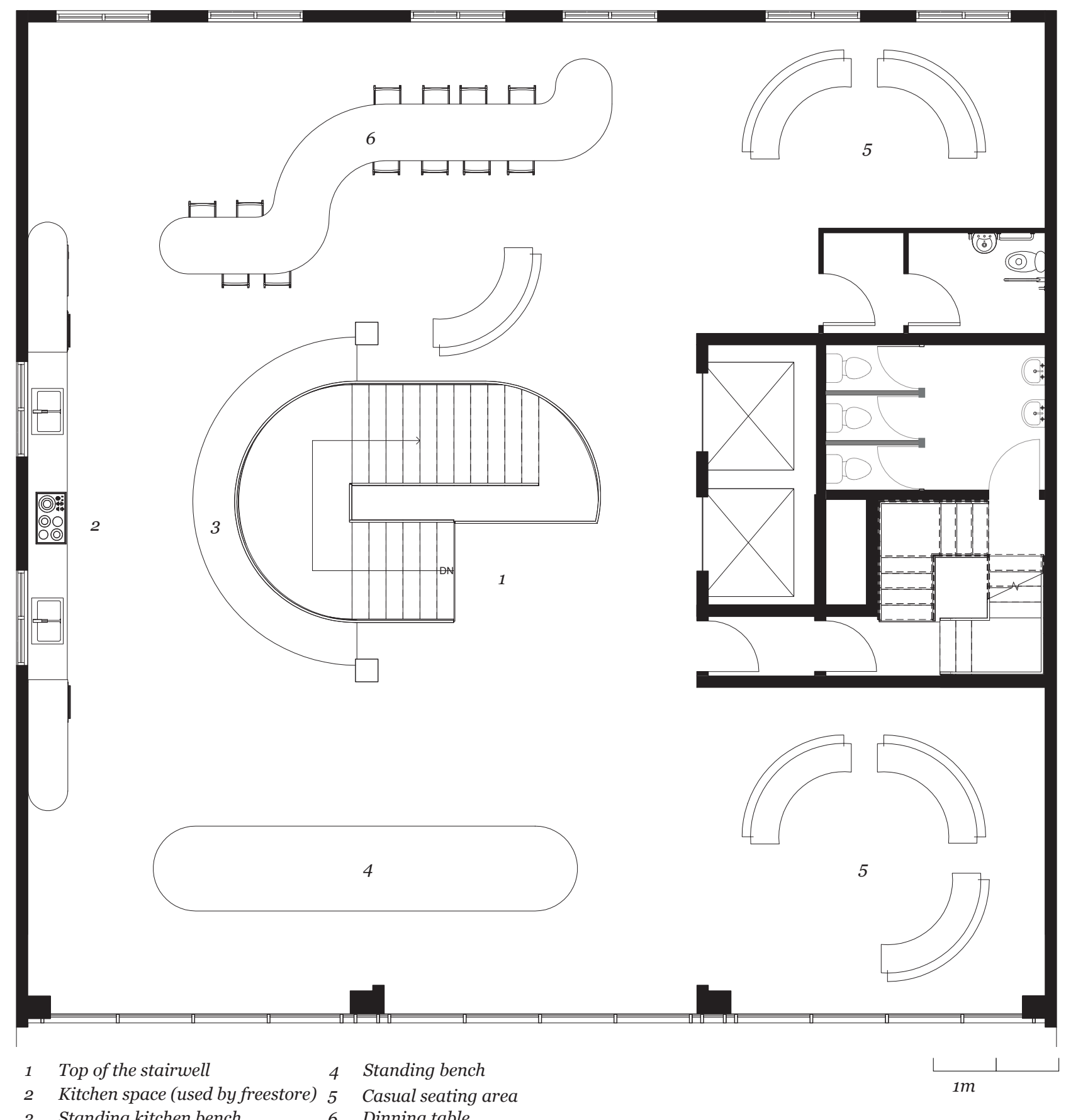

$\begin{array}{llll}2 & \text { Kitchen space (used by freestore) } & 5 & \text { Casual seating area } \\ 3 & \text { Standing kitchen bench } & 6 & \text { Dinning table }\end{array}$

Figure 6.2

Plan view of first floor.

The open space is divided by unique furniture that has a singular language to create unity in the space. At the centre is the top of the large central staircase that connects to the ground floor. There is a large kitchen and dinning area to allow the public and the free store to utilise. There is an accessible bathroom on this floor and other bathrooms on the halffloor 

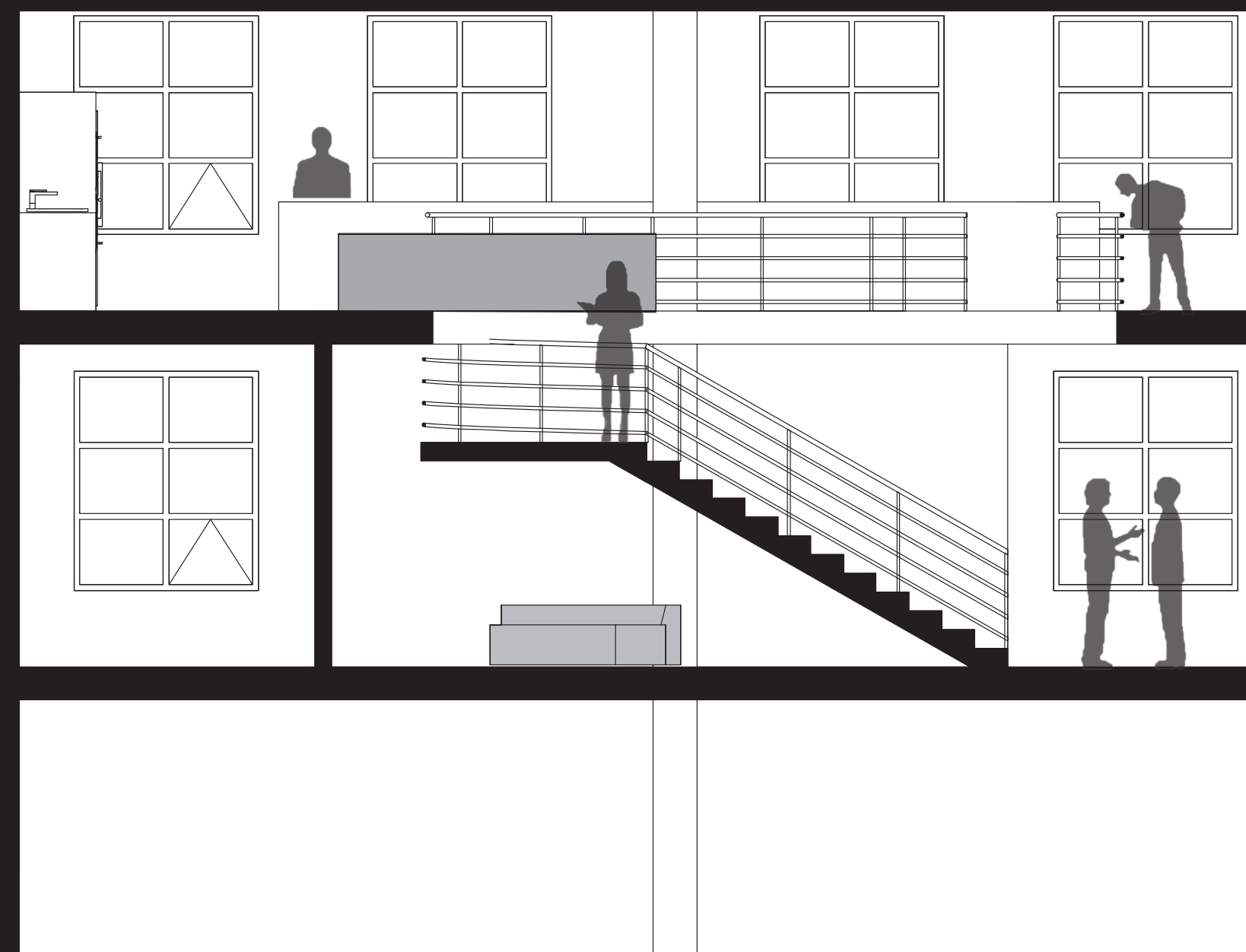

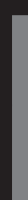

Figure 6.3

Section view of the open public space.

This section explores the open public space of the building, and explicitly the central staircase which joins the space together creating connection between the two floors. Also explored is the Bathrooms on the halffloor. 


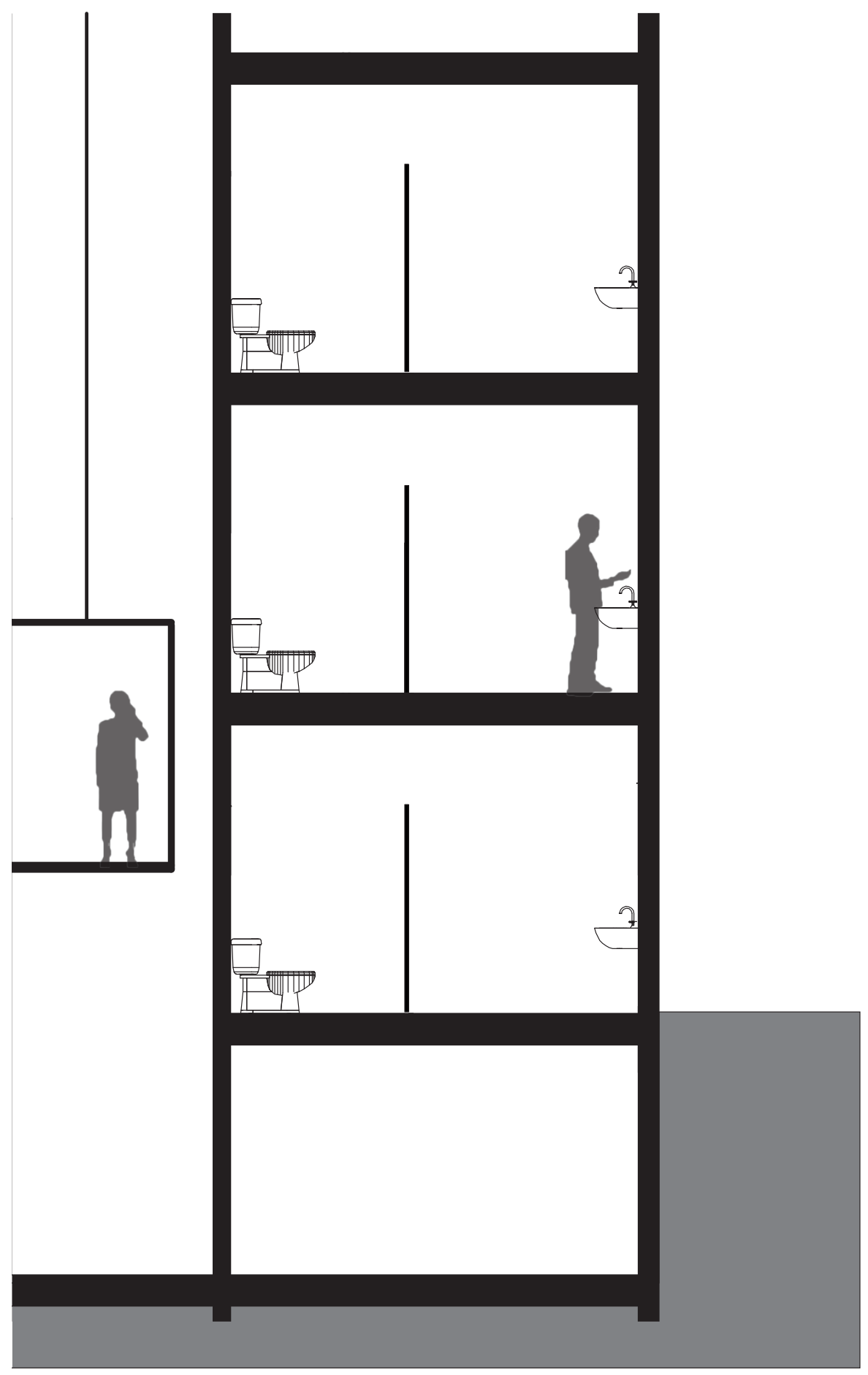



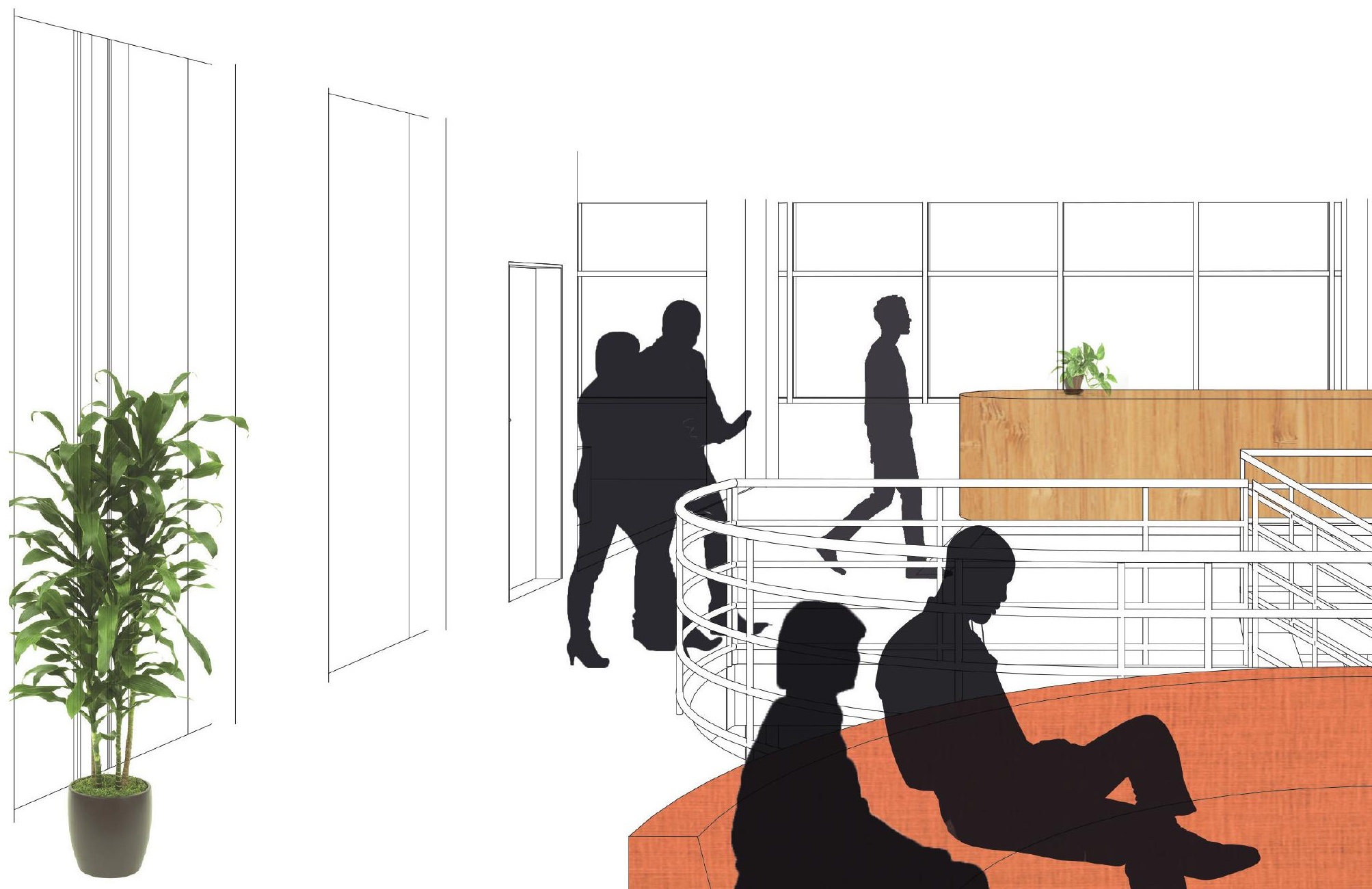

Figure 6.4

Perspective view of the first floor.

A view across the second floor, in the centre is the large connecting

staircase. In the distance is a series of tables and seating areas. On the

far right is the large kitchen used by the free store. 


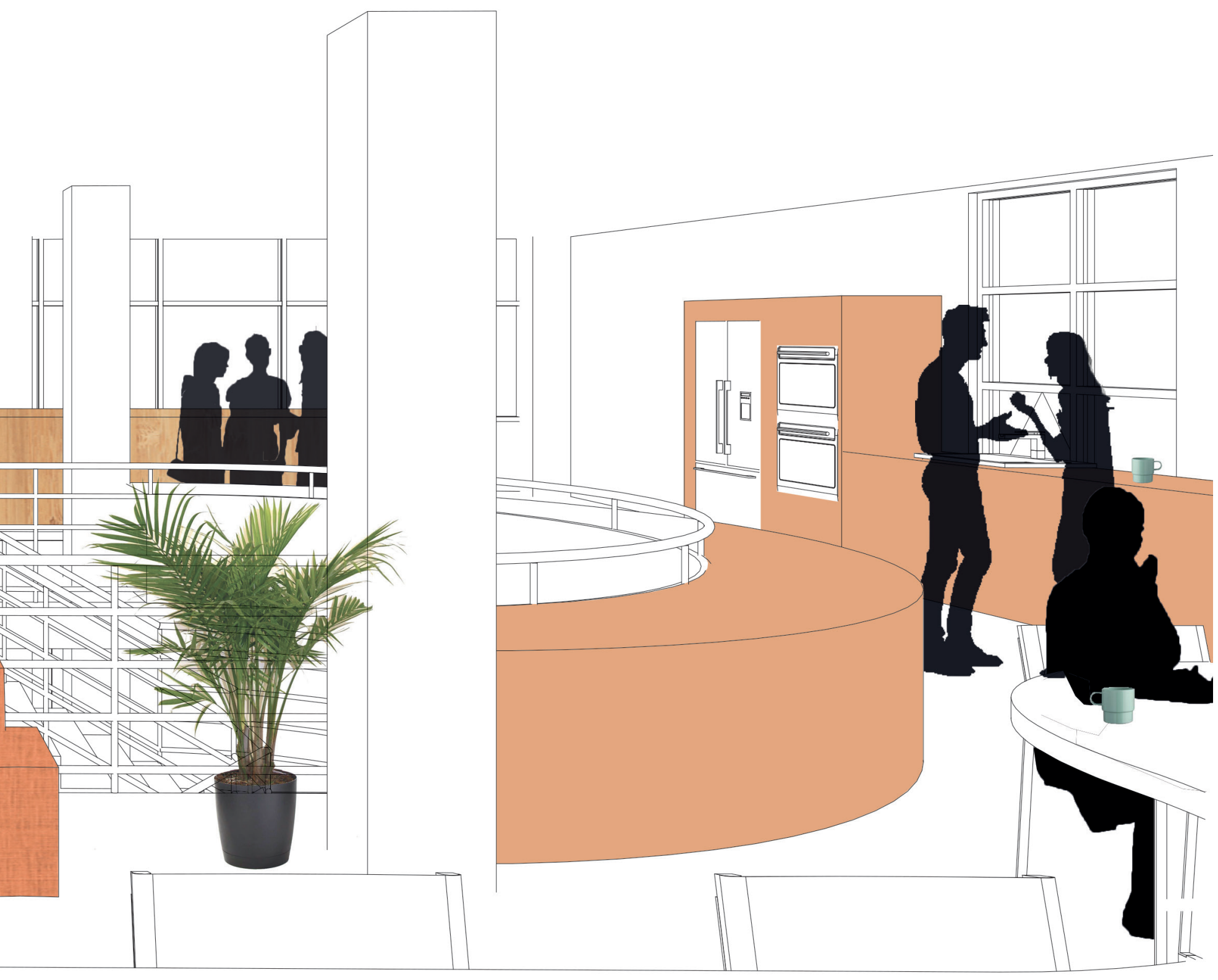




\section{Sleeping}
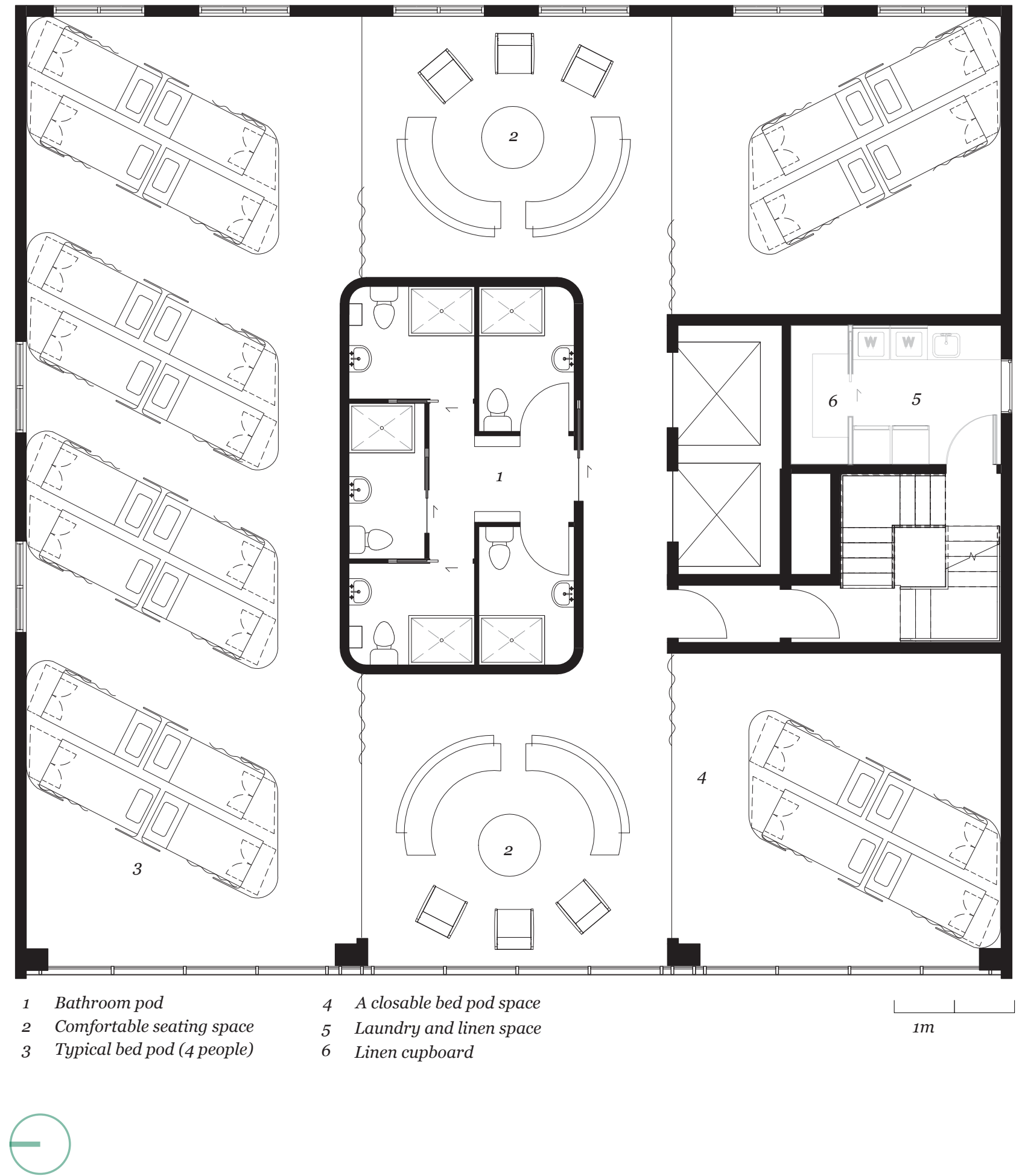

Figure 6.5

A plan view of the typical sleeping floor.

The language of the central services is repeated in the middle this time for the bathrooms. All of the language of the furniture relates to one another to create a comfortable space. The laundry space is located on the halffloor which has multiple washing machines and dryers. The space also has large linen cupboards for storage of blankets and sheets. 


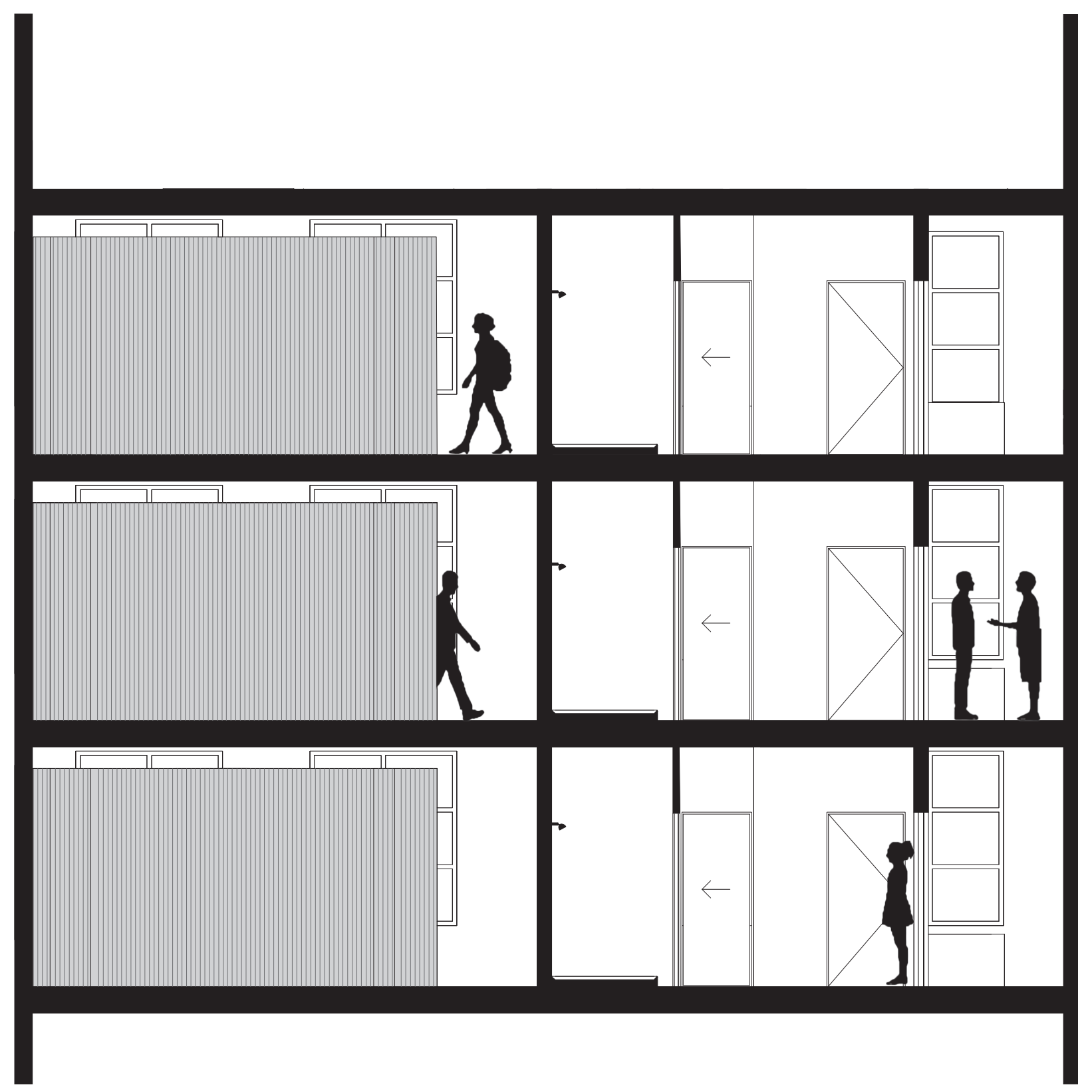

Figure 6.6

Section view of the sleeping space.

The sleeping pods create an intimate privacy and explore a similar

language of design as the central bathroom pods. The laundry rooms

on the far right have multiple washing machines and dryers. There is a large linen cupboard to store blankets and sheets for the sleeping space. 


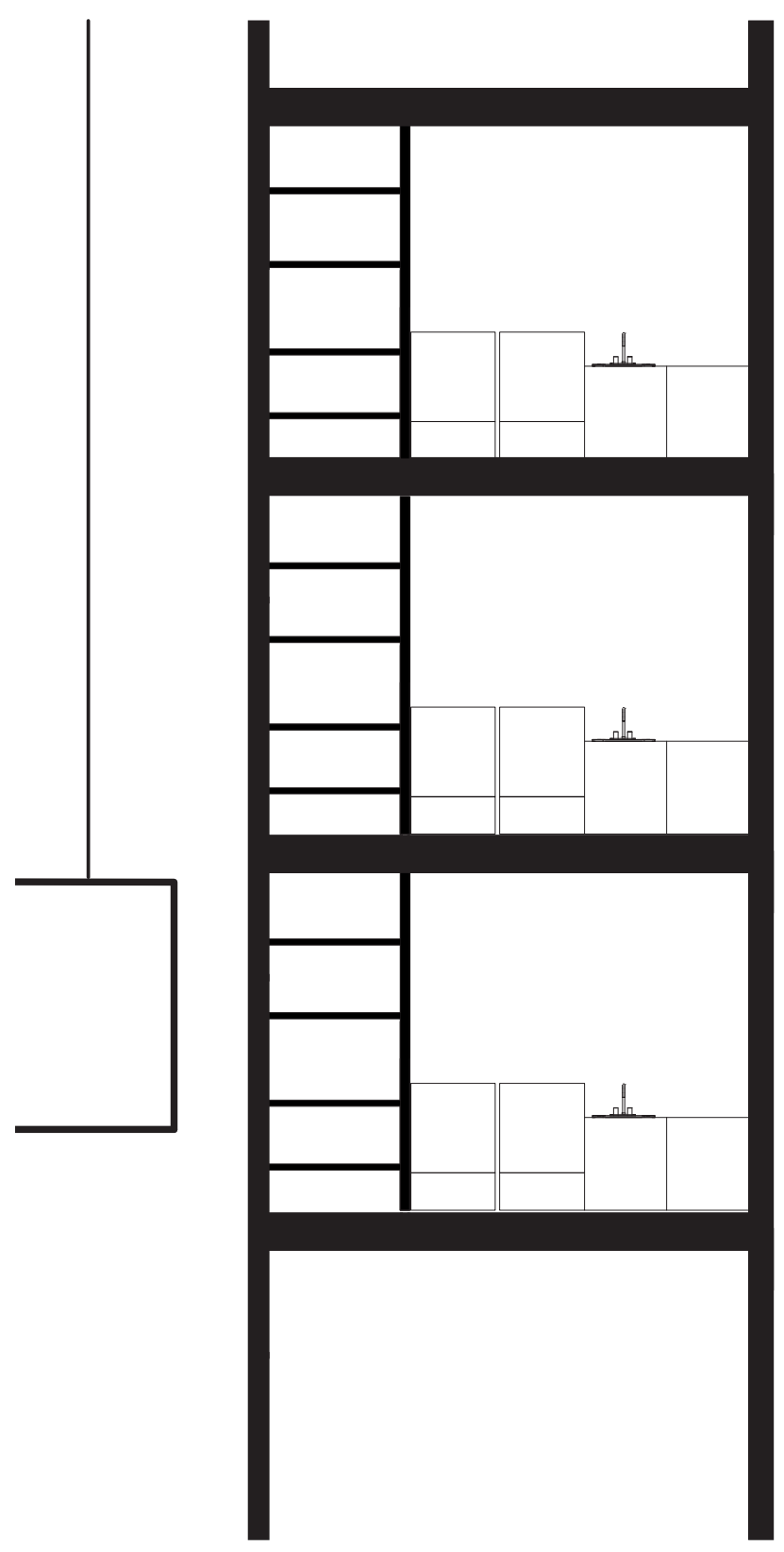




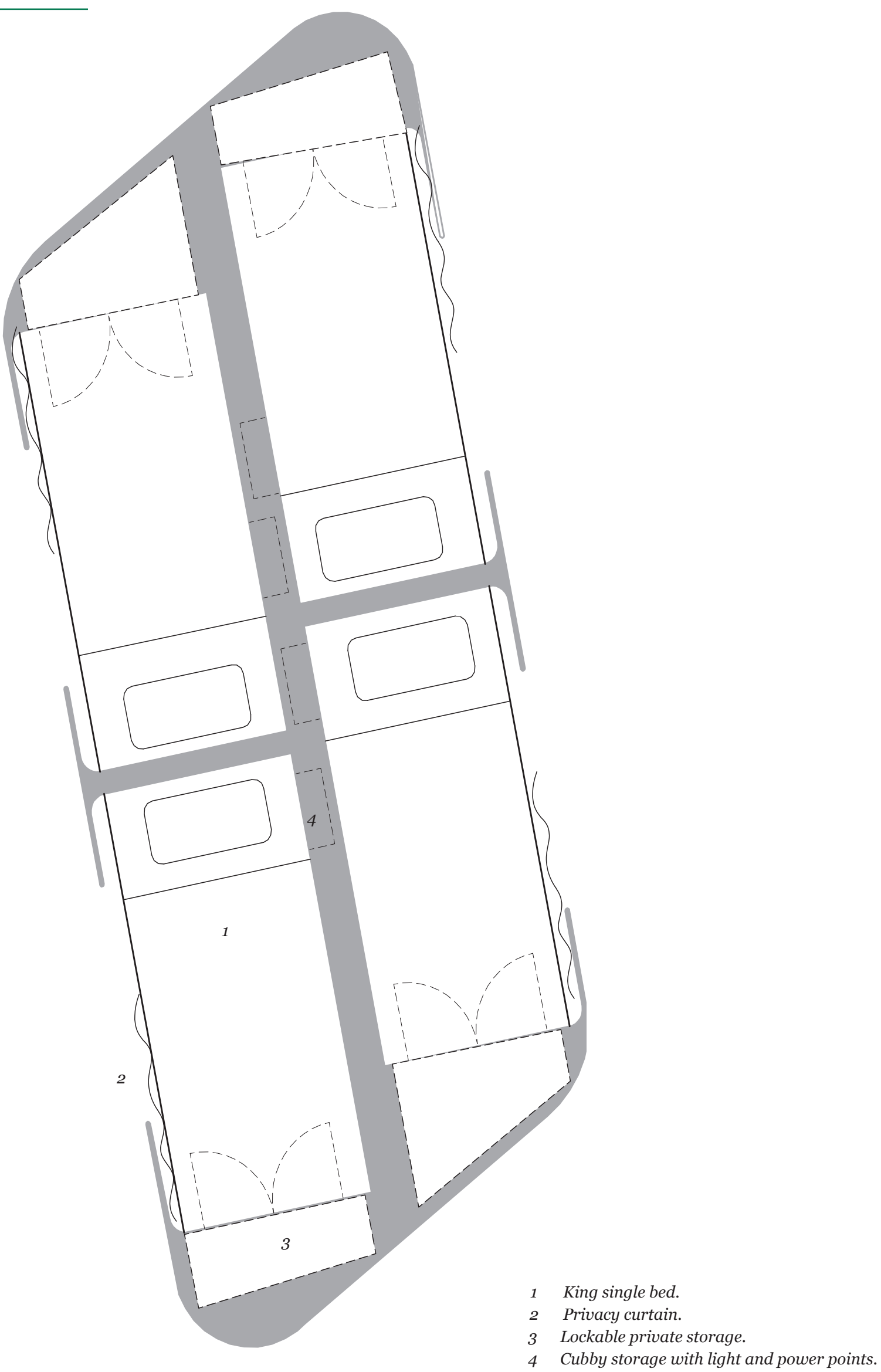

Figure 6.7

A detailed plan of the sleeping pods.

The plan explores the sleeping pods which are divided into four individual, private sleeping spaces. Within each space there is a heavy curtain for privacy, a large storage cupboard for belongings and a small cubby hole with plugs. Each bed is a kind single and has ventilation bellow to air out during the day. 


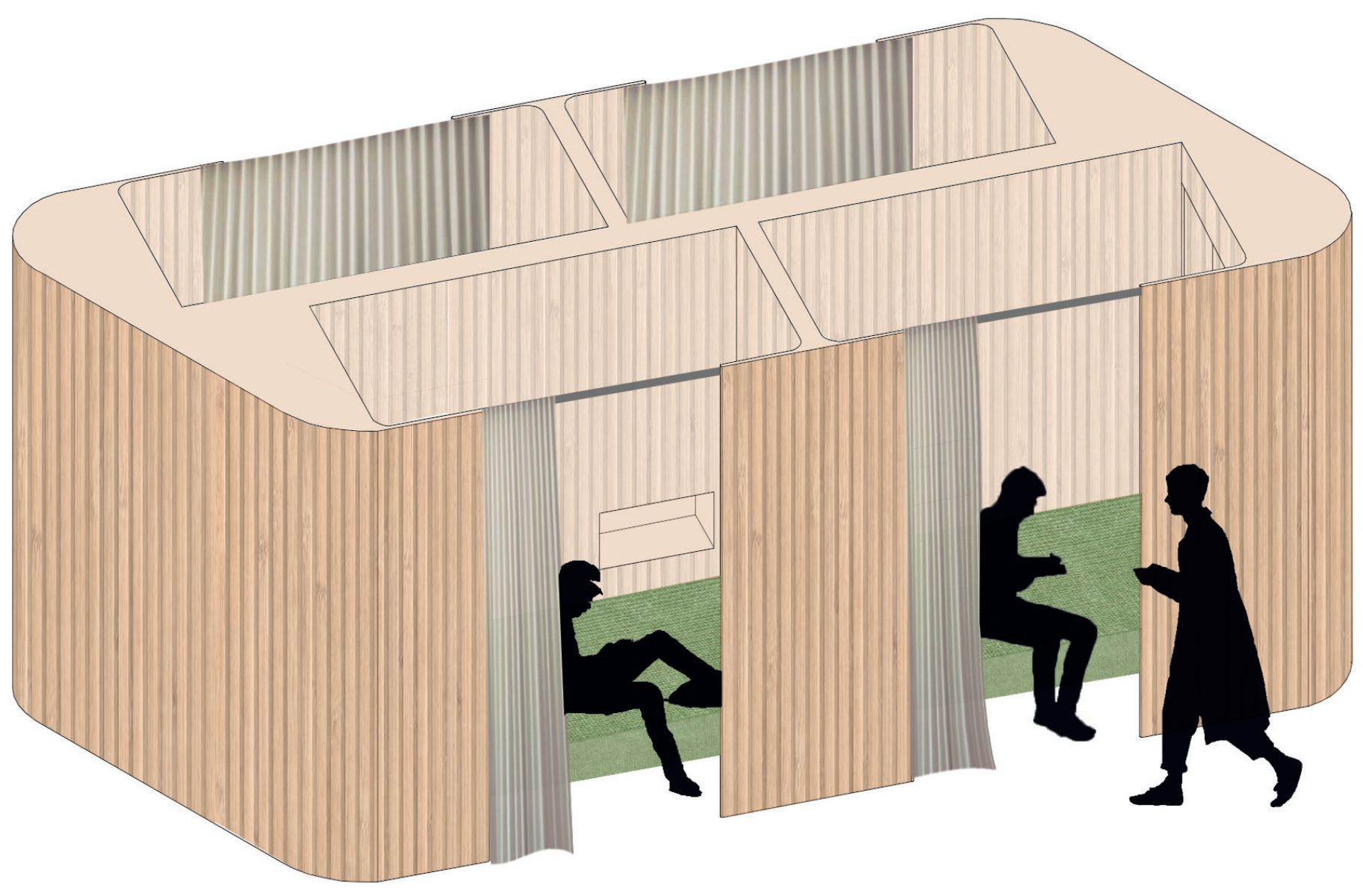

Figure 6.8

An axon-metric view of the sleeping pod.

The use of bamboo slats as a material that can wrap around the curves of the pods was reflective of the use of heavy curtains to allow privacy for those with the space. 


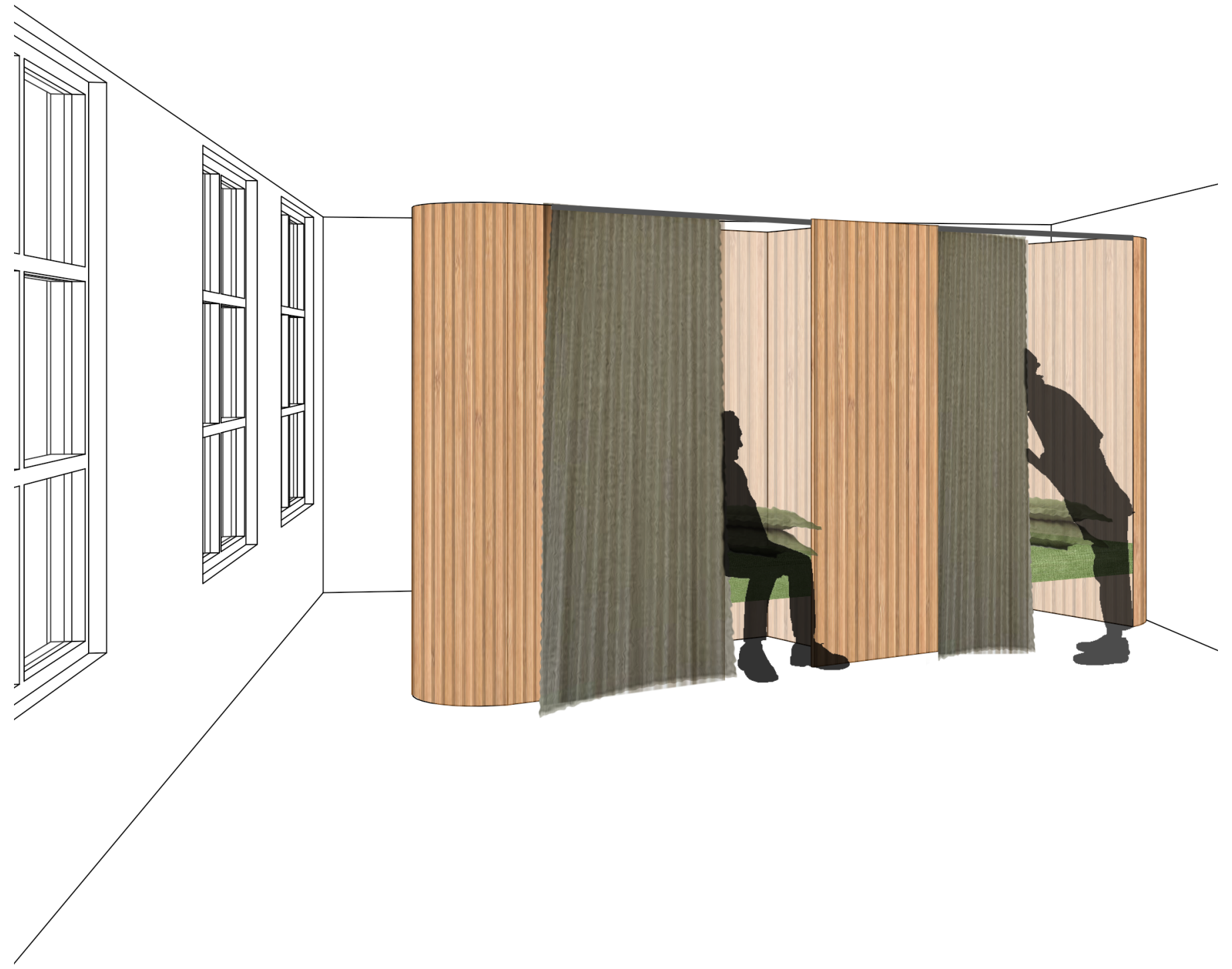

Figure 6.9

A perspective view of the bed pods within the sleeping floors.

Exploring the levels of privacy and connection the pods allow people to have to on another and to the wider space. 

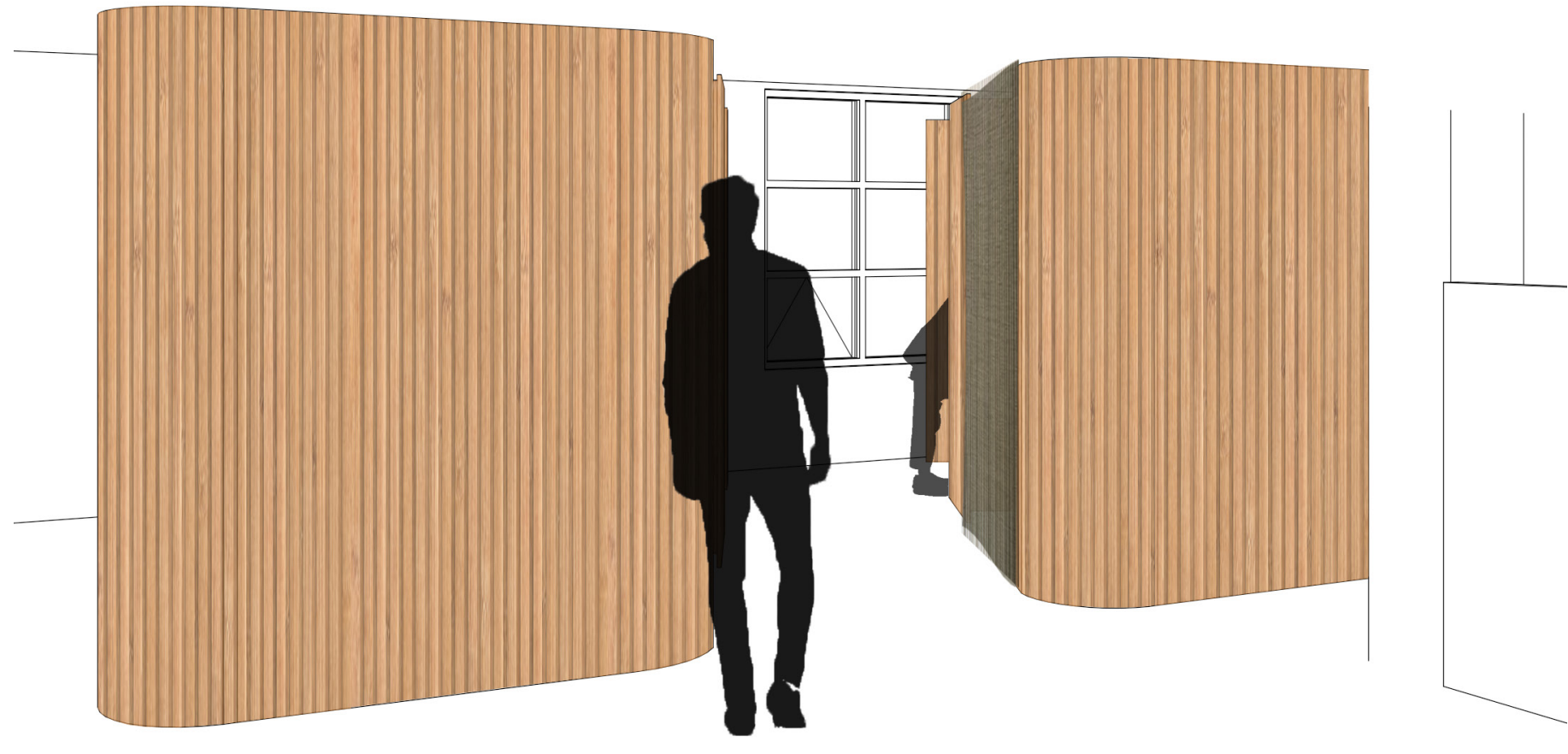

Figure 6.10

A view of the aisle between the bed pods.

Exploring the connection between pods and the level of privacy you are able to still have. 
Working:

Open

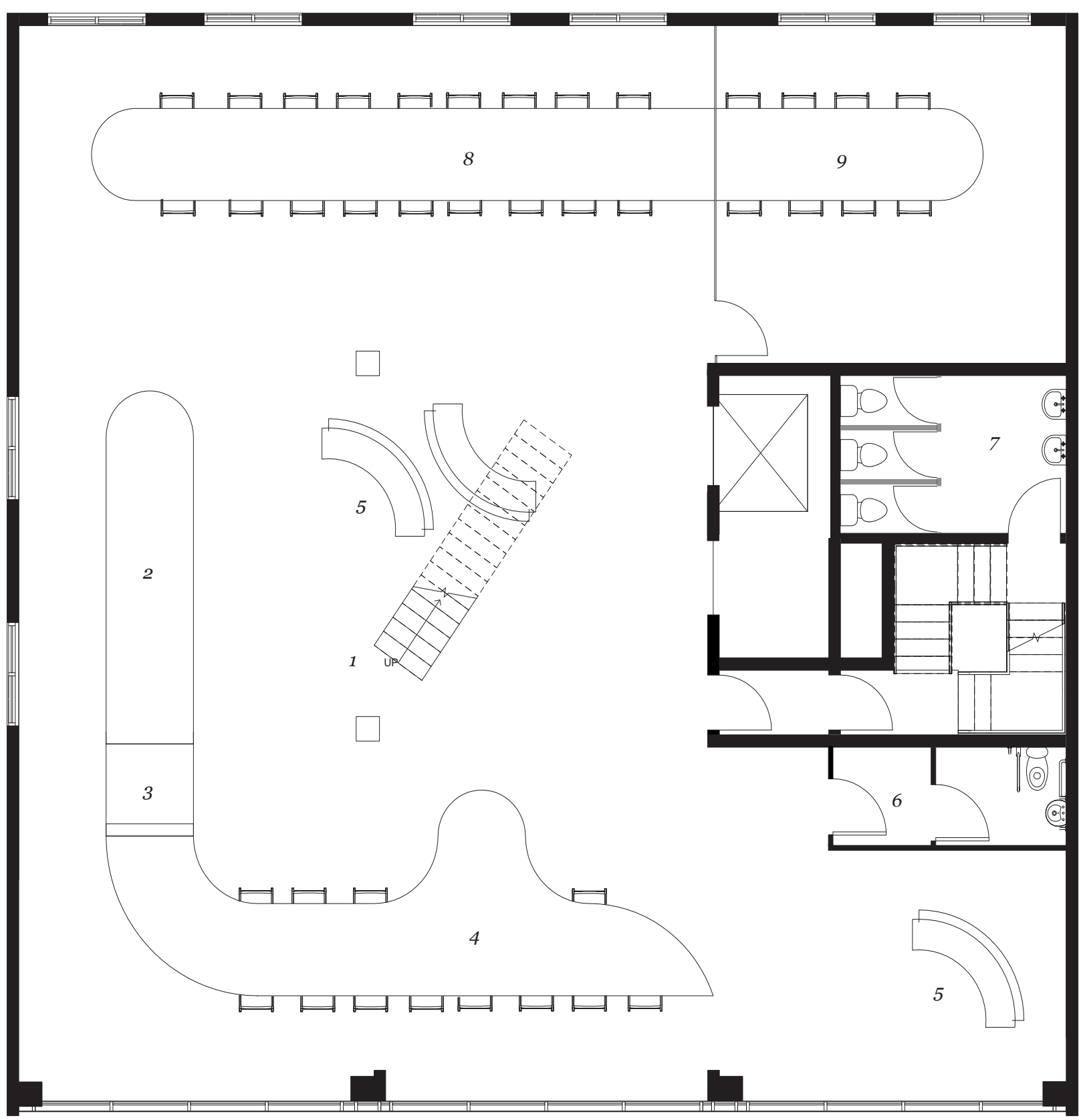

\section{Central connecting staircase} Standing desk

Sitting desk

A closable bed pod space

5 Casual seating area
6 Accessible Bathroom

7 Bathroom on the halffloor

8 Communal working desk

9 Meeting room/desk

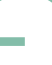

Figure 6.11

A plan view of the 6th floor that connects to the 7 th through a central staircase. This floor is used for working away from the individual desk.

There are many different areas to work including a large table that blends into a meeting room through the use of a glass wall for sound privacy. 

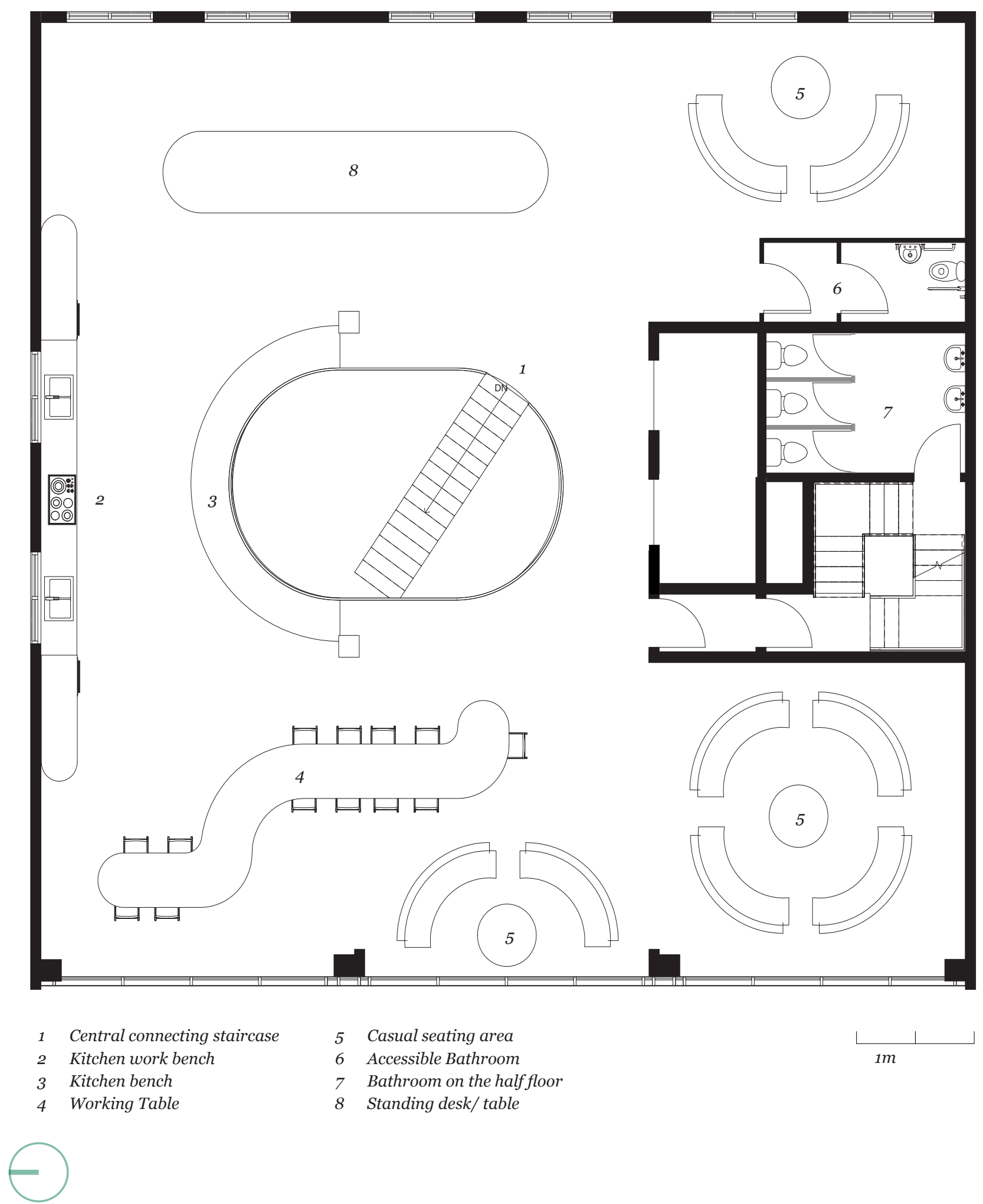

Figure 6.12

A plan view of the 7 th floor that connects to the 6th floor through a central staircase. This floor has the co-working kitchen and eating area on it. There are many area for casual conversation and meetings. 


\section{Working: \\ Quiet}

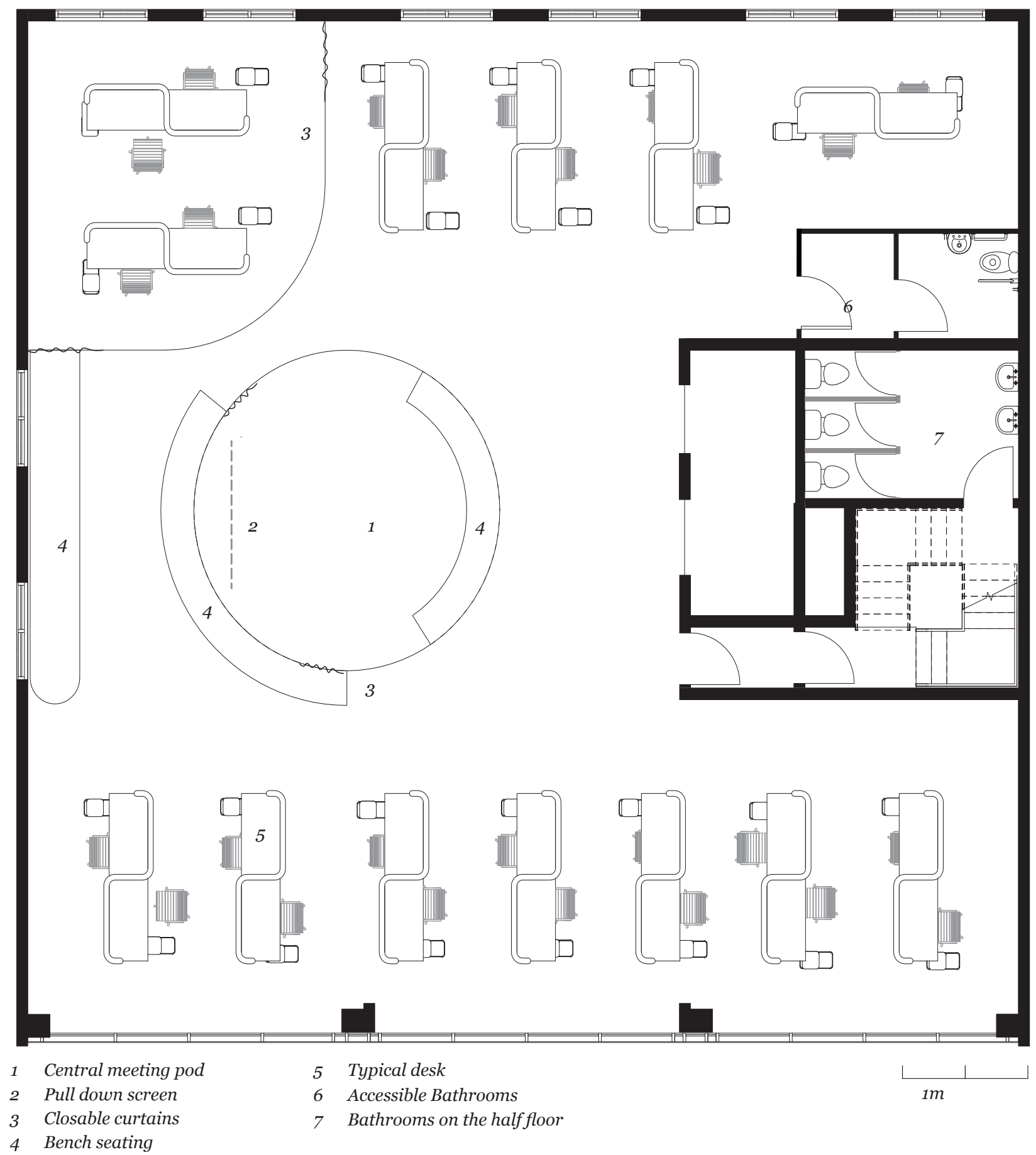

\section{Figure 6.13}

A plan view of working floors 8 and 10.

On this floor at the centre is a large circular arena that can be open or

$130 \quad$ closed off with the use of curtains, a large pull down screen can be used for presentations. Each desk has it's own moveable storage pod that includes a seat on the top. 

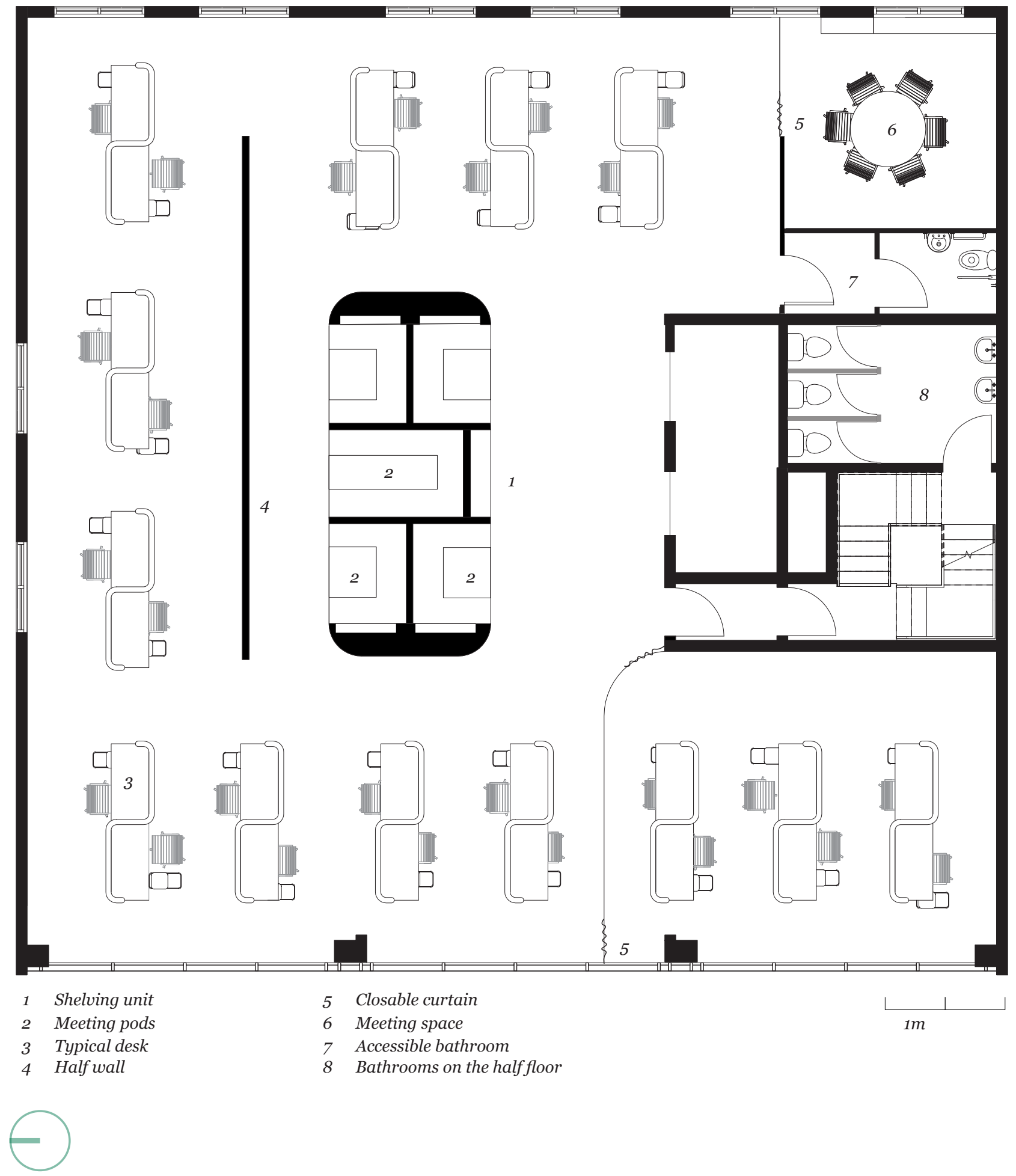

Figure 6.14

A plan view of the typical working floors 9 and 11.

A large unit at the centre houses 5 small meeting pods for group work and interaction. There is a half wall between the meeting unit and desks as a sort off privacy buffer. Through the use of curtains particular desks can be shut off for private work. 

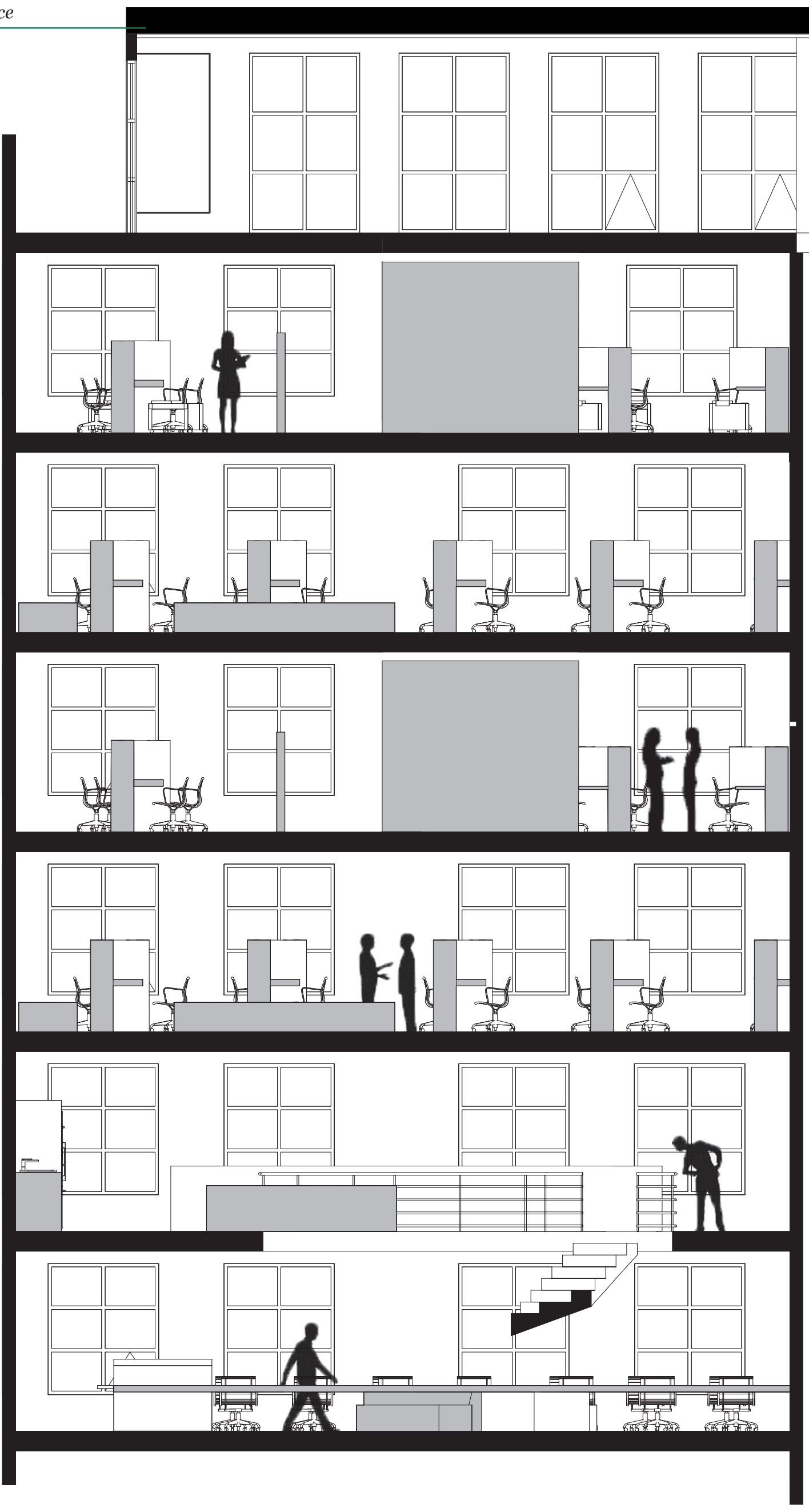


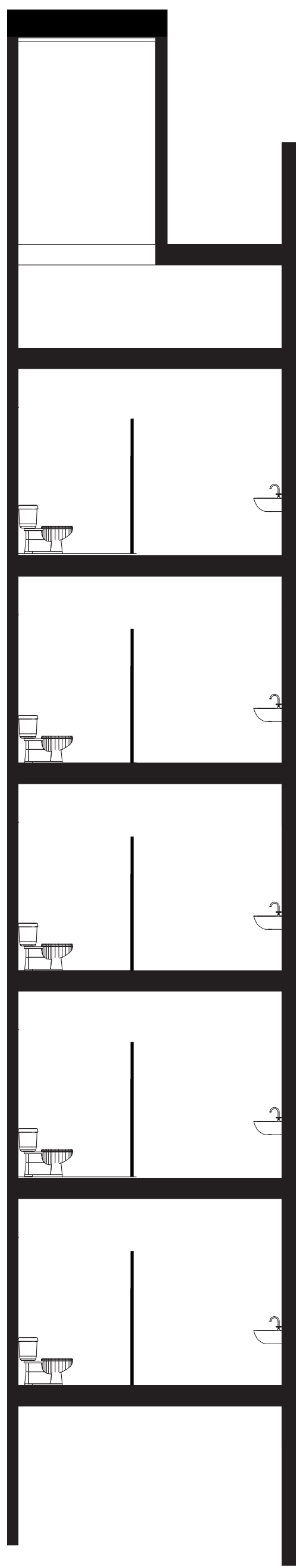

Figure 6.15

A section view of the working floors.

Through this section the connection between floors 6 and 7 is

understood, allowing a connection between noisy floors. The next 4 floors are for focused work and meetings. 


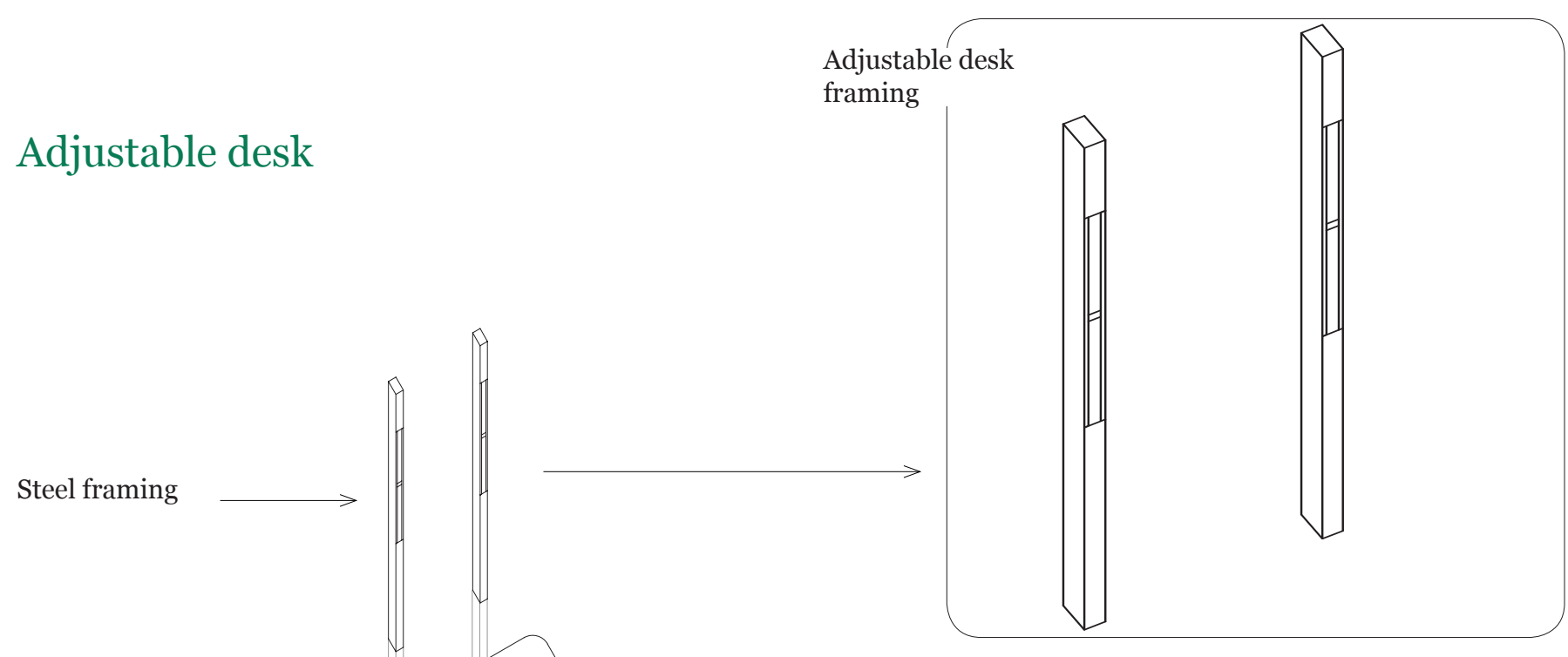

Desk top: Laminated

bamboo

Desk top: Laminated

bamboo

Timber framing
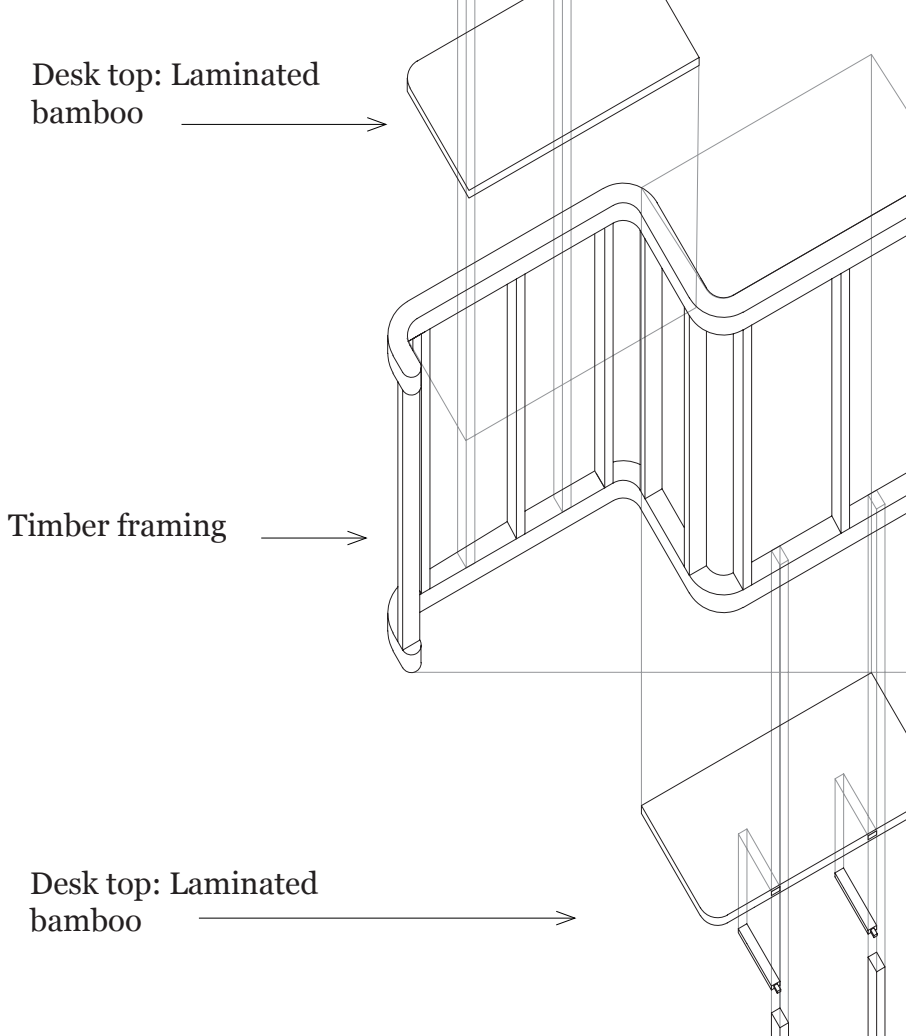

Steel framing

Cork backed onto plywood 


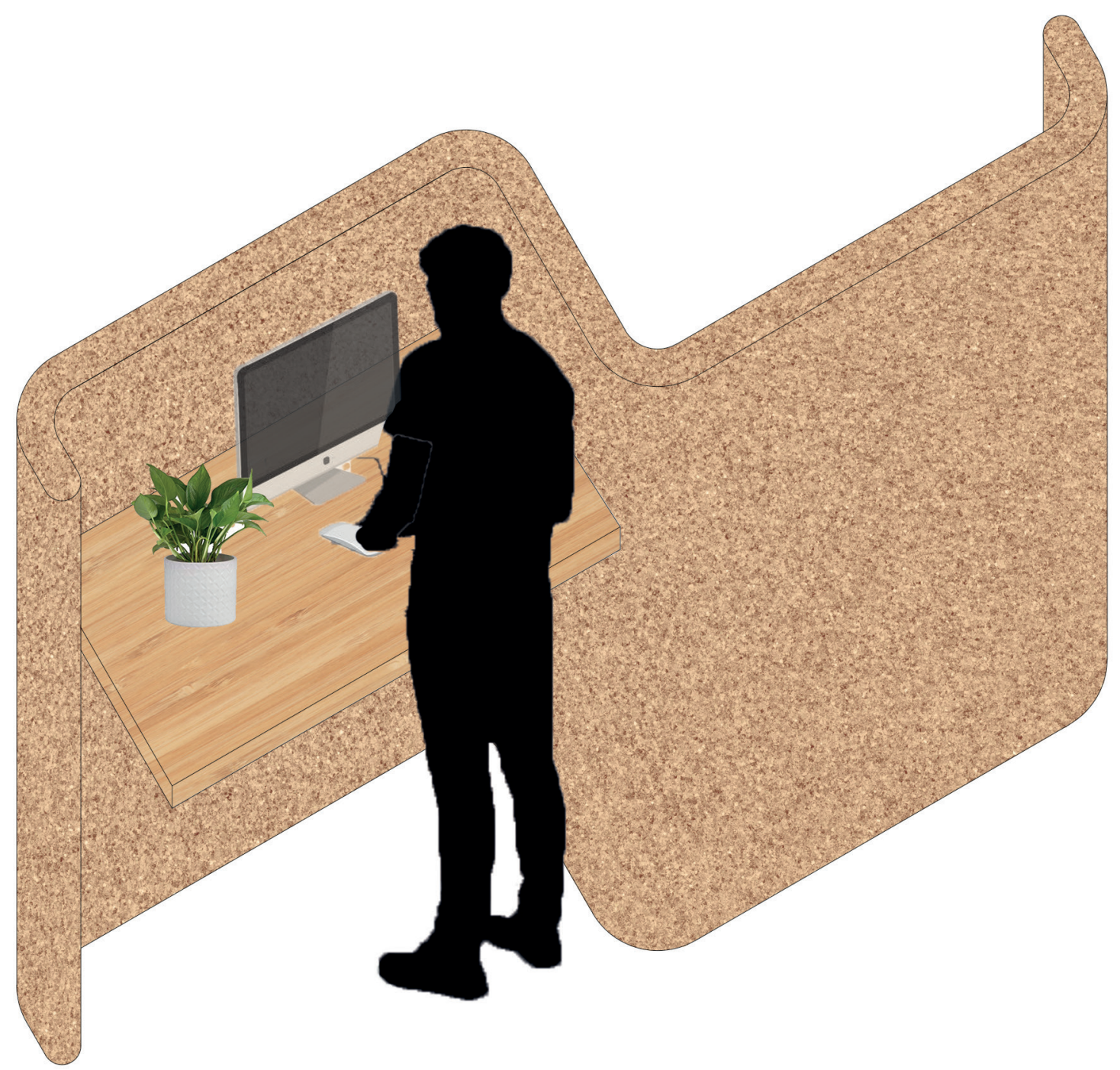

Figure 6.17

A view of the desk pod. The pod has the ability to move up and down to create a sitting or standing desk. 


\section{Working: Open}

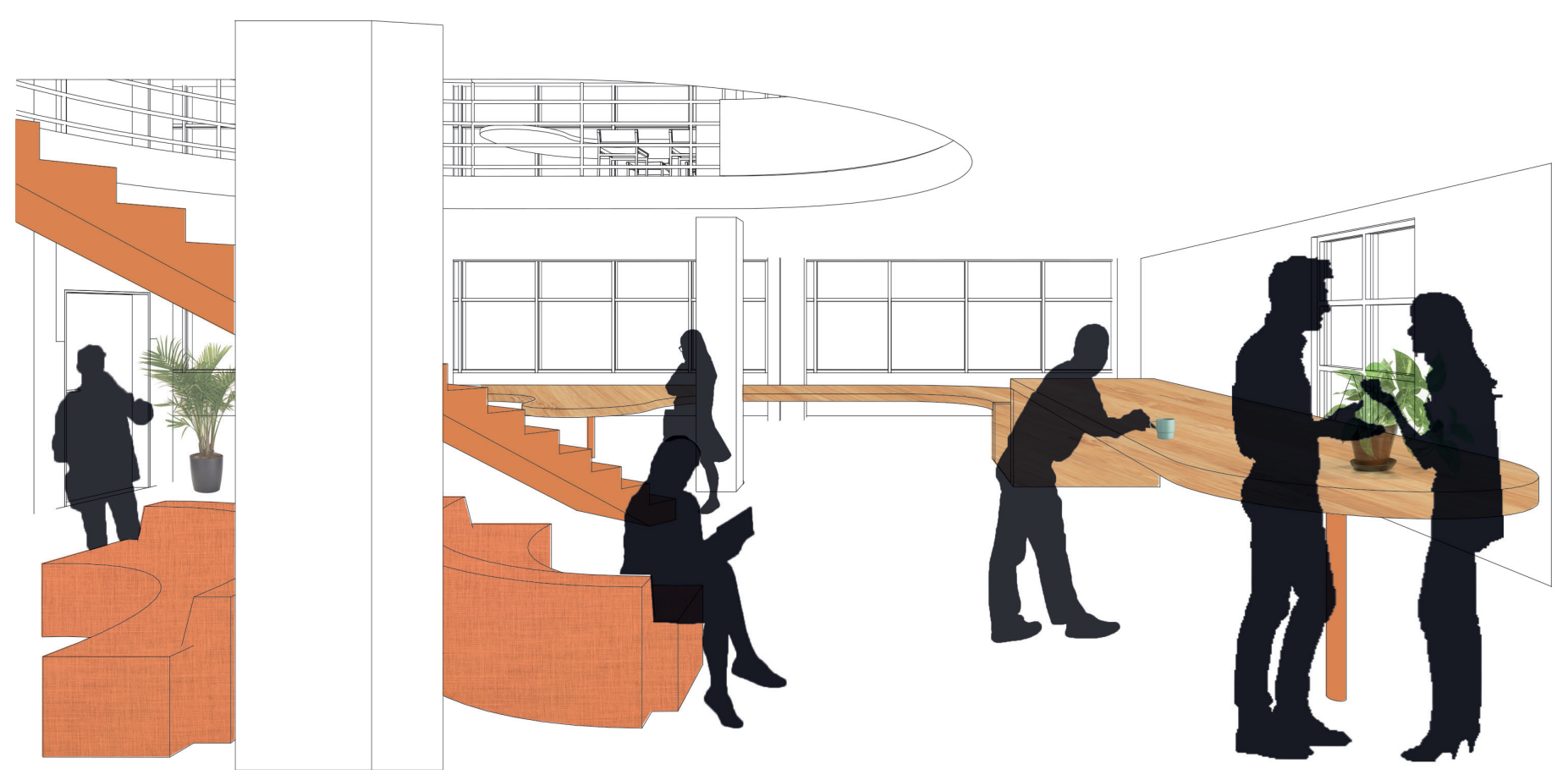

Figure 6.18

A view of the 6th floor, showing the large table unit that flows from a standing desk to a sitting desk throughout the space. There are also informal couches placed around for a more relaxed seat. The staircase is prominent in the space connecting to the floor above. 


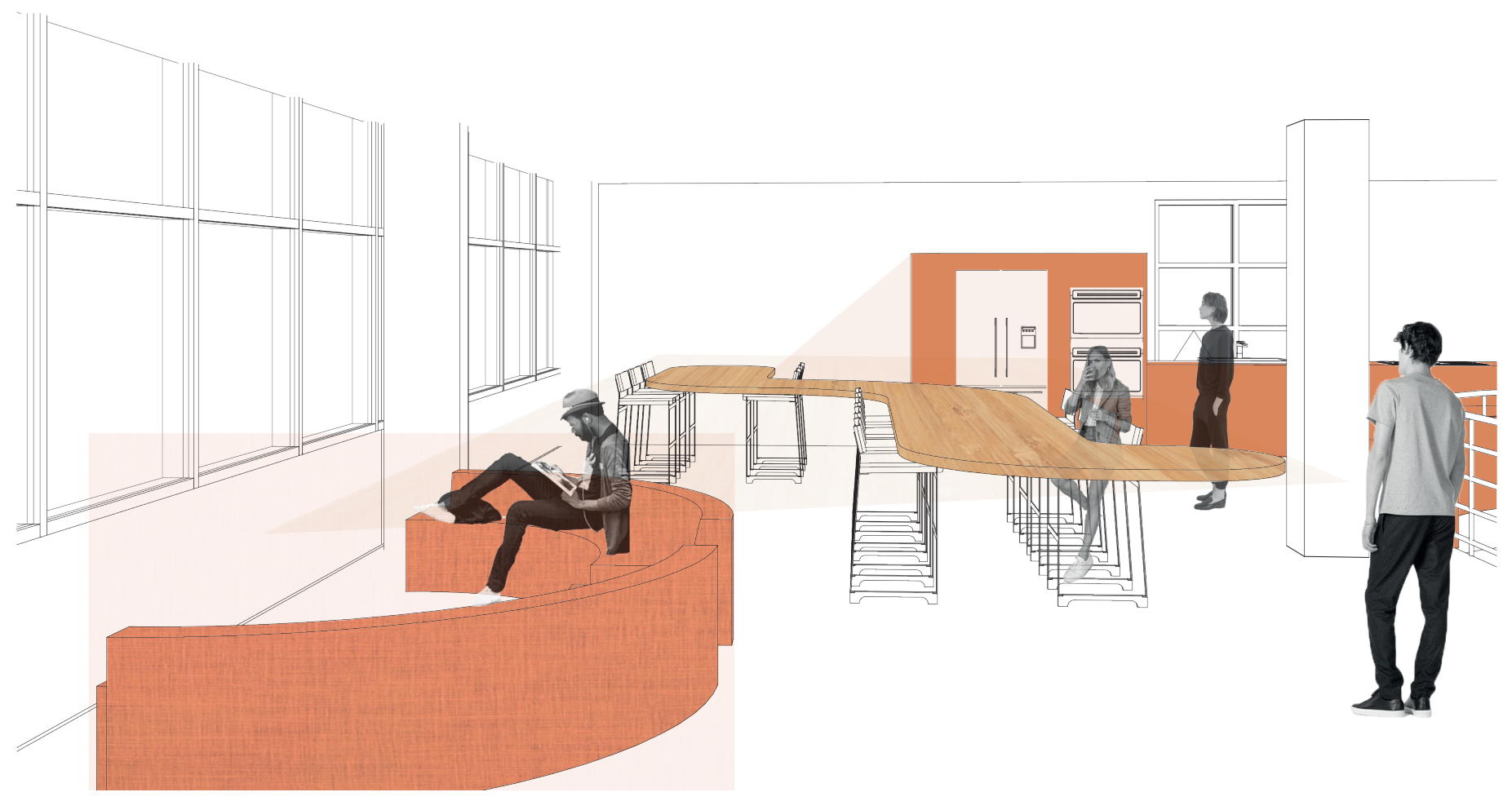

Figure 6.19

A view of the 7 th floor, showing the large open kitchen and adjoining dining tables and more casual couch seating areas. 


\section{Working: Quiet}

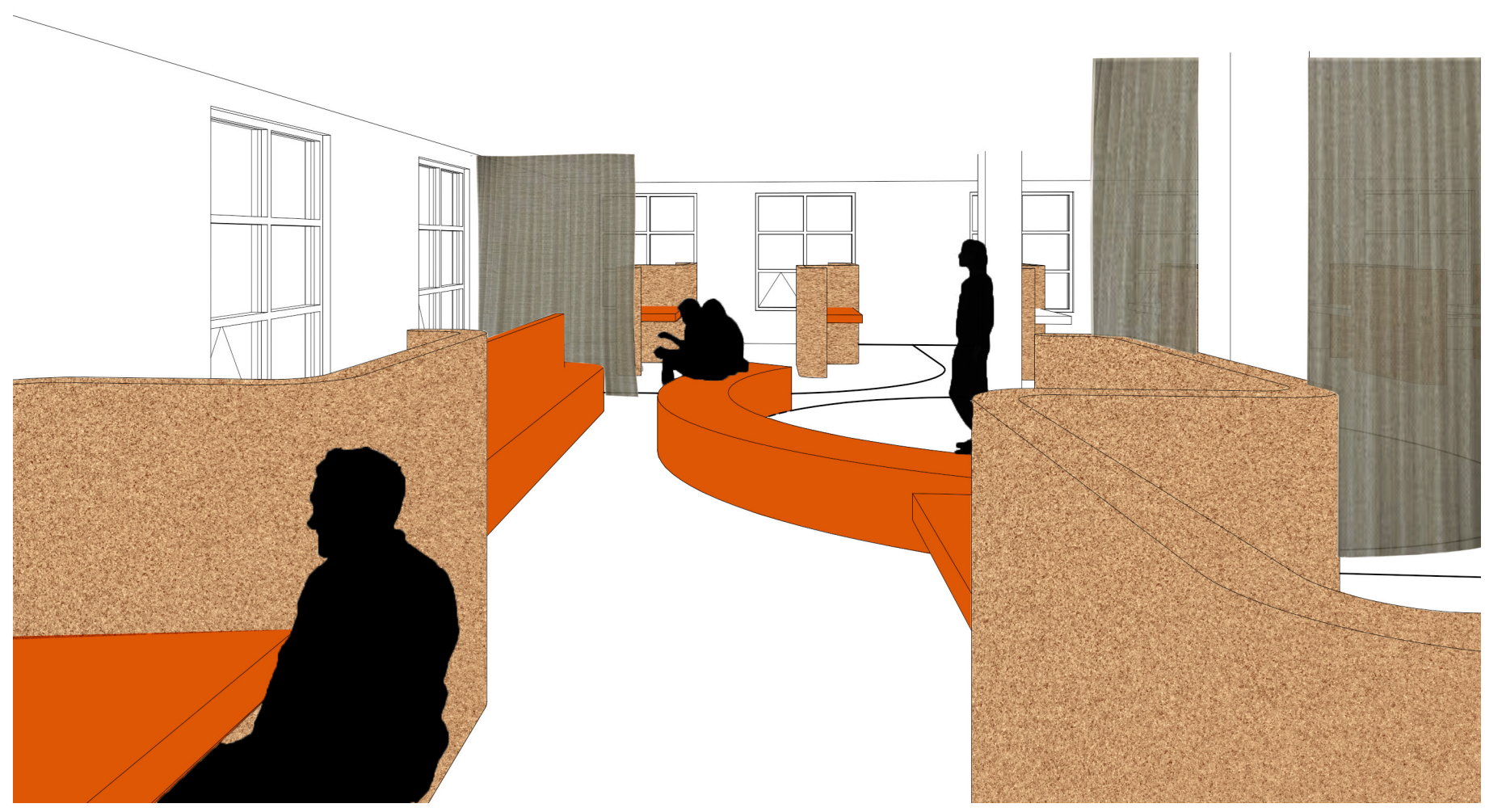

Figure 6.20

A view of the typical working floors 8 and 10 .

The large meeting arena is visible in the background, with a close up of the working desk in the foreground. 


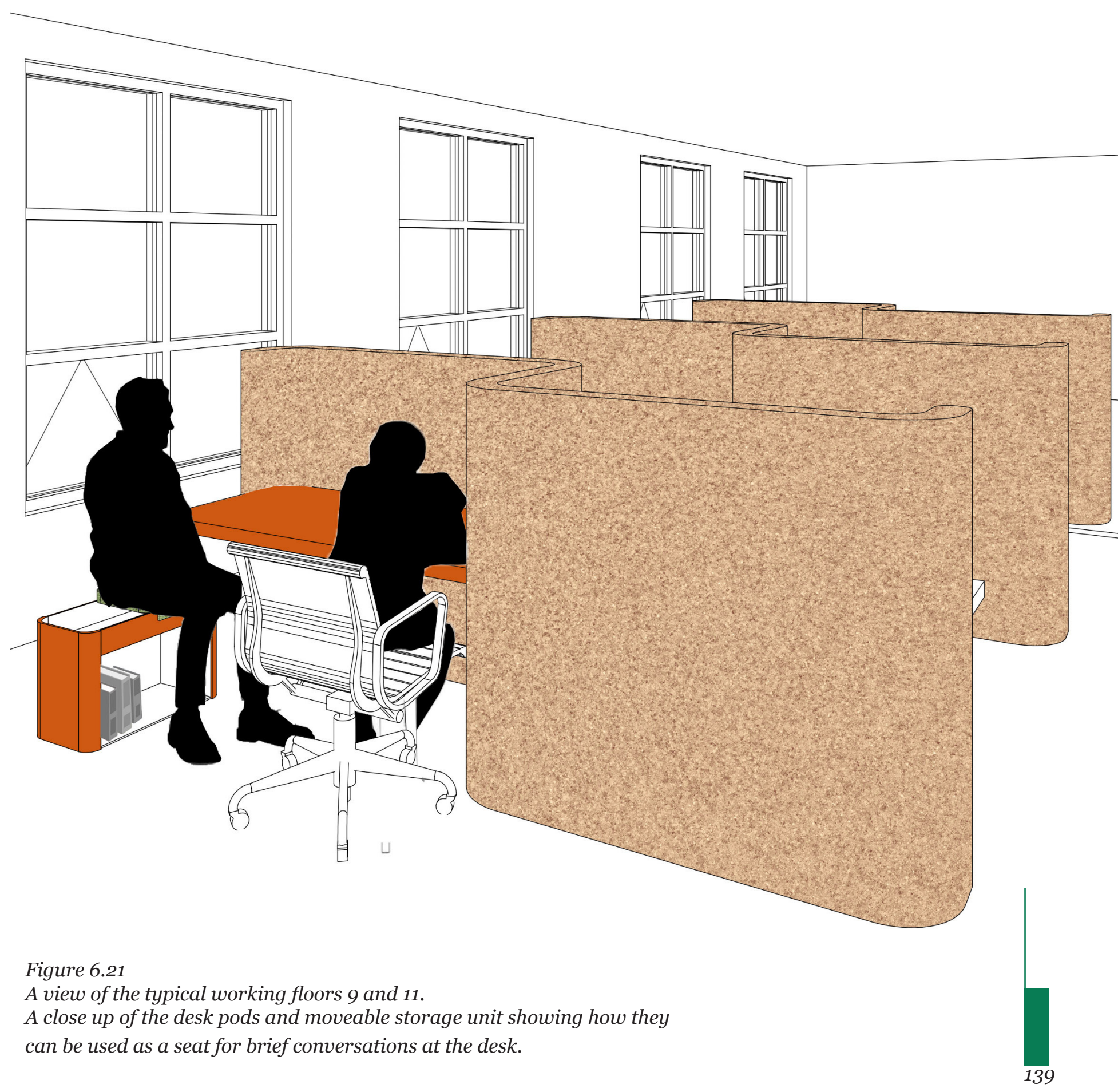




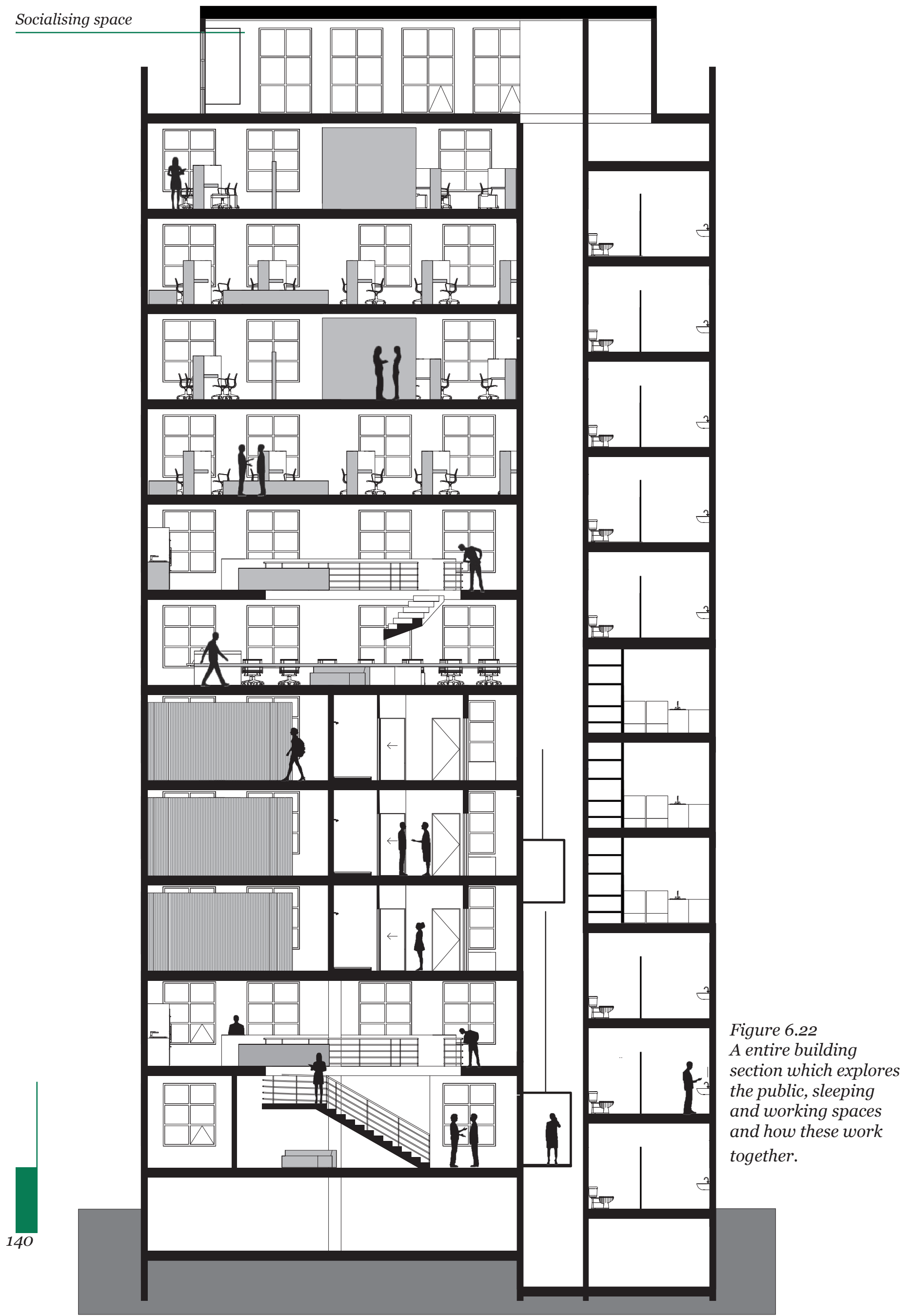


Through the use of cross-programming,

the building now

works along a 24 hour

timespan. Housing

a co-working office,

community space and

a night shelter, the

building models a more

efficient use of office

space within our central

cities. A focus on the

individual allows a

meaningful connection

to the space and to

others through parallel

design interventions that

operate as desks and as

sleeping pods. 


\section{Critical Reflection}

The use of a specific site was useful in the development of the potential of the flexible workspace. It also allowed an interesting exploration of cross-programming through the use of sectional relationships to reconfigure existing and new programmes. 181 Willis Street has 11 levels that are connected through a central core with half floors. Exploiting cross-programming vertically, the building was split into three zones: open public space, the night shelter, and the co-working office space. The use of cutouts between the ground and first floor, and the sixth and seventh floor was successful in creating a connection between floors. This allowed the spaces to open and expand beyond the normal building constraints. The union of spaces was limited to only certain floors to ensure privacy on the sleeping floors and some quiet working floors.
Privacy and security were important to initiate in the night shelter space to ensure the safety of those in a vulnerable position. These three floors are the most private; as you exit from the elevator you are greeted by the bathroom pod which has a similar language to the shape and size of the sleeping pods. The sleeping pods were successful in creating an intimate private space for each person in need. Each pod contained useful storage and heavy curtains to ensure a meaningful connection to the space.

Within the office-oriented floors, the use of parallel furniture and tables was successful in creating unique identities for the floors and therefore for the people on each floor, successfully to ensuring a level of personalisation for the individual.

The cross-programme of the office space, a night shelter, and an open public floor creates a space that continues to work over a 24 hour timespan, ensuring efficient use of space in our centre cities. The use of a cohesive language of furniture throughout added to the feeling of unity between the three key programmes within the building. This was also highlighted through the consistent use of materials such as cork, bamboo and linen. The use of flexibility and cross-programming between each level is unique and thoughtful and allows each individual a meaningful connection to the space. 


$$
7
$$


Conclusion 


\section{Conclusion}

This research study began with the question of non-territorial offices and the lack of personalisation they create for those working within them. Recent studies critique the trend of non-territorial offices which inherently remove the ability to personalise a space. This limitation has serious ramifications for the employees of these spaces (Elsbach, 2003 and Voordt, 2004). From the understanding of the need for personalisation, the idea of flexibility was identified as an important area to explore.

This was explored through an understanding of the history of offices, an in-depth literature review of flexibility and personalization within office spaces, and a study of the proxemics of the office. This literature review lead to a series of tests exploring visual, physical and environmental factors affecting people in the office. This research prompted a new understanding of what flexibility is and how it may be extended within an office environment, beyond traditional office functions.
Flexibility through this study was identified as a building having the ability to morph and change depending on the needs of the users throughout the course of a day, a week, a month, or a year. The ability for a space to begin to anticipate the needs of those inhabiting it is incredibly useful. The idea of flexibility also promoted research into crossprogramming to understand how to more successfully utilise the space within our central cities. The use of Tschumi's (2012) idea of crossprogramming brought a level of complexity to the final design that elevated the use of flexible design throughout the spaces.

These ideas were further tested within a specific site, a midtwentieth century office building located in Willis Street, Wellington. Cross-programming was used in order to create a building that successfully works along a 24 hours timespan, incorporating public space, a night shelter, and a co-working office. The various functions within the building are connected through a similar language of furniture and materials to create a cohesive flexible building. Openness and privacy are utilized throughout the building to allow privacy and security in the night shelter and a balance of open and focused working space within the co-working office. 


\section{Bibliography}

Brunia, S., \& Hartjes-Gosselink, A. (2009). Personalization in non-territorial offices: A study of a human need. Journal of Corporate Real Estate, 11(3), 169182.

Caruso St Joan Architects. (2017). A Short History of the Development of the Office Explained in Terms of the Economic and Social Context of the Last 100 Years. In The office on the grass: The evolution of the workplace / edited by Javier Mozas, Aurora Per Fernández ; edition by Caruso St. John Architects. Vitoria-Gasteiz: A + T.

Eggler, M. (2009). Divide and Conquer: Ludwig Mies van der Rohe and Lilly Reich's Fabric Partitions at the Tugendhat House. Studies in the Decorative Arts, 16(2), 66-9o. https://doi.org/10.1086/652505

Elsbach, K. D. (2003). Relating Physical Environment to Self-Categorizations: Identity Threat and Affirmation in a Non-Territorial Office Space. Administrative Science Quarterly, 48(4), 622-654.

Elsbach, K. D. (2004). Interpreting Workplace Identities: The Role of Office Décor. Journal of Organizational Behavio, 25(1), 99-128.

Hall, E. T. (1969). The hidden dimension. Garden City, N.Y: Anchor Books.

Hall, M. R. (1975). The fourth dimension in architecture: The impact of building on man's behavior : Eero Saarinen's administrative center for Deere \& Company, Moline, Illinois / by Mildred and Edward Hall. Santa Fe, N.M.: Sunstone Press.

Hybrid Office / Edward Ogosta Architecture. (2012, April 26). Retrieved November 16, 2019, from ArchDaily website: http://www.archdaily. com/229636/hybrid-office-edward-ogosta-architecture/

Idenburg, F. (2013). Workspheres: Anticipatory Environments that Foster Interaction. In A-typical plan: Projects and essays on identity, flexibility and atmosphere in the office building / edited by Jeannette Kuo. (pp. 116-123). Zurich: Park Books.

Inamizu, N. (2014). Two Densities for Successful Non-territorial Offices: A Case of Microsoft Japan. Annals of Business Administrative Science; Tokyo, 13(2), $105^{-127 .}$ 
Kuo, J. (2013). A-typical plan: Projects and essays on identity, flexibility and atmosphere in the office building / edited by Jeannette Kuo. Zurich: Park Books.

Lai, J. (2013). The District of Madness: Grpahic Essay on the Search for Flexibility. In A-typical plan: Projects and essays on identity, flexibility and atmosphere in the office building / edited by Jeannette Kuo. (pp. 158-165). Zurich: Park Books.

Lieber, C. (2018, September 17). Burberry says it won't destroy unsold merch anymore. But plenty of other fashion brands still do. Retrieved November 14, 2019, from Vox website: https://www.vox.com/thegoods/2018/9/17/17852294/fashion-brands-burning-merchandise-burberrynike-h-and-m

Marsh, M., \& Sayre, M. (2018, May 9). People First: Embracing Your Whole Self in the People-Centric Workplace. Retrieved April 24, 2019, from Work Design Magazine website: https://workdesign.com/2018/o5/embracing-your-wholeself-people-centric-workplace/

Morris + Company Imagines London Tube Station Repurposed for the Homeless. (2019, January 8). Retrieved November 16, 2019, from ArchDaily website: https://www.archdaily.com/909115/morris-plus-company-imagineslondon-tube-station-repurposed-for-the-homeless

Mozas, J. (2017). The liquid nature of workspace. In The office on the grass: The evolution of the workplace / edited by Javier Mozas, Aurora Per Fernández ; edition by Caruso St. John Architects. Vitoria-Gasteiz: A + T.

Paramount by the Office Space. (n.d.). Retrieved November 16, 2019, from Woods Bagot website: https://www.woodsbagot.com/projects/paramount-bythe-office-space/

Saval, N. (2014). Cubed: A secret history of the workplace / Nikil Saval. (First edition..). New York: Doubleday.

Stickells, L. (2013). Swiss Cheese and Beanbags: Producing Interior Urbanism. In G. Brooker \& L. Weinthal (Eds.), The Handbook of Interior Architecture and Design (pp. 180-189). Bloomsbury Academic. 
Sundstrom, E. D. (1986). Work places: The psychology of the physical environment in offices and factories / Eric Sundstrom in collaboration with Mary Graehl Sundstrom. Cambridge [Cambridgeshire] ; New York: Cambridge University Press.

The office on the grass: The evolution of the workplace / edited by Javier Mozas, Aurora Per Fernández ; edition by Caruso St. John Architects. (2017). VitoriaGasteiz: A + T.

Tschumi, B. (2012). Architecture concepts: Red is not a color. New York: Rizzoli.

Van Der Voordt, T. J. M. (2004). Productivity and employee satisfaction in flexible workplaces. Journal of Corporate Real Estate, 6(2), 133-148. 


\section{Table of Figures}

All other figures are authors own.

Figure. 1.2. Skidmore Owings and Merrill.Chase Manhattan Bank, New York, 1961. Adapted from The office on the grass: The evolution of the workplace ( ), by Caruso St Joan Architects. 2017, Vitoria-Gasteiz: A + T. Copyright 2017 by Vitoria-Gasteiz: A + T.

Figure. 1.3. Walter Henn. Osram offices. Munich, 1963. Adapted from The office on the grass: The evolution of the workplace ( ), by Caruso St Joan Architects. 2017, Vitoria-Gasteiz: A + T. Copyright 2017 by Vitoria-Gasteiz: A + T.

Figure. 1.4. Herman Hertzberger. Centraal Beheer. Apeldoorn, 1970-73. Adapted from The office on the grass: The evolution of the workplace ( ), by Caruso St Joan Architects. 2017, Vitoria-Gasteiz: A + T. Copyright 2017 by Vitoria-Gasteiz: A + T.

Figure. 1.5. Steidle and Kiessler. Gruner \& Jahr. Hamburg, 1985. Adapted from The office on the grass: The evolution of the workplace ( ), by Caruso St Joan Architects. 2017, Vitoria-Gasteiz: A + T. Copyright 2017 by Vitoria-Gasteiz: A + T.

Figure. 1.6. Foster and Partners. Citibank Headquarters. London, 1996-2000. Adapted from The office on the grass: The evolution of the workplace ( ), by Caruso St Joan Architects. 2017, Vitoria-Gasteiz: A + T. Copyright 2017 by Vitoria-Gasteiz: A + T.

Figure. 1.7. DEGW (fit out). British Telecom offices. Stockley Park, 1996. Adapted from The office on the grass: The evolution of the workplace ( ), by Caruso St Joan Architects. 2017, Vitoria-Gasteiz: A + T. Copyright 2017 by Vitoria-Gasteiz: A + T.

Figure 1.8. Ground and mezzanine plan view of the Hybrid Office showing the unique office landscape and typologies for working. Adapted from "Hybrid Office / Edward Ogosta Architecture", by Edward Ogosta Architecture. 2012, ArchDaily. Copyright 2012 by Edward Ogosta Architecture.

Figure 1.9. A view of the 'book arena' within the Hybrid Office, an area that has arena like seating combined with bookcases. Adapted from "Hybrid Office / Edward Ogosta Architecture”, by Edward Ogosta Architecture. 2012, ArchDaily. Copyright 2012 by Edward Ogosta Architecture. 
Figure 1.10. A view of some desks within the Hybrid Office, showing the use of encasement for privacy. Adapted from "Hybrid Office / Edward Ogosta Architecture”, by Edward Ogosta Architecture. 2012, ArchDaily. Copyright 2012 by Edward Ogosta Architecture.

Figure 1.12. Inside one of the office spaces showing built in storage and intelligent lighting combined with right timber, the space can be shut off from the corridor with the use of a door. Adapted from Woods Bagot. Retrieved from https://www.woodsbagot.com/projects/paramount-by-the-office-space/. Copyright 2015 by Woods Bagot.

Figure 1.13. A plan showing the layout of the Paramount offices. Adapted from Woods Bagot. Retrieved from https://www.woodsbagot.com/projects/ paramount-by-the-office-space/. Copyright 2015 by Woods Bagot.

Figure 1.14. A view showing one of the meeting pods with curved glass that mimic the use of curves of the office spaces. The view down the hallway shows the use timber, glass and marble throughout the space. Adapted from Woods Bagot. Retrieved from https://www.woodsbagot.com/projects/paramount-bythe-office-space/. Copyright 2015 by Woods Bagot.

Figure. 1.15. A plan view showing the first floor which has a mix of short term and long term accommodation. Adapted from "Morris + Company Imagines London Tube Station Repurposed for the Homeless," by Morris + Company, 2019. ArchDaily. Copyright 2019 by Morris + Company

Figure. 1.16. A plan view showing the first floor which has co-working desks and a garden space, along with facilities for both the office workers and the rough sleepers. This floor is a space where conversation between the two groups can happen. Adapted from "Morris + Company Imagines London Tube Station Repurposed for the Homeless," by Morris + Company, 2019. ArchDaily. Copyright 2019 by Morris + Company

Figure. 1.17. A render view showing the main entrance to the space along with the large central staircase that moves up through the project. Adapted from "Morris + Company Imagines London Tube Station Repurposed for the Homeless," by Morris + Company, 2019. ArchDaily. Copyright 2019 by Morris + Company 
Figure. 2.3. A test exploring the environmental aspects of understanding the individual in the work environment, specifically around lighting and air conditioning. "Hybrid Office / Edward Ogosta Architecture", by Edward Ogosta Architecture. 2012, ArchDaily. Copyright 2012 by Edward Ogosta Architecture.

Figure. 2.6

A diagram of the proxemic bubble created by Edward T Hall, showing the distances between intimate, personal, social and public space as perceived by people. Adapted from "The hidden dimension," by Hall, E. T., 1969. Copyright 1969 by Garden City, N.Y: Anchor Books.

Figure 2.7

A series of analysis of an economy, premium economy and business class seats on Air New Zealand. The analysis explores the proxemics of the space where people's comfort is pushed to the extreme. Adapted from, Premium Economy | Air New Zealand. (n.d.). Retrieved November 17, 2019, from https://www. airnewzealand.com/premium-economy

Figures $4.3-4.28$

Authors own collage over the top of Willis Chambers Archive drawings to understand space within selected building.

Porter And Martin. 1963. Willis Chambers 181 - 183 Willis Street. [Architectural drawing]. Retrieved from Wellington City Council. 